Priscilla Barreira Avegliano

\title{
Simulação da formação de parcerias entre agentes baseadas no conceito de reputação
}

\author{
Dissertação apresentada à Escola \\ Politécnica da Universidade de São \\ Paulo para obtenção do Título de \\ Mestre em Engenharia.
}


Priscilla Barreira Avegliano

\title{
Simulação da formação de parcerias entre agentes baseadas no conceito de reputação
}

\author{
Dissertação apresentada à Escola \\ Politécnica da Universidade de São \\ Paulo para obtenção do Título de \\ Mestre em Engenharia. \\ Área de concentração: \\ Sistemas Digitais \\ Orientador: \\ Prof. Dr. Jaime Simão Sichman
}


Este exemplar foi revisado e alterado em relação a versão original, sob responsabilidade única do autor com a anuência de seu orientador.

São Paulo, 11 de janeiro de 2008.

Assinatura do autor

Assinatura do orientador

\section{Ficha Catalográfica}

Avegliano, Priscilla Barreira

Simulação da formação de parcerias entre agentes baseadas no conceito de reputação. São Paulo, 2008. 85 p. CD-ROM em Anexo.

Dissertação (Mestrado) — Escola Politécnica da Universidade de São Paulo. Departamento de Engenharia de Computação e Sistemas Digitais.

1. Inteligência Artificial. 2. Sistemas Multiagentes. 3. Simulação. 4. Reputação. I. Universidade de São Paulo. Escola Politécnica. Departamento de Engenharia de Computação e Sistemas Digitais. II. Título. 
O homem está condenado a ser livre (Jean-Paul Sartre) 


\section{Agradecimentos}

Meus agradecimentos ao Prof. Dr. Jaime Simão Sichman, que, com sua orientação precisa, norteou o desenvolvimento deste trabalho, tornando-o uma realidade.

Esta conquista é dedicada à minha mãe e a meus avós e tios, que me ofereceram todo o carinho e suporte necessários para que meu caminho como "agente autônomo" fosse trilhado. Dedico também este trabalho ao Lucas, pessoa especial, que, mesmo a distância, mantém-se tão presente e essencial.

Agradeço a todos do Laboratório de Técnicas Inteligentes (LTI), especialmente Dra. Anarosa, Profa. Dra. Anna Helena Reali Costa, Antônio, Bianchi, Diana, Inácio, Marcelo e Valdinei, que, ao longo deste tempo, dividiram comigo experiências e idéias cruciais para a realização deste trabalho e com os quais estabeleci vínculos de amizade.

Meus agradecimentos também a todos os amigos que me apoiaram e que, compreensivamente, souberam respeitar minha dedicação aos estudos.

Finalmente, gostaria de expressar o meu muito obrigada aos que, com sua atitude, de alguma maneira se tornaram importantes ao longo de minha trajetória como pessoa: Maria Elisabeth Kobinger, Profa. Dra. Selma Shin Shimizu Melnikoff e Prof. Dr. Edson Fregni. 


\section{Resumo}

Os conceitos de reputação e confiança, tão difundidos em outras áreas de pesquisa, mostraram-se úteis também em sistemas multiagentes (SMA), particularmente no processo de formação de parcerias, em que agentes selecionam parceiros com os quais irão cooperar. Apesar dos inúmeros trabalhos desenvolvidos na área de SMA que propõem modelos para o cálculo de reputação e confiança, um aspecto essencial do uso de tais modelos ainda não foi suficientemente estudado: como estes conceitos podem efetivamente ajudar agentes autônomos a agir em um sistema aberto. Do ponto de vista do agente, existem algumas questões importantes relacionadas a este cenário: (1) como escolher um parceiro, levando em conta a reputação do candidato e o custo associado à parceria? (2) o quão vantajoso é manipular informação? (3) como agir em uma sociedade norteada pelo conceito de reputação a fim de atingir melhores resultados? Este trabalho tem por objetivo promover uma análise de tais questões por meio da discussão de resultados obtidos com uma ferramenta de simulação denominada RePart, criada especificamente para este fim. As simulações apresentam como cenário um modelo simplificado de um mercado constituído por consumidores e empresas. 


\section{Abstract}

The concepts of reputation and trust, largely researched in other fields, have proved to be also very useful in multi-agent systems (MAS), specially in the process of partnership formation, in which agents select partners to cooperate with. Despite all research that has been carried out in the past few years concerning different reputation and trust models for autonomous agents, an essential aspect related to the use of these models was not sufficiently stressed: how these concepts may effectively help an autonomous agent in order to better evolve in an open MAS scenario. From an agent perspective, there are some important questions regarding this issue: (1) how to choose a partner, taking into account its reputation and the costs associated with the partnership? (2) is it worth to manipulate information? (3) how to act in a society guided by the concept of reputation in order to achieve better results? This work promotes the analysis of these questions through the discussion of the results obtained from a reputation-based partnership formation simulator called RePart, which was specifically designed for this goal. The simulations present a simplified consumer/enterprise market scenario as a target domain. 


\section{Lista de Figuras}

Figura 2.1 - Exemplo de rede de dependência (SICHMAN; CONTE, 2002) . 12

Figura 2.2 - Exemplo de evolução da reputação em um modelo fuzzy . . . 19

Figura 3.1 - Arquitetura interna do modelo Repage, adaptado de (PAOLUCCI et al., 2005). . . . . . . . . . . . . . . 25

Figura 3.2 - Imagem transmitida pelo agente ag-1. . . . . . . . . . . . . . 29

Figura 3.3 - Cálculo do predicado Candidato a Imagem do agente ag-2 como vendedor . . . . . . . . . . . . . . . 30

Figura 3.4 - Cálculo do predicado Imagem do agente ag-2 como vendedor 30

Figura 3.5 - Cálculo do predicado Imagem do agente ag-1 como informante 31

Figura 3.6 - Cálculo do predicado Imagem do agente ag-1 como vendedor 31

Figura 3.7 - Cálculo do predicado Reputação do agente ag-1 como vendedor 32

Figura 4.1 - Vizinhança linear com $\mathrm{r}=3$. . . . . . . . . . . . . . . . 40

Figura 4.2 - Arquitetura da ferramenta de simulação RePart . . . . . . . 42

Figura 4.3 - Arquitetura interna dos agentes consumidores integrantes do sistema RePart . . . . . . . . . . . . . . . . . 43

Figura 4.4 - Memória dos agentes consumidores . . . . . . . . . . . . . . 44

Figura 4.5 - Memória ordenada segundo o perfil conservador . . . . . . . 46

Figura 4.6 - Memória ordenada segundo o perfil ousado . . . . . . . . . . 46

Figura 4.7 - Memória ordenada segundo o perfil avaro . . . . . . . . . . . 46

Figura 4.8 - Interface do sistema RePart . . . . . . . . . . . . . . 50

Figura 5.1 - Média de qualidade dos agentes consumidores . . . . . . . 56

Figura 5.2 - Média de custos dos agentes consumidores . . . . . . . . 60

Figura 5.3 - Impacto de uma propaganda enganosa (falso boato positivo) no número de parcerias da empresa alvo . . . . . . . . . . 64 
Figura 5.4 - Impacto de uma propaganda enganosa (falso boato positivo) na qualidade de mercadorias recebidas pelos consumidores

Figura 5.5 - Impacto de difamação (falso boato negativo) no número de parcerias da empresa alvo . . . . . . . . . . . . 66

Figura 5.6 - Número médio de parcerias da empresa com melhor desempenho sem inserção de boato . . . . . . . . . . . . . 67

Figura 5.7 - Impacto de publicidade verdadeira (boato positivo verdadeiro) no número de parcerias da empresa alvo . . . . . . . . . 68

Figura 5.8 - Desempenho de perfis de agentes empresa orientados à qualidade. . . . . . . . . . . . . . . . 70

Figura 5.9 - Desempenho de perfis de agentes empresa orientados ao custo 72

Figura 5.10 - Desempenho de perfis de agentes empresa investidor e ganancioso . . . . . . . . . . . . . . . . . . . 74 


\section{Lista de Tabelas}

Tabela 5.1 - Valores médios da qualidade da mercadoria recebida acumulada ao longo dos ciclos de simulação . . . . . . . . . . 55

Tabela 5.2 - Resultados detalhados da qualidade da mercadoria recebida pelos agentes conservadores . . . . . . . . . . . 57

Tabela 5.3 - Resultados detalhados da qualidade da mercadoria recebida pelos agentes ousados . . . . . . . . . . . . . . 58

Tabela 5.4 - Resultados detalhados da qualidade da mercadoria recebida pelos agentes avaros . . . . . . . . . . . . . . 58

Tabela 5.5 - Valores médios do custo acumulado ao longo dos ciclos de simulação . . . . . . . . . . . . . . . . . . . 59

Tabela 5.6 - Resultados detalhados dos custos associados às parcerias de agentes conservadores . . . . . . . . . . . . . 61

Tabela 5.7 - Resultados detalhados dos custos associados às parcerias de agentes ousados ...................... 61

Tabela 5.8 - Resultados detalhados dos custos associados às parcerias de agentes avaros ......................... 62

Tabela 5.9 - Valores médios do benefício líquido acumulado ao longo dos ciclos de simulação . . . . . . . . . . . . . . . . 63

Tabela 5.10 - Desempenho de perfis orientados à qualidade . . . . . . . . . 69

Tabela 5.11 - Desempenho de perfis orientados ao custo . . . . . . . . . . . 71

Tabela 5.12 - Desempenho de perfis mistos . . . . . . . . . . . . . . 73 


\title{
Abreviaturas e Siglas
}

\author{
IA Inteligência Artificial \\ IAD Inteligência Artificial Distribuída \\ MABS Multi-Agent Based Simulation \\ SMA Sistemas Multiagentes
}




\section{Sumário}

1 Introdução 1

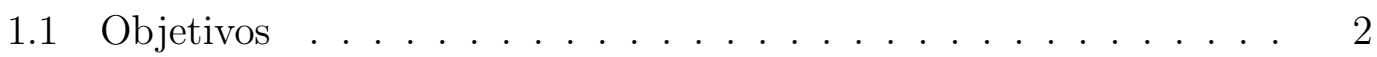

1.2 Metodologia .......................... 3

1.3 Contribuições . . . . . . . . . . . . . . . . . . 4

1.4 Organização do texto . . . . . . . . . . . . . . . . 4

2 Fundamentos básicos $\quad 5$

2.1 Simulação baseada em multiagentes . . . . . . . . . . . . 5

2.1.1 Características básicas ............... 5

2.1.2 Ambientes de simulação . . . . . . . . . . . . 7

2.1.3 Análise comparativa dos ambientes de simulação . . . . . . 9

2.2 Formação de parcerias em sistemas multiagentes . . . . . . . . . . 10

2.2.1 Teoria da dependência . . . . . . . . . . . . . . . 10

2.2.2 Mecanismo de raciocínio social . . . . . . . . . . . . 11

2.3 Reputação e confiança entre agentes . . . . . . . . . . . . . . . 12

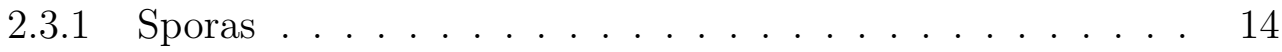

2.3.2 Modelo baseado em probabilidades bayesianas . . . . . . . 15

2.3.3 Modelo baseado na teoria de Dempster-Shafer . . . . . . 16

2.3.4 Modelo baseado na teoria fuzzy . . . . . . . . . . . . . . 18

2.3.5 Regret ..................... 20

2.3.6 Repage . . . . . . . . . . . . . . . . . . . . . 21

2.4 Síntese . . . . . . . . . . . . . . . . . . . . . . . 22 
3.1 Introdução . . . . . . . . . . . . . . . . . . . . . . 23

3.2 Arquitetura do modelo . . . . . . . . . . . . . . . . . . . . 24

3.3 Agregação de avaliações . . . . . . . . . . . . . . . . . . . . 27

3.4 Exemplo de funcionamento . . . . . . . . . . . . . . . . . . . 29

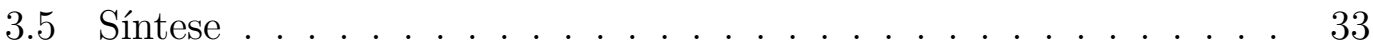

4 RePart $\quad 34$

4.1 Introdução . . . . . . . . . . . . . . . . . . . 34

4.2 Descrição do sistema . . . . . . . . . . . . . . . . . . . . 35

4.2 .1 Cenário da aplicação . . . . . . . . . . . . . . . . . . 36

4.2 .2 Perfis dos agentes . . . . . . . . . . . . . . . . . . 37

4.2.3 Estabelecimento de parcerias . . . . . . . . . . . . . . 38

4.2.4 Comunicação entre agentes . . . . . . . . . . . . . . . . . 40

4.3 Arquitetura do sistema . . . . . . . . . . . . . . . . . . . 41

4.3.1 Visão geral . . . . . . . . . . . . . . . . . . . . . 41

4.3.2 Agentes consumidores . . . . . . . . . . . . . . 43

4.3.3 Agentes empresas . . . . . . . . . . . . . . . . . . . 47

4.3 .4 Núcleo de simulação . . . . . . . . . . . . . . . . . . . . . 49

4.3 .5 Interface . . . . . . . . . . . . . . . 50

4.4 Síntese . . . . . . . . . . . . . . . . . . 51

5 Experimentos $\quad 53$

5.1 Metodologia de testes . . . . . . . . . . . . . . . . 53

5.2 Experimento 1: análise dos perfis de consumidores . . . . . . . . . 54

5.2.1 Análise da qualidade . . . . . . . . . . . . . . . 55

5.2 .2 Análise do custo . . . . . . . . . . . . . . . . . . 59

5.2 .3 Análise do benefício líquido . . . . . . . . . . . . . 62

5.3 Experimento 2: análise do impacto da manipulação de informações 63

5.3.1 Análise do efeito de propaganda enganosa . . . . . . . . 64 
5.3 .2 Análise do efeito de difamação . . . . . . . . . . . . . . 66

5.3.3 Análise do efeito de publicidade verdadeira . . . . . . . . . 67

5.4 Experimento 3: análise dos perfis de empresas . . . . . . . . . . 68

5.4.1 Análise de desempenho de perfis orientados à qualidade das mercadorias . . . . . . . . . . . . . . . 69

5.4.2 Análise de desempenho de perfis orientados ao custo das mercadorias . . . . . . . . . . . . . . 71

5.4.3 Análise de desempenho de perfis mistos . . . . . . . . . . . 73

5.5 Síntese dos resultados . . . . . . . . . . . . . . . . . . 74

$\begin{array}{llr}6 & \text { Conclusões } & 77\end{array}$

$\begin{array}{ll}\text { Referências Bibliográficas } & 80\end{array}$ 


\section{Introdução}

Com o crescente desenvolvimento em áreas como Engenharia e Ciência da Computação, houve uma mudança do paradigma da computação centralizada para a computação distribuída. Tal fato também ocorreu na área de Inteligência Artificial (IA) com o surgimento da vertente da Inteligência Artificial Distribuída (IAD) e, posteriormente, dos Sistemas Multiagentes (SMA).

Diferentemente da IA Clássica, que possui como foco a inteligência individual, os SMA têm como cerne a inteligência emergente das interações entre os agentes, sendo o estudo da inteligência proveniente do comportamento social (GARCIA; SICHMAN, 2003). Em um SMA, as entidades artificiais (agentes) apresentam cada qual sua autonomia e capacidade de socialização, havendo cooperação, negociação e competição entre as entidades, assim como na sociedade humana.

Por apresentar tal semelhança, os SMA beneficiam-se do fato de tomar emprestados certos conceitos estudados nas Ciências Sociais. É o caso do conceito de reputação, que permeia os trabalhos em áreas como a Psicologia (KARLINS; ABELSON, 1970; BROMLEy, 1993), Sociologia (BUSKens, 1998), Filosofia (PlatÃo, 2005; NIETZSCHE, 2005) e Economia (CELETANI et al., 1996; MARIMON; NICOLINI; TELES, 2000). O estudo do papel da reputação como um mecanismo na seleção de um parceiro passou a ser alvo de estudos já no ínicio da década de 80 (KREPS; WILSON, 1982).

O surgimento de sociedades virtuais baseadas na Internet fez com que conceitos como o de reputação e confiança também passassem a ser alvo de grande interesse dos pesquisadores na área de SMA. Conseqüentemente, diversos modelos embasados em teorias distintas foram propostos para o cálculo da reputação e confiança (RUBIERA; LOPEZ; MURO, 2001; YU; SINGH, 2002; MUI; MOHTASHEMI; HALBERSTADT, 2002a; SABATER; SIERRA, 2001; SABATER; PAOLUCCI; CONTE, 2005), com o intuito de inferir qual o agente, possível parceiro no caso de cooperação, desempenha suas ações de forma mais satisfatória.

Devido à grande variedade de modelos propostos, foram desenvolvidos al- 
guns cenários e plataformas de teste para a análise de desempenho dos mesmos (CARBO; MOLINA; DAVILA, 2002; FULlAM et al., 2005). Estes trabalhos visam, em linhas gerais, realizar uma comparação entre os modelos e determinar qual apresenta o desempenho mais satisfatório, ou seja, identifica mais rápida ou precisamente um parceiro fraudador. Sendo assim, considera-se que os agentes sempre escolhem o parceiro com a melhor reputação.

Tal atitude pode representar, porém, custos mais elevados. No seu processo de inferência, os agentes devem raciocinar não somente sobre a reputação do agente parceiro, mas também sobre a utilidade e custos associados à parceria. Além disso, um agente pode atuar de forma a extrair algum benefício de sua boa reputação construída ao longo do tempo em sociedades na qual este conceito está presente. Do ponto de vista dos agentes, estes são aspectos cruciais e que ainda não foram suficientemente estudados no campo de SMA.

\section{$1.1 \quad$ Objetivos}

Este trabalho tem como objetivo estudar o uso do conceito de reputação como fator integrante do processo de decisão de agentes autônomos. Mais especificamente, três questões serão analisadas do ponto de vista do agente:

Questão 1 Como escolher um parceiro, levando em conta a reputação do candidato e o custo associado à parceria?

Questão 2 O quão vantajoso é manipular informações visando benefício próprio?

Questão 3 Como agir em uma sociedade norteada pelo conceito de reputação a fim de que melhores resultados sejam obtidos?

Para alcançar este objetivo, serão tomados como base alguns trabalhos anteriores que abordam a cooperação e o estabelecimento de parcerias entre agentes. Em (CASTELFRANCHI, 1990; SICHMAN, 1998), cada agente possui um certo número de objetivos a serem alcançados, sendo que para tanto, uma dada seqüência de ações deve ser realizada. Como nem sempre um agente tem a capacidade de efetuar todas as ações necessárias, este se torna dependente de outros agentes (CASTELFRANCHI, 1990). Surge, então, o conceito de parceria, no qual um agente executa uma ação a fim de que um outro agente atinja seu objetivo em troca de um benefício posterior.

A escolha de um parceiro pode englobar a análise da reputação do mesmo, o custo associado à parceria, bem como sua utilidade. Segundo (SICHMAN et al., 
1994), agentes cognitivos podem apresentar estratégias diferentes em seus mecanismos de raciocínio interno quando deparados com uma série de alternativas.

Analogamente aos simuladores PartNet (CONTE; PEDONE, 1998) e PartNet++ (MONTEIRO; SICHMAN, 2005), que estudam a formação de parcerias entre agentes heterogêneos considerando o custo, importância e utilidade de uma parceria, neste trabalho foi desenvolvida uma ferramenta de simulação, denominado RePart, na qual os agentes apresentam perfis distintos com relação ao uso da reputação no processo de seleção de um parceiro.

Este tipo de dinâmica está presente em diversos campos de atuação na sociedade. Poderão ser beneficiadas áreas como Economia, em estudos de simulação de mercados financeiros e comércio eletrônico, Sociologia e Psicologia Social, na comprovação de teses que analisem a dinâmica do processo de transmissão de reputação e seus impactos no estabelecimento de parcerias e formações de grupos e organizações.

\subsection{Metodologia}

O trabalho descrito neste documento foi subdividido em quatro etapas principais: (1) pesquisa sobre o estado da arte em reputação (em SMA e outras áreas de pesquisa) e modelos computacionais para seu cálculo; (2) desenvolvimento da plataforma de simulação RePart para o estabelecimento de múltiplas parcerias baseadas no conceito de reputação; (3) realização dos experimentos e (4) análise dos resultados obtidos.

A primeira etapa consistiu, essencialmente, em uma análise do estado da arte das pesquisas sobre reputação em SMA. A partir das necessidades na área levantadas neste estudo, foi possível estabelecer o foco do trabalho.

Na segunda etapa, a ferramenta de simulação denominada RePart (Reputationbased Partnership) e os agentes integrantes, cada qual com seu perfil, foram implementados em Java. O mecanismo interno dos agentes para o cálculo de reputação é baseado no modelo Repage ${ }^{1}$ (SABATER; PAOLUCCI; CONTE, 2005). A ferramenta de simulação foi validada com alguns experimentos bastante simples, sendo iniciadas, então, a terceira e quarta etapas, que consistiram na realização dos experimentos em diversos cenários e a posterior análise dos resultados obtidos.

\footnotetext{
${ }^{1} \mathrm{~A}$ justificativa para a escolha deste modelo encontra-se descrita na seção 2.4.
} 


\subsection{Contribuições}

A eficiência dos diferentes modelos para o cálculo de reputação já foi extensamente analisada e comparada por meio de competições internacionais, como por exemplo a ART-testbed Competition ${ }^{2}$. Entretanto, o impacto da utilização de tal conceito nos mecanismos internos de decisão de agentes autônomos ainda não o foi. Seria mais vantajoso para um agente sempre escolher o parceiro com melhor reputação? É recompensador manipular informação visando benefício próprio? Estas perguntas poderão ser respondidas por meio da análise dos resultados obtidos nas simulações realizadas na plataforma desenvolvida.

A principal contribuição deste trabalho consiste em uma maior compreensão do uso do conceito da reputação na escolha de uma parceria e de seus desdobramentos em sociedades de agentes heterogêneos. Outra contribuição que podemos mencionar é a ferramenta de simulação RePart, desenvolvida para a realização dos experimentos que integram este trabalho.

\subsection{Organização do texto}

Este texto foi estruturado em 6 capítulos. O capítulo 2 aborda os principais conceitos teóricos chave na elaboração do trabalho proposto, como a simulação baseada em sistemas multiagentes (MABS), o estabelecimento de parcerias em SMA e os conceitos de reputação e confiança em SMA. Na síntese deste capítulo, é apresentado o encadeamento lógico destes conceitos utilizados para o desenvolvimento deste trabalho.

O capítulo 3 é dedicado ao modelo Repage, adotado para integrar os agentes no processo de simulação.

O capítulo 4 contém a descrição da ferramenta de simulação RePart. Sua arquitetura e modelos internos de decisão dos agentes são detalhados neste capítulo.

O capítulo 5 apresenta os experimentos realizados, bem como a análise dos resultados obtidos.

Finalmente, o capítulo 6 relata as conclusões e discute possíveis trabalhos futuros.

\footnotetext{
${ }^{2}$ Para mais detalhes, acessar http://www.lips.utexas.edu/art-testbed/competition.htm.
} 


\section{Fundamentos básicos}

Este capítulo tem como objetivo apresentar o arcabouço teórico que fundamenta este trabalho e está organizado da seguinte forma: primeiramente, a área de pesquisa denominada Simulação Baseada em Multiagentes é apresentada na seção 2.1, o que possibilitará uma visão geral da inserção do trabalho. Conceitos fundamentais para o sistema a ser desenvolvido, como o estabelecimento de parcerias entre agentes e noções de reputação e confiança são, então, discutidos respectivamente nas seções 2.2 e 2.3. Finalmente, o encadeamento de tais conceitos é apresentado na seção 2.4 .

\subsection{Simulação baseada em multiagentes}

A área denominada Simulação Baseada em Multiagentes (MABS, do inglês MultiAgent Based Simulation), combina técnicas oriundas das áreas de simulação computacional e SMA. Diversos ambientes de simulação já foram desenvolvidos, cada qual priorizando aspectos distintos e oferecendo diferentes graus de usabilidade.

Uma discussão mais detalhada da área é apresentada nas subseções seguintes.

\subsubsection{Características básicas}

MABS ${ }^{1}$ é a simulação computacional baseada e implementada sob a égide do modelo de agentes, o que a diferencia dos demais tipos de simulação computacional (DAVIDSSON, 2000).

Segundo a visão defendida em (PARUNAK; SAVIT; RIOLO, 1998),

"A modelagem baseada em agentes é mais indicada para domínios caracterizados por um alto grau de distribuição, que apresentem predominantemente decisões discretas. A modelagem baseada em equações

\footnotetext{
${ }^{1}$ Como a notação mais utilizada na literatura é MABS, em inglês, adotaremos a mesma terminologia neste documento.
} 
matemáticas é, naturalmente, aplicável a sistemas que possam ser modelados centralmente e cuja dinâmica seja preponderantemente governada por leis físicas, em detrimento do processamento de informações".

Em suma, MABS é indicada para a simulação de sistemas complexos e distribuídos. Ela é influenciada por modelos de simulação tradicionais, como a simulação de eventos discretos (MISRA, 1986), simulação orientada a objetos (ZEIGLER, 1990), além da chamada micro-simulação (HARDING, 1996).

O que diferencia MABS da simulação orientada a objetos é a dimensão das entidades no que diz respeito à sua pró-atividade, linguagem de comunicação, noções espaciais, mobilidade, adaptabilidade e modelagem de estados mentais, como crenças, desejos e intenções no caso dos chamados agentes cognitivos (RAO; GEORGEFF, 1991). Não existe uma divisão clara entre MABS e a simulação orientada a objetos, que podem ser vistas como um contínuo (DAVIDSSON, 2000).

Da simulação de eventos discretos, MABS herdou o objetivo de simular os eventos que ocorrem em um sistema, a fim de demonstrar seus efeitos. Já da micro-simulação, herdou a função de simular o efeito do passar do tempo sob os indivíduos (DAVIDSSON, 2000).

Assim como SMA, MABS é característicamente interdisciplinar. Em (EDMONDS, 2001), são elencadas possíveis áreas de aplicação de MABS, que variam das Artes às Ciências, passando pelo Entretenimento e Comunicação. Aplicações utilizando MABS nos mais distintos domínios já foram apresentadas, como a simulação de uma colônia de formigas (DROGOUL; FERBER, 1994) e simulação robótica (MACKENZIE; ARKIN; CAMERON, 1997). Entretanto, MABS vem sendo utilizada majoritariamente para simulações de cunho social (DAVIDSSON, 2000). Isto se deve ao fato da abordagem baseada em agentes favorecer o uso da simulação computacional para a comprovação de teses no âmbito das ciências sociais (CONTE; GILBERT; SICHMAN, 1998), dado o caráter heterogêneo e autônomo dos agentes computacionais, que é similar ao dos agentes (pessoas) na sociedade.

A junção de MABS com disciplinas que a utilizam originou linhas de pesquisa bastante interessantes, como a Agent-Based Computational Economics (ACE), que é responsável pelo estudo computacional de economias modeladas como sistemas evolutivos de agentes autônomos interativos (TESFATSION, 2003) e a AgentBased Social Simulation (ABSS), sendo esta a vertente originada pela intersecção de 2 campos científicos, MABS e as ciências sociais (como Sociologia, Psicologia Social, Antropologia) (DAVIDSSON, 2002). 
Dado um problema a ser estudado, geralmente desenvolve-se um simulador específico que atenda às suas necessidades. Há, entretanto, alguns ambientes de simulação mais genéricos, que serão enumerados e analisados a seguir.

\subsubsection{Ambientes de simulação}

Pesquisadores da área de MABS desenvolveram diferentes ambientes de simulação que têm por objetivo oferecer uma infra-estrutura que privilegie o foco do usuário na modelagem e implementação do problema. Tais ambientes tentam suprir as necessidades básicas de qualquer simulação baseada em agentes, o que evidentemente é uma meta difícil de ser atingida.

A seguir, os ambientes que atualmente apresentam maior destaque e utilização na área de MABS são elencados.

\subsubsection{MadKit}

MadKit (GUTNECHT; FERBER, 2000) é uma plataforma para a simulação baseada em multiagentes que tem como proposta ser uma ferramenta bastante genérica e flexível. A estrutura dos agentes integrantes está baseada no modelo AGR (FERBER; GUTKNECHT; MICHEL, 2004), que define três conceitos principais: agentes, grupos e papéis.

De forma resumida, agentes desempenham papéis em determinados grupos, sendo que cada papel tem associado a si um conjunto de objetivos a cumprir ou tarefas a executar.

A plataforma possui uma arquitetura composta por três elementos centrais: (1) o microkernel, responsável pelo controle local dos grupos e papéis na sociedade, supervisão do ciclo de vida dos agentes e distribuição de mensagens; (2) os agentes, que são definidos por uma classe que determina seu ciclo de vida ; (3) utilização de agentes que realizam diversas funcionalidades no sistema, como controle de migração e segurança, uma propriedade única da arquitetura do MadKit. Estes serviços são definidos na plataforma como papéis especiais em determinados grupos.

A plataforma MadKit, implementada em Java, também apresenta uma interface gráfica, que pode ser definida para cada agente individualmente. A troca de mensagens no sistema é feita de modo assíncrono e o escalonador do sistema permite uma maior variedade na ordem e na estratégia de execução das ações por parte dos agentes (MICHEL; FERBER; GUTKNECHT, 2001). Para desenvolver uma 
aplicação, são necessárias a especialização e a instanciação da classe que define os agentes, tornando indispensável o conhecimento da linguagem Java por parte do usuário.

\subsubsection{SWARM}

Desenvolvida por pesquisadores do Instituto de Santa Fé, a plataforma SWARM (MINAR et al., 1996) é uma das mais antigas na área de MABS. A unidade básica de simulação é um swarm, que pode representar uma estrutura emergente, um grupo de agentes ou um único agente. Os swarms apresentam uma representação interna do tempo e podem ser modelados hierarquicamente. Implementada em Objective-C, a plataforma oferece dois tipos de swarms: (1) o Model Swarm, que são aqueles que executam as ações no sistema e representam o modelo da simulação e sua topologia e (2) Observer Swarm, cujo propósito é observar os demais agentes a fim de gerar os gráficos de saída e arquivos de dados. A interface gráfica do sistema baseia-se na linguagem de programação Tcl/Tk. Tal como no caso anterior, os usuários devem ter conhecimentos de programação em ObjectiveC para criar uma nova aplicação.

\subsubsection{CORMAS}

CORMAS (Common-Pool Resources and Multi-Agent Systems) (PAGE et al., 2000) é uma plataforma de simulação multiagente que tem como foco o estudo da dinâmica das interações entre um grupo de agentes e um ambiente compartilhado com recursos naturais renováveis. Nesta plataforma, as entidades podem ser (1) espaciais, sendo responsáveis pela modelagem do ambiente; (2) passivas, que são utilizadas como objetos para a troca de mensagens entre os agentes; (3) agentes, que podem estar alocados em grupos, constituindo entidades sociais organizadas hierarquicamente. A plataforma é implementada em SmallTalk e apresenta uma interface gráfica visual.

Além disso, a plataforma permite ser integrada a outros sistemas por meio do uso do modelo de computação baseada em serviços (ADAMATTI, 2007), como no caso do simulador VipJogoman (ADAMATTI; SICHMAN; COELHO, 2007), um sistema de apoio à negociação em grupo que envolve a gestão de recursos naturais. 


\subsubsection{StarLogo}

StarLogo (RESNICK, 1996) é um ambiente de simulação voltado para usuários que não sejam especialistas na área de programação (como estudantes do Ensino Médio), que permite que os padrões emergentes em sistemas descentralizados sejam compreendidos. O StarLogo baseia-se no paradigma do paralelismo massivo e na linguagem de programação Logo. O componente principal do sistema é a tartaruga (turtle), sendo que cada tartaruga pode executar ações em paralelo às demais presentes no sistema. As tartarugas apresentam "sentidos", que incluem a noção de vizinhança. A plataforma apresenta uma interface gráfica visual, através da qual o usuário interage com o sistema.

Diferentemente das plataformas anteriores, esta não demanda do usuário conhecimento de programação para o desenvolvimento de uma aplicação.

\subsubsection{NetLogo}

NetLogo (TISUE; WILENSKY, 2004) é um ambiente de modelagem para a simulação de fenômenos sociais e naturais. Implementado em Java, o NetLogo é uma evolução do StarLogo. Portanto, a entidade central no sistema continua a ser a tartaruga, que move-se em um reticulado de células, que também são agentes programáveis. O NetLogo é utilizado basicamente por cientistas sociais. O sistema apresenta dezenas de exemplos que variam de automatas celulares a simulações de mercados, dinâmica das populações e sociedades artificiais. Apresenta interface gráfica visual e a programação dos agentes é feita por meio da linguagem de programação também denominada NetLogo, uma extensão da linguagem de programação Logo. Conseqüentemente, também não requer do usuário conhecimento de programação para o desenvolvimento de uma aplicação.

\subsubsection{Análise comparativa dos ambientes de simulação}

Os ambientes StarLogo e NetLogo, voltados para um público não especializado na área de computação e baseados na linguagem de programação Logo, apresentam certas limitações na modelagem do sistema a ser simulado. Não é possível, por exemplo, utilizar bibliotecas e modelos de agentes já desenvolvidos na área de SMA, que utilizam outras linguagens de programação (na sua maioria, a linguagem Java), além das limitações apresentadas pela própria linguagem Logo.

Já os demais ambientes supramencionados não apresentam tais limitações. As plataformas MadKit, CORMAS e SWARM disponibilizam uma gama maior 
de recursos, oferecendo ao pesquisador um maior grau de liberdade com relação à utilização de recursos externos (bibliotecas, modelos internos de agentes, protocololos de comunicação) e na própria modelagem do sistema em si. Por outro lado, esta maior complexidade dos ambientes de simulação acarreta uma curva de aprendizado maior, visto que o pesquisador deve se tornar ciente de inúmeros detalhes dos recursos disponibilizados nestes ambientes. Em muitos casos, torna-se impraticável para um usuário externo ao desenvolvimento do projeto realizar modificações necessárias nestas plataformas a fim de que as necessidades do modelo a ser simulado sejam supridas (MICHEL; FERBER; GUTKNECHT, 2001).

Em razão destes aspectos, optou-se neste trabalho pelo desenvolvimento de uma ferramenta de simulação voltada especificamente para a simulação do estabelecimento de parcerias, baseadas no conceito de reputação. Tal ferramenta de simulação será descrita em detalhes no capítulo 4 deste documento.

\subsection{Formação de parcerias em sistemas multia- gentes}

Tipicamente, em um SMA existe uma interdependência entre os agentes que, sozinhos, são incapazes de atingir todos os seus objetivos. Sendo assim, os agentes devem formar parcerias, que consistem em trocas que beneficiam a todas as partes envolvidas.

\subsubsection{Teoria da dependência}

No final dos anos 80, foi proposta uma teoria denominada Teoria da Dependência (CASTELFRANCHI; MICELLI; CESTA, 1992; HANNOUN et al., 1998), que tenta identificar quais as razões pelas quais agentes autônomos decidem cooperar entre si.

Esta teoria parte do princípio de que agentes são heterogêneos, isto é, possuem crenças, capacidades de ação e objetivos distintos. Assim, podem depender da ação de outros agentes para atingirem suas metas, ou seja, seus objetivos podem exceder sua capacidade de agir isoladamente.

O conceito principal desta teoria é o de relação de dependência: às vezes, agentes necessitam de outros para atingir seus objetivos. Estas necessidades podem requerer esforços distintos e com diferentes níveis de comprometimento dos possíveis parceiros.

Assim, a motivação que leva um agente a iniciar o processo de formação de 
uma parceria é sua dependência. Já a concretização da parceria baseia-se na existência de uma dependência recíproca.

Parcerias podem envolver apenas um par de agentes ou múltiplos agentes. Neste caso, para todos os participantes da parceria, temos que um determinado agente realiza uma ação que beneficia a um outro e assim sucessivamente, até que o ciclo seja fechado.

A definição das parcerias a serem estabelecidas é um problema que notavelmente envolve uma grande complexidade, que cresce exponencialmente com o número de agentes envolvidos.

\subsubsection{Mecanismo de raciocínio social}

Baseado na Teoria da Dependência, foi proposto um Mecanismo de Raciocínio Social (SICHMAN et al., 1994), com o qual os agentes ponderam sobre suas relações de dependência, a fim de tentar estabelecer parcerias que permitam atingir seus objetivos.

Os conceitos chave que definem um agente no sistema são:

1. objetivos a serem perseguidos e atingidos;

2. ações que podem ser realizadas;

3. recursos sob seu controle;

4. planos, que consistem em uma sequência de ações e recursos associados às mesmas e que definem como atingir um objetivo.

Para o estabelecimento de uma pareria, um agente deve:

1. escolher um objetivo a ser perseguido;

2. selecionar um plano para atingir tal objetivo;

3. verificar se todas as ações que compõe o plano podem ser executadas por ele;

4. caso não seja possível, escolher um parceiro que esteja capacitado a desempenhá-las.

O processo de estabelecimento de parcerias pode ser melhor elucidado com o auxílio da Figura 2.1, na qual um agente ag1 representa numa rede suas relações 
de dependência. Neste exemplo, o agente ag1 possui o objetivo g1. Para atingi-lo, deve executar o plano p111, que consiste nas ações a1, a2 e a4. O agente ag1 não é capaz de executar a ação a2, tornando-se dependende de outros agentes para a execução de seu plano e, por conseguinte, para a obtenção de seu objetivo. Os agentes ag2 e ag3 são capazes de executar a ação a2. Se o agente ag1, em contrapartida, souber executar uma ação que beneficie qualquer um destes agentes, uma parceria entre eles pode ser firmada.

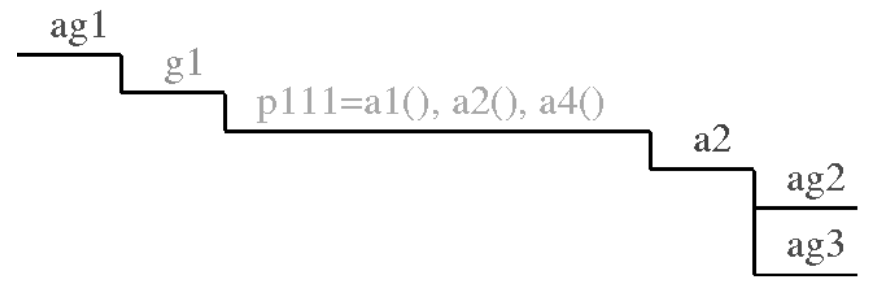

Figura 2.1: Exemplo de rede de dependência (SICHMAN; CONTE, 2002)

Em uma parceria, um dos agentes deve realizar uma ação que favoreça ao outro agente, sem ainda ter sido beneficiado. Se houver uma "quebra de contrato" por parte do outro agente, ou seja, se este não cumprir sua parte no acordo firmado, o primeiro agente será prejudicado. Portanto, a cooperação e o estabelecimento de parcerias representam um risco (BARBER; FULLAM; KIM, 2003). Torna-se necessária, então, a adoção de parâmetros que exprimam o grau de comprometimento do agente em uma parceria. É o papel desempenhado pelo conceito de reputação, apresentado a seguir.

\subsection{Reputação e confiança entre agentes}

Reputação é um conceito disseminado na sociedade, tendo, provavelmente, coevoluído com a linguagem e a formação de organizações sociais (DUNBAR, 1996). A reputação tem como finalidade desencorajar fraudes e trapaças, além de favorecer a cooperação entre pessoas. As sociedades virtuais e os SMA passaram a utilizar a reputação de forma similar, ou seja, como uma forma de punir transgressores (SABATER; PAOLUCCI; CONTE, 2005). Tal fato é apontado por Sabater e Sierra (SABATER; SIERRA, 2005) como o fator crucial para a disseminação e popularização de sites de comércio eletrônico. Nestes, o usuário pode tornar público o seu grau de (in)satisfação com o serviço efetuado.

O conceito de reputação está comumente associado ao de confiança. Em Barber et al. (2003), entretanto, afirma-se que é possível diferenciá-los. Segundo ela, confiança é uma crença na habilidade e na intenção de um agente em executar 
determinada ação; a reputação é um valor que exprime esta confiança individual. Entretando, a maioria dos modelos desenvolvidos na área de SMA não faz diferenciação entre os conceitos.

Inúmeras pesquisas em SMA visam desenvolver modelos de reputação e confiança que possam ser implementados em agentes artificiais. Tais modelos podem apresentar duas abordagens: a cognitiva e a baseada na Teoria dos Jogos. A primeira reflete um estado mental do agente, de acordo com suas crenças. Um exemplo desta abordagem é a apresentada em (ESFANDIARI; CHANDRASEKHARAN, 2001), no qual se afirma que "confiança e reputação são constituídos por crenças internas e individuais e são uma função do grau destas crenças". O foco deste tipo de modelo é o processo interno de inferência que dá origem à reputação atribuída a um alvo. Por outro lado, a reputação nos modelos baseados na Teoria dos Jogos resulta de manipulações estritamente numéricas e são definidas em (GAMBETTA, 1988) como sendo "a probabilidade subjetiva com a qual um indivíduo A espera que um outro indivíduo B execute determinada ação, da qual depende seu bem-estar". Estes modelos geralmente fazem uso de técnicas de raciocínio probabilístico, como a teoria de Bayes e de Dempster-Shafer.

Os modelos baseados na Teoria dos Jogos têm predominância nos trabalhos desenvolvidos nesta área (MUI; MOHTASHEMI; HALBERSTADT, 2002a; YU; SINGH, 2002; RUBIERA; LOPEZ; MURO, 2001). Por serem mais simples, são também menos adaptativos a ambientes diferentes daqueles para os quais foram desenvolvidos. Já os modelos cognitivos possuem uma maior adaptabilidade, apresentando resultados satisfatórios em cenários mais complexos. Sabater e Sierra (2005) acreditam que, no futuro, as soluções deverão ser mistas, combinando a abordagem embasada na Teoria dos Jogos à cognitiva.

A seguir serão apresentados brevemente alguns dos modelos de reputação e confiança desenvolvidos na área de SMA.

Os modelos descritos foram selecionados de forma a representar ambas as vertentes, a cognitiva e a baseada na Teoria dos Jogos, além de denotar a grande variedade de soluções encontradas para o cálculo de tais conceitos. Alguns destes modelos propuseram o uso de heurísticas, enquanto outros adotaram descrições matemáticas baseadas em análises probabilísticas. 


\subsubsection{Sporas}

Sendo um dos primeiros trabalhos em SMA que propuseram um modelo para o cálculo da reputação de um agente, SPORAS (ZACHARIA, 1999) pode ser considerado uma versão mais sofisticada dos mecanismos de reputação presentes em sites de comércio eletrônico, nos quais usuários fornecem aos demais informações sobre seu grau de satisfação com um serviço.

Este modelo é norteado pelos seguintes princípios (ZACHARIA; MOUKAS; MAES, 1999):

1. Novos usuários recebem um valor mínimo inicial para sua reputação, que deve ser construída a partir de sua atividade no sistema;

2. O valor da reputação de um agente não pode ser inferior a este valor inicial de reputação, não importa o quão fraudador ele seja. Com isso, a opção de abandonar o sistema e reingressar com uma nova identidade não é atrativa;

3. A reputação de um agente é atualizada segundo informações fornecidas pelo seu parceiro;

4. Dois agentes não podem fornecer mais do que uma avaliação um ao outro. Caso haja mais de uma interação entre estes agentes, somente a última avaliação será utilizada;

5. Agentes com uma reputação muito boa apresentam uma variação muito menor no seu valor de reputação após cada atualização do que agentes com uma baixa reputação.

Com este modelo, novos usuários apresentam uma reputação igual a 0 e que pode chegar a 3000. Os valores de avaliação de um parceiro estão no intervalo de 0,1 a 1 .

O modelo SPORAS incorporou a medida de confiança (reliability) na reputação de um agente, que se baseia na variação das avaliações recebidas por parte de seus parceiros. Neste modelo a reputação é uma propriedade global, que apresenta um único valor, independente de contexto.

Assim como nos mecanismo de reputação de sites de comércio eletrônico, a reputação de um agente é visível a todos os demais agentes e é construída por meio das informações fornecidas por agentes com os quais o alvo já tenha firmado uma parceria. Entretanto, o uso da variação nas avaliações como um dos parâmetros 
para o cálculo da reputação de um alvo torna o modelo SPORAS mais robusto que a maioria dos mecanismos de reputação de sites de comércio eletrônico.

\subsubsection{Modelo baseado em probabilidades bayesianas}

Um modelo de cálculo de reputação probabilístico fortemente embasado na teoria de Bayes foi apresentado em (MUI; MOHTASHEMI; HALBERSTADT, 2002a).

Sendo $a, b$ dois agentes (com $a$ como o agente avaliador), a proporção estimada do número de parcerias bem sucedidas $\theta$ entre $a$ e $b$ segue uma distribuição Beta, a priori:

$$
p(\theta)=\operatorname{Beta}\left(c_{1}, c_{2}\right)
$$

Os parâmetros $c_{1}$ e $c_{2}$ recebem o valor 1, determinando assim uma distribuição uniforme de probabilidades para uma parceria bem-sucedida entre os agentes.

Assumindo que cada parceria entre os agentes $a$ e $b$ sejam eventos independentes, a reputação do agente $b$ frente ao agente $a$ reflete a probabilidade da parceria entre estes agentes ser bem sucedida na sua próxima interação. Portanto, dados $p$ sucessos nas $n$ parcerias estabelecidas entre os agentes $a$ e $b$, a reputação de $b$ pode ser calculada como:

$$
R e p=p\left(\theta_{n+1} \mid p, n\right)=E[\theta \mid p, n]
$$

onde:

$$
E[\theta \mid p, n]=\frac{c_{1}+p}{c_{1}+c_{2}+n}
$$

Este modelo também propõe um método para o cálculo da reputação de um agente desconhecido. Se, por exemplo, o agente $a$ nunca tenha interagido com o agente $b$ e o agente $c$ já tenha realizado parcerias com ambos os agentes, é possível determinar a reputação do agente $b$ frente ao agente $a$ a partir das informações obtidas com o agente $c$. Desta maneira, aplicando-se recursivamente este mecanismo, é possível calcular a reputação de um agente distante e desconhecido, desde que haja um caminho na rede social entre o agente avaliador e o alvo.

O peso das informações coletadas com agentes intermediários ao longo do caminho na rede social é determinado de acordo com o número de interações já realizadas entre os dois agentes vizinhos. 


\subsubsection{Modelo baseado na teoria de Dempster-Shafer}

Um método para o cálculo da reputação, baseado em um modelo evidencial que utiliza os conceitos da Teoria de Dempster-Shafer, foi apresentado em (YU; SINGH, 2002).

Os autores optaram por este modelo de representação após avaliarem diversas possíveis soluções:

- Fatores de Certeza: são valores escalares que representam a crença de um agente a respeito de outro agente (BUCHANAN; SHORTLIFFE, 1984). Este modelo provê um mecanismo para a combinação de opiniões, embora não represente as medidas de crença absoluta. Esta metodologia é indicada preferencialmente para representar as alterações na avaliação da reputação de um agente;

- Abordagem Bayesiana: permite expressar uma incerteza com relação à avaliação da reputação de um agente e permite que diversas opiniões sejam combinadas, resultando em um único valor (JENSEN, 2001). Entretanto, não é possível diferenciar entre a falta de opinião e uma má reputação;

- Teoria de Dempster-Shafer: prega que não há uma relação causal entre uma hipótese e sua negação, fazendo com que a falta de um valor para a reputação não implique uma má reputação (DEMPSTER, 1967; SHAFER, 1976).

O cálculo da reputação é feito da seguinte maneira: são atribuídos valores referentes à qualidade do serviço (QoS) de cada parceria efetivada entre dois agentes. Estes valores estão no intervalo de $[0,1]$ e possuem precisão de uma casa decimal. O vetor $S_{i}$ representa o conjunto dos valores de todas as parcerias avaliadas.

São estabelecidos então dois patamares de valor da reputação de um agente, sendo um o inferior $(\omega)$ e outro o superior $(\Omega)$ de modo que:

$$
0 \leq \omega \leq \Omega \leq 1
$$

A função $f(x)$ retorna a probabilidade de que o valor $x$ da qualidade de serviço ocorra em um estabelecimento de parceria com o agente alvo. Esta função retorna o número de ocorrências deste valor de qualidade de serviço dentre os valores armazenados no vetor $S_{i}$, dividido pelo número de elementos do vetor. 
Sendo assim, a distribuição de massas da reputação do agente $i$ é feito da seguinte forma:

$$
\begin{gathered}
m(\neg \text { Confiavel })=\sum_{0}^{\omega_{i}} f(x) \\
m(\text { Confiavel }, \neg \text { Confiavel })=\sum_{\omega_{i}}^{\Omega_{i}} f(x) \\
m(\text { Confiavel })=\sum_{\Omega_{i}}^{1} f(x)
\end{gathered}
$$

A reputação local de um agente alvo é igual á crença de que este agente seja confiável, ou seja:

$$
\text { Rep }=\operatorname{Bel}(\text { Confiavel })
$$

onde,

$$
\begin{aligned}
& \text { Bel }(\text { Confiavel })=m(\text { Confiavel }), \\
& \operatorname{Bel}(\neg \text { Confiavel })=m(\neg \text { Confiavel }), \\
& \operatorname{Bel}(\text { Confiavel }, \neg \text { Confiavel })= \\
& =m(\text { Confiavel })+m(\neg \text { Confiavel })+m(\text { Confiavel }, \neg \text { Confiavel })=1 .
\end{aligned}
$$

Se a diferença entre $\operatorname{Bel}($ Confiavel $)$ e $\operatorname{Bel}(\neg$ Confiavel $)$ for maior que um patamar de confibilidade estabelecido, então o agente alvo é considerado confiável.

Quando houver ainda poucas interações entre o agente avaliador e o agente alvo, as opiniões dos demais agentes sobre a reputação do agente alvo devem ser coletadas. Tais evidências devem ser combinadas de modo a originarem um valor para a reputação do agente alvo, por meio da regra de combinação de Dempster.

Como exemplo de funcionamento desta regra, suponha que as distribuições de massa de dois agentes 1 e 2 sejam as seguintes, onde $\mathrm{C}$ é confiável, $\neg \mathrm{C}$ é não confiável e $\oplus$ é o operador soma ortogonal:

$$
\begin{array}{lll}
m_{1}(C)=0.8 & m_{1}(\neg C)=0 & m_{1}(C, \neg C)=0.2 \\
m_{2}(C)=0.9 & m_{2}(\neg C)=0 & m_{2}(C, \neg C)=0.1
\end{array}
$$

Obtemos:

$$
\begin{aligned}
& m_{12}(C)=m_{1}(C) \oplus m_{2}(C)= \\
& =m_{1}(C) * m_{2}(C)+m_{1}(C, \neg C) * m_{2}(C)+m_{1}(C) * m_{2}(C, \neg C)= \\
& =0.72+0.18+0.08=0.98 \\
& m_{12}(\neg C)=0 \\
& m_{12}(C, \neg C)=m_{1}(C, \neg C) * m_{2}(C, \neg C)=0.02
\end{aligned}
$$


Os pesos atribuídos às informações obtidas com os demais agentes são idênticos, não diferenciando entre um agente com uma boa reputação de outro tido como mentiroso.

\subsubsection{Modelo baseado na teoria fuzzy}

Esta seção descreve um modelo cujo cálculo da reputação de agentes é baseado na Teoria Fuzzy (RUBIERA; LOPEZ; MURO, 2001). Esta abordagem foi escolhida devido ao grau de subjetividade na predição do comportamento futuro de um outro agente, visto que um bom comportamento passado não fornece nenhuma garantia de continuidade no futuro.

O domínio da reputação foi dividido em 3 cenários:

1. Pedir referências a outro agente: Os agentes a serem questionados serão aqueles que possuam um valor acima de suficiente para perguntar;

2. Responder a um agente: Quando questionado, um agente responderá somente às perguntas de um agente que possua um valor acima de suficiente para responder;

3. Estabelecer parceira: Isto ocorre quando o valor da reputação de um agente é maior que suficiente para cooperar.

Ao receber a resposta sobre a reputação de um agente alvo ou após a avaliação de uma parceria estabelecida, temos uma atualização da reputação do agente alvo que é calculada segundo a equação:

$$
R e p=\frac{\text { freshness } \cdot \text { rep } p_{\text {new }}+(2-\text { freshness }) \cdot \text { rep } p_{\text {old }}}{2}
$$

A variável freshness expressa o quão relevante é a última experiência para a determinação da reputação de um agente. A relevância da última experiência é diretamente proporcional a este valor.

O peso associado ao valor da reputação antiga é de 2-freshness.

Os agentes que atenderam à requisição de informação sobre o agente alvo também terão seus valores de reputação atualizados. O comportamento do agente alvo será a base para a avaliação da resposta fornecida: será analisado o grau de similaridade entre a satisfação obtida e a informação fornecida. Quanto maior a similaridade, maior será a nova reputação do agente consultado. O valor obtido será então avaliado de modo que ele seja classificado dentre os conjuntos fuzzy 
estabelecidos para confiança (extremamente confiável, muito confiável, razoavelmente confiável, pouco confiável e muito pouco confiável).

A seguir, é possível ver a evolução na avaliação de um agente que teve seu comportamento avaliado como desapontador, cujo estado inicial é ilustrado na Figura 2.2. Nos gráficos, a reputação do agente alvo é representado pelo trapézio, que indica os valores difusos atribuídos a este conceito, sendo sua base superior valores com um maior grau de confiança e sua base inferior valores com um menor grau de confiança.

O valor da reputação é então defuzzificado (por meio do cálculo do seu centro de massa). Este valor obtido é novamente fuzzificado, só que agora no cenário que classifica esta reputação como suficiente ou insuficiente para iniciar a parceria.

ANTES
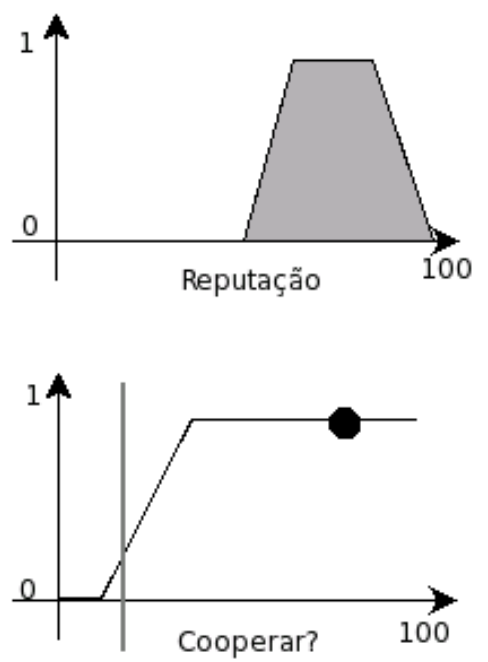

DEPOIS

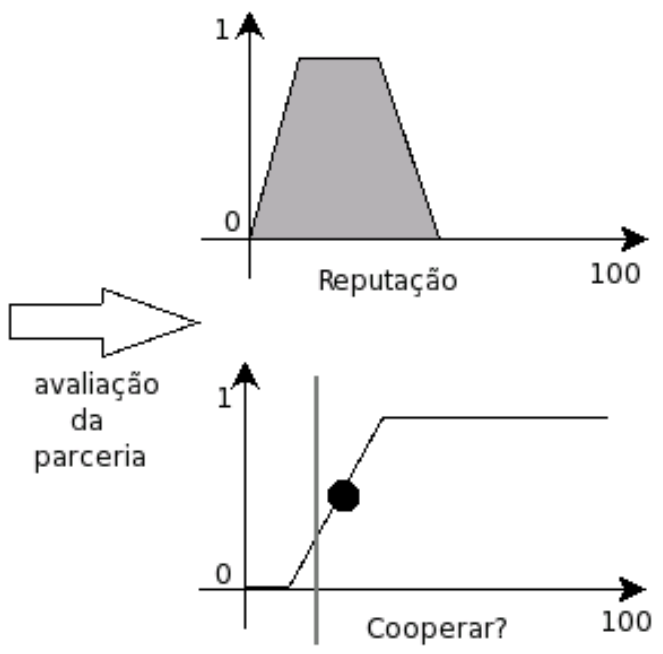

Figura 2.2: Exemplo de evolução da reputação em um modelo fuzzy

Na Figura 2.2, nota-se a reavaliação da reputação do agente alvo após uma parceria classificada como insatisfatória. O trapézio que representa a reputação deslocou-se para a esquerda, implicando um centro de massa com um valor menor e, por conseguinte, diminuindo a reputação do agente alvo.

O novo valor da reputação do agente alvo, calculado em 0,6, é novamente classificado como suficiente para cooperar, embora tenha havido uma diminuição no seu valor com relação à avaliação anterior. 


\subsubsection{Regret}

ReGreT (SABATER; SIERRA, 2001) é um modelo de reputação que se baseia em uma heurística para determinar a reputação de um agente.

Ele implementa o conceito de impressão, que é um valor que reflete a satisfação obtida em um aspecto de uma parceria como a eficiência, tempo de resposta e conteúdo. As impressões são então combinadas de modo que a reputação de um agente possa ser determinada.

A impressão é representada pela tupla:

$$
\mathrm{i}=(\mathrm{a}, \mathrm{b}, \mathrm{o}, \varphi, \mathrm{t}, \mathrm{W})
$$

onde $a, b$ são agentes pertencentes ao sistema (sendo $a$ o agente que está avaliando a reputação do agente $b$ ), $o$ a parceria a ser analisada, $\varphi$ o aspecto da parceria a ser analisado, $t$ o tempo no qual a impressão foi gerada e $\mathrm{W}$ que representa a opinião subjetiva do agente $a$ sobre o aspecto $\varphi$ da parceria $o$. O valor de $\mathrm{W}$ está no intervalo entre [-1,1], o que faz com que o desempenho possa ser avaliada por meio de um valor difuso: -1 para uma baixo desempenho, 0 para uma neutra e +1 para uma eficiente.

As impressões geradas são armazenadas na chamada base de dados de impressões, que no caso do agente $a$, é representada por $I D B^{a}$.

A reputação em um instante de tempo $t$ é definido pela equação:

$$
R^{t}\left(I D B_{p}^{a}\right)=\sum_{i \in I D B_{p}^{a}} \rho\left(t, t_{i}\right) \cdot W_{i}
$$

onde $\rho(t, t i)=\frac{f\left(t, t_{i}\right)}{\sum_{j \in I D B_{p}^{a}} f\left(t_{j}, t\right)}$ e $f\left(t_{j}, t\right)$ é uma função dependente do tempo, que atribui um peso maior a valores próximos de $t$, e $p$ é a condição que determina quais são os alvos da reputação, isto é, o agente e o aspecto da relação a serem avaliados. A reputação do agente $b$ frente ao agente $a$ será denotada pelo símbolo $R_{a \rightarrow b}(\varphi)$ e representa $R^{t}\left(I D B_{p}^{a}\right)$ com $p=(a, b,-, \varphi,-,-)$, onde - representa um valor qualquer.

Este valor representa a reputação de um agente frente a um determinado aspecto. Ainda é preciso calcular a confiança relacionada a este valor, representado por $R L\left(I B D_{p}^{a}\right)$. Isto é feito de acordo com o número de impressões utilizadas para a determinação do valor da reputação, $N_{i}\left(I D B_{p}^{a}\right)$, e da variação deste valores, $D t\left(I D B_{p}^{a}\right)$. 
O valor de $R L\left(I B D_{p}^{a}\right)$ é obtido por meio da equação:

$$
R L\left(I B D_{p}^{a}\right)=(1-\mu) \cdot N_{i}\left(I D B_{p}^{a}\right)+\mu \cdot D t\left(I D B_{p}^{a}\right)
$$

A reputação final de uma parceria será então a somatória de todas as reputações parciais vinculadas a um aspecto da parceria.

Este modelo também aborda a chamada reputação social, na qual um indivíduo herda a reputação do grupo ao qual pertence.

Este modelo apresentou um desempenho satisfatório em simulações de um cenário simples, no qual um agente parceiro agia de forma honesta até atingir uma alta reputação para, a partir daí, passar a atuar de forma fraudulenta. O agente com o modelo ReGreT atualizou correta e rapidamente os valores da reputação deste agente parceiro, decrementando-a após suas ações desonestas.

\subsubsection{Repage}

Repage: REPutation and ImAGE (SABATER; PAOLUCCI; CONTE, 2005) é um sistema computacional que emprega uma abordagem cognitiva da reputação. Sua grande inovação é a diferenciação entre os conceitos de imagem e reputação.

Segundo a visão defendida por Sabater et al. (2005), imagem é uma crença avaliadora sobre determinado alvo (agente), podendo ser uma crença individual ou compartilhada por um conjunto de agentes, sendo então denominada imagem compartilhada. Por outro lado, a reputação é uma "voz compartilhada" anonimamente entre os agentes, ou seja, é uma crença sobre o que os outros agentes dizem a respeito de determinado alvo. Conseqüentemente, imagem e reputação podem divergir.

Este modelo baseia-se na existência de predicados organizados conceitualmente em níveis interconectados. Desta forma, cada predicado possui antecessores e sucessores. Existem também os chamados detectores, que são unidades lógicas responsáveis por gerar conhecimento novo, ou seja, inferir um novo predicado a partir de seus antecessores. Cada detector é especializado em um único predicado.

Seu funcionamento nos remete ao modelo clássico do quadro negro (blackboard) (ENGELMORE; MORGAN, 1998), desenvolvido na década de 80 e utilizado em IAD desde então.

Além disso, este modelo faz uso da teoria fuzzy: as avaliações de parcerias 
e os conceitos de imagem e reputação enquadram-se nos conjuntos muito ruim, ruim, neutro, bom e muito bom.

\subsection{Síntese}

Este trabalho, situado dentro da área de MABS (descrito em 2.1), propõe o estudo por meio de simulações da formação de parcerias entre agentes (descrita em 2.2) baseadas no conceito de reputação (descrito em 2.3). Para tanto, os agentes necessitam de um modelo interno que calcule a reputação dos possíveis parceiros.

Após a análise dos diversos modelos apresentados na seção 2.3, o modelo Repage foi selecionado como base para o trabalho. Tal modelo foi adotado por ser bastante completo e por possuir um enfoque cognitivo do conceito de reputação, sendo adequado para os objetivos da ferramenta de simulação a ser desenvolvida. Maiores detalhes a respeito deste modelo são apresentados no capítulo a seguir. 


\section{Repage}

Este capítulo tem por finalidade apresentar com maiores detalhes o modelo $R e$ page, que foi adotado neste trabalho para o cálculo e gerenciamento da reputação de possíveis parceiros. A teoria que fundamenta este modelo é introduzida na seção 3.1. A seguir, na seção 3.2, é apresentada a arquitetura do modelo. As seções 3.3 e 3.4 descrevem, respectivamente, o processo de agregação de valores e um exemplo de funcionamento do modelo.

\subsection{Introdução}

Como apresentado anteriormente na seção 2.3.6, o modelo Repage utiliza dois conceitos distintos: imagem e reputação. Os benefícios da clara diferenciação entre estes conceitos foram comprovados por meio de experimentos apresentados em (PINYOL et al., 2007)

A imagem de um agente alvo pode ser proveniente de experiências diretas do próprio agente avaliador com o agente alvo ou de informações sobre a imagem do agente alvo frente a agentes informantes, chamada de imagem de terceiros. Um agente $\mathrm{A}$, por exemplo, pode pedir informações sobre o agente $\mathrm{B}$ a um terceiro agente C. Se o agente C responder: "O agente B é bom", ele estará transmitindo, supostamente $^{1}$, a imagem que ele possui do agente $B$, sendo isto chamada de imagem de terceiros. Se, por outro lado, o agente $\mathrm{C}$ responder que "Dizem que o agente B é bom“, ele estará apenas repassando uma informação sem identificar sua origem. Ele estará, então, retransmitindo a reputação do agente B.

Por conseguinte, é possível dizer que a reputação é o processo e o efeito da transmissão anônima da imagem de um alvo, sendo uma meta-crença (PAOLUCCI et al., 2005). Tal diferenciação permite que uma informação seja transmitida por um agente sem que este tenha que comprometer-se com sua veracidade, já que ela

\footnotetext{
${ }^{1}$ Supostamente, pois um agente pode mentir. Transmitir a imagem de um alvo apenas faz com que o agente seja responsável pelo conteúdo transmitido e não o impede de propagar uma informação que não condiz com suas crenças internas. Este comportamento não será considerado no restante deste texto.
} 
representa um boato, um rumor sobre determinada informação. Sendo assim, a reputação pode espalhar-se pela sociedade de agentes sem que a maioria de seus integrantes acredite que ela seja merecida.

Devido à diferenciação feita entre imagem e reputação no modelo, é possível que um agente alvo tenha uma imagem frente a um agente avaliador que difere de sua reputação. A correlação entre imagem e reputação pode então levar à incerteza e a inconsistências. Entretanto, tal dicotomia está de acordo com o caráter autônomo e ao mesmo tempo sociável dos agentes. Sua autonomia está refletida no fato de cada agente possuir uma crença interna no que toca à confiança de um agente alvo (imagem). Por outro lado, a reputação do agente alvo é um dado proveniente do meio social e que deve influenciar a opinião do agente avaliador com relação ao agente alvo.

Neste modelo, os valores da imagem e da reputação são contextuais, ou seja, um agente pode possuir uma boa imagem como vendedor, mas uma imagem ruim como informante. Portanto, uma informação sobre a imagem ou reputação deve conter o alvo e o papel desempenhado por este.

Os valores das imagens e reputações são representados por tuplas de valores positivos: mais precisamente, esta tupla é composta por 5 números, que indicam o grau de aderência da avaliação a cada conjunto fuzzy e que somados resultam em 1, além de mais um número que indica o grau de crença na avaliação. Tais conjuntos significam muito ruim, ruim, neutro, bom e muito bom. Esta estratégia foi adotada por se assemelhar ao mundo real. Quando nos referimos a uma pessoa, não dizemos que sua reputação é 0,672 boa. Afirmamos, apenas, que a pessoa possui uma boa reputação. Sendo assim, o modelo consegue lidar com a falta de precisão inerente à transmissão de uma avaliação subjetiva ou a uma recordação reavivada.

No modelo Repage, uma tupla é expressa da seguinte forma:

$$
\left\{\left[w_{m r}, w_{r}, w_{n}, w_{b}, w_{m b}\right], g c\right\}
$$

onde $w_{j}$ representa o grau de aderência ao conjunto fuzzy $j$ e $g c$ o grau de crença na avaliação.

\subsection{Arquitetura do modelo}

A arquitetura interna do agente segundo o modelo Repage consiste em três módulos, ilustrados na Figura 3.1: 


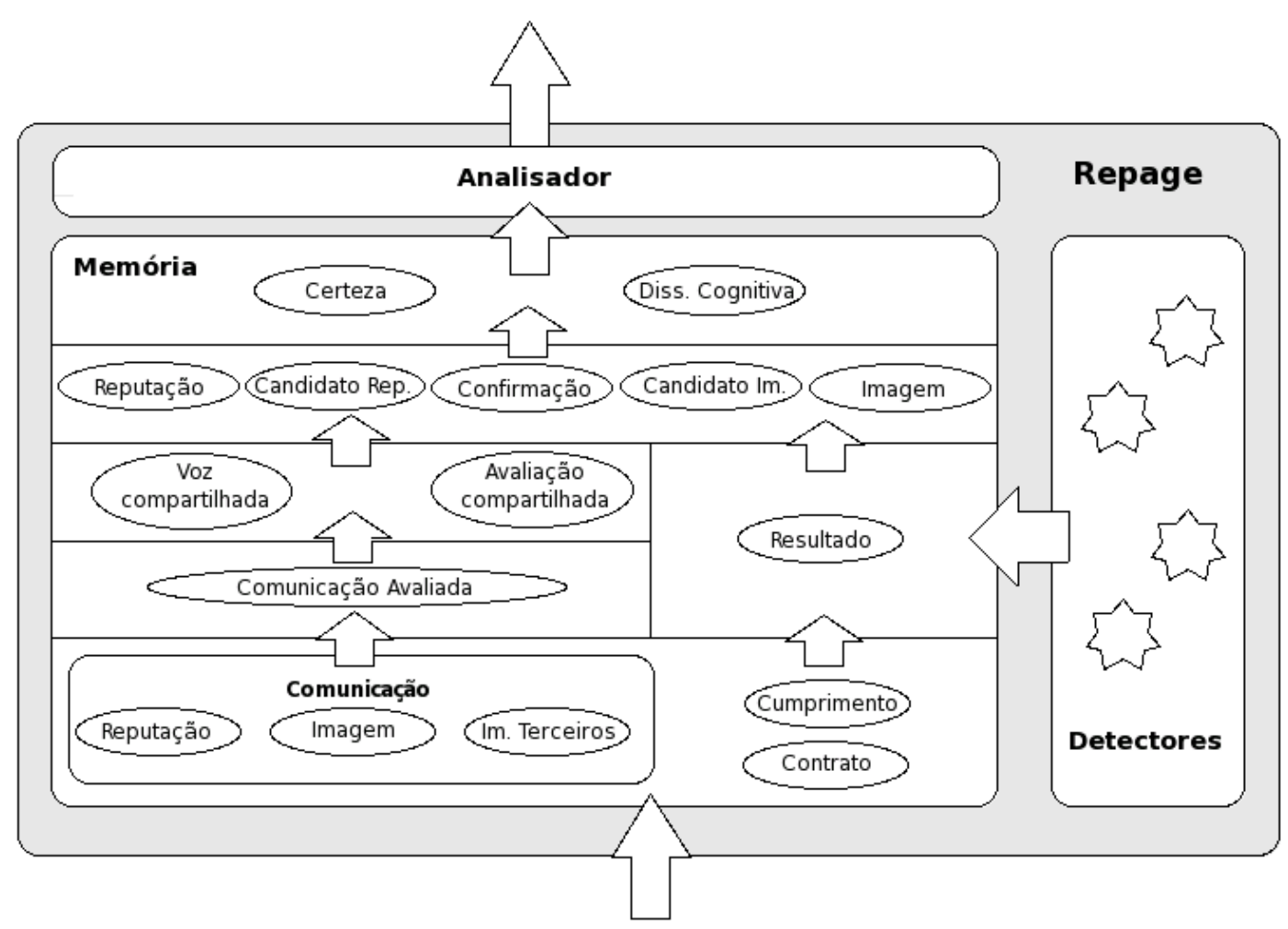

Figura 3.1: Arquitetura interna do modelo Repage, adaptado de (PAOLUCCI et al., 2005).

- Memória: responsável por armazenar as crenças do agente. É definida como um conjunto de predicados interconectados, organizados em diferentes níveis, refletindo assim as dependências existentes entre eles;

- Detectores: são pequenas unidades de inferência, que atuam sobre a memória do agente, inferindo novos predicados a partir daqueles já armazenados;

- Analisador: possui a função de melhorar a acurácia dos predicados armazenados na memória do agente e resolver problemas de dissonância cognitiva, que ocorre quando existe uma contradição entre duas informações relevantes e que se referem ao mesmo alvo. Isto pode ocorrer, por exemplo, se o agente avaliador possuir uma imagem interna de um agente alvo que difere da imagem fornecida por um agente informante, que também possui uma boa imagem frente ao agente avaliador. Tal dissônancia gera instabilidade na mente do agente avaliador e precisa ser solucionada. Para tanto, são feitas algumas sugestões de ação por parte do módulo analisador ao mecanismo principal de raciocínio do agente, que visam sanar tal contradição. 
Como mencionado anteriormente, os predicados que populam a memória do agente possuem diferentes níveis e estão interconectados. Nesta arquitetura, os predicados de níveis mais baixos na hierarquia fundamentam os predicados do nível superior e assim sucessivamente. Quanto maior o número de predicados tomados como base para a inferência, maior será a força do predicado gerado (PINYOL et al., 2007).

No primeiro nível, são necessárias 3 informações: Contrato, que representa o acordo firmado entre os agentes (agente avaliador e agente alvo); Cumprimento, que consiste em uma descrição dos resultados do contrato, avaliados qualitativamente, e Comunicação, um predicado de segunda ordem. Este é formado por 3 outros predicados de primeira ordem: a imagem que o informante possui do alvo (Imagem); a imagem que, segundo o informante, outros agentes devidamente identificados possuem do alvo (Imagem de Terceiros) e a reputação do agente (Reputação).

No nível subseqüente, temos a ação de dois detectores que, a partir dos predicados do primeiro nível, geram os do segundo nível. O primeiro detector infere o resultado do cumprimento do contrato, baseando-se nos predicados Contrato e Cumprimento do nível anterior. A partir deste processo de inferência, é gerado o predicado denominado Resultado. O outro detector efetua a avaliação das informações obtidas por meio do informante, balanceando-as segundo a imagem que o agente avaliador possui de tal informante e gerando o predicado Comunicação Avaliada.

No próximo nível, a Comunicação Avaliada dá subsídio a dois predicados: Voz Compartilhada e Avaliação Compartilhada. A Voz Compartilhada é o elemento central na determinação da reputação de um agente alvo e origina-se da reputação do agente alvo propagada. Já a Avaliação Compartilhada é formada a partir das imagens transmitidas entre agentes (Imagem de Terceiros). A construção da imagem de um alvo está calcada na avaliação compartilhada do mesmo e dos resultados das parcerias efetuadas entre o agente avaliador e o alvo.

O quarto nível apresenta 5 tipos distintos de predicados: Candidato a Imagem, Candidato a Reputação, Imagem, Reputação e Confirmação. Como evidenciado pelos nomes, os predicados Candidato a Imagem e Candidato a Reputação não apresentam força suficiente para serem adotados como Imagem e Reputação, o que pode ser ocasionado por falta de informações ou inconsistências. Na medida em que o grau de certeza em um candidato a imagem ou reputação aumenta e um certo nível é atingido, eles se transformam respectivamente em Imagem 
ou Reputação. A Confirmação é o predicado que determina se a imagem que o agente avaliador possui do agente alvo está de acordo com a informação fornecida pelo informante. A Reputação (ou Candidato a Reputação) é obtida a partir do predicado Voz Compartilhada, do nível imediatamente anterior. Já a Imagem (ou Candidato a Imagem) é gerada a partir dos predicados Avaliação Compartilhada (nível 3) e Resultado (nível 2).

Por fim, no último nível, existem os predicados denominados Dissonância Cognitiva e Certeza. O predicado Dissonância Cognitiva ativa o módulo analisador, responsável por solucioná-la caso exista, por exemplo, uma inconsistência entre a imagem já calculada de um agente (Imagem) e a imagem de terceiros coletada, que originiu o predicado Avaliação Compartilhada. Por outro lado, o predicado Certeza implica uma maior confiança na imagem obtida.

\subsection{Agregação de avaliações}

Um aspecto importante do modelo proposto é a agregação de valores. Por lidar com diversas informações coletadas de agentes distintos, uma das principais operações a serem realizadas é a agregação das tuplas de valores que representam as avaliações fuzzy. Dadas $n$ avaliações fuzzy distintas, obtém-se $n$ tuplas distintas, que representam os pesos atribuídos a cada conjunto naquela avaliação (muito ruim, ruim, neutro, bom, muito bom), bem como seu grau de crença ( $g c)$.

Caso existam $n$ avaliações a serem agregadas, temos $A=\left\{a_{1}, \ldots, a_{n}\right\}$, onde $a_{i}=\left\{\left[w_{m r}^{a_{i}}, w_{r}^{a_{i}}, w_{n}^{a_{i}}, w_{b}^{a_{i}}, w_{m b}^{a_{i}}\right], g c_{i}\right\}$.

Os pesos $W_{j}$ que compõem a tupla que resulta da agregação destas avaliações são calculados segundo a equação abaixo:

$$
W_{j}=\sum_{i=1}^{n} \frac{g c_{i} \cdot w_{j}^{a_{i}}}{\sum_{k=1}^{n} g c_{k}} \quad \forall j \in\{m r, r, n, b, m b\}
$$

Já para o cálculo do grau de crença gc da tupla, faz-se necessário um mecanismo que permita determinar o grau de semelhança/discrepância entre as avaliações agregadas. Se tivermos, por exemplo, duas avaliações que apontam para a mesma direção, devemos obter uma tupla resultante com um grau de crença maior do que se as informações fossem conflitantes.

O mecanismo adotado para a agregação de graus de crença baseia-se no momento angular.

Ao se comparar dois valores, primeiramente calcula-se a diferença dos valores 
absolutos entre os valores fuzzy, nível a nível. Sendo $w_{j}^{a_{1}}$ o peso associado ao conjunto $j$ na tupla $a_{1}$ e $w_{j}^{a_{2}}$ o peso associado ao conjunto $j$ na tupla $a_{2}, d_{j}=$ $\left|w_{j}^{a_{1}}-w_{j}^{a_{2}}\right|$. O centro de massa é então calculado:

$$
c=\frac{\sum_{j} \frac{(j-1)}{4} d_{j}}{\sum_{j} d_{j}}
$$

Já a distância de um valor até seu cento de massa é calculado segundo a equação:

$$
d i s t=\sum_{j} d_{j}\left|c-\frac{j-1}{4}\right|
$$

Com isto, diferenças situadas nos extremos (conjuntos $m r$ e $m b$ ) são privilegiadas. Em outras palavras, quanto maior for o momento angular, maior é a diferença entre as avaliações e, por conseguinte, menor deverá ser o gc resultante.

Sendo assim, o grau de crença resultante é calculado segundo a equação:

$$
g c=\min \left(1, \sum_{i=1}^{n}\left(g c_{i} \cdot\left(1-d i s t_{c}\right)\right)^{\rho}\right)
$$

onde $\rho$ é o parâmetro responsável por diminuir a relevância de avaliações com baixo grau de crença. Quanto maior ele for, maior será o número de avaliações com baixo grau de crença necessário para que o grau de crença resultante seja alterado. Já dist cé a distância entre a avaliação $a_{i}$ e a tupla resultante da agregação dos valores em $\mathrm{A}$.

Para a determinação do grau de crença adotou-se a operação que retorna o mínimo entre 1 e o valor calculado, visto que não é possível se obter um grau de crença maior que 1.

As equações 3.2 e 3.3 também são utilizadas no momento da comparação de duas avaliações. Esta operação é realizada, por exemplo, para determinar o grau de satisfação de uma parceria, comparando-se as avaliações dos predicados Cumprimento e Resultado.

Para o processo de agregação de avaliações, surge a necessidade de um valor identidade, ou seja, uma avaliação fuzzy que quando combinada com uma outra, deixa a mesma inalterada e que representa a falta de informação. Esta "avaliação identidade" é aquela na qual todos os conjuntos fuzzy apresentam o mesmo peso. Como no modelo Repage cada avaliação apresenta 5 conjuntos, a avaliação identidade será uma tupla $[0.2,0.2,0.2,0.2,0.2]$, que expressa total indiferença quanto aos conjuntos fuzzy. 


\subsection{Exemplo de funcionamento}

O processo para a obtenção da imagem e da reputação de um agente alvo pode ser melhor elucidado por meio de dois exemplos (PAOLUCCI et al., 2005). No primeiro, é demonstrado o processo de cálculo da imagem de um agente desconhecido. Já o segundo exemplo denota claramente a diferenciação entre imagem e reputação do modelo Repage.

No primeiro caso, temos o agente avaliador ag-0, que desconhece o agente ag2, mas que recebe de seu agente vizinho ag-1 a informação de que a imagem que este possui de ag-2 como vendedor é muito boa (vide Figura 3.2). Esta informação será o predicado Imagem, no primeiro nível da arquitetura Repage, representada nas figuras como o predicado de segunda ordem denominado Comunicação.

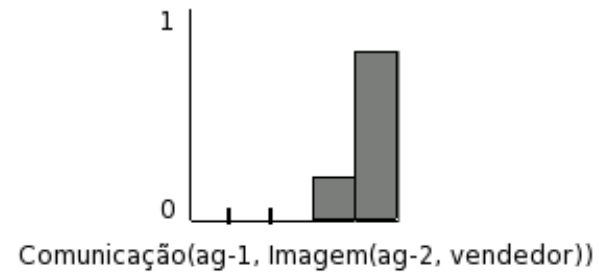

Figura 3.2: Imagem transmitida pelo agente ag-1.

Como o agente alvo ag-2 é totalmente desconhecido para o avaliador, que nunca recebeu nenhum tipo de informação a seu respeito, o predicado Reputação do primeiro nível será um valor padrão, estabelecido como a "avaliação identidade". Da mesma forma, como o agente ag-1 não transmitiu a imagem que outros agentes possuem do agente ag-2 como vendedor, o predicado Imagem de Terceiros também receberá o valor da "avaliação identidade".

O predicado Comunicação Avaliada, no segundo nível da Figura 3.3, é calculado a partir dos predicados do nível inferior. Como os predicados Imagem e Reputação apresentam valores neutros, o resultado é um predicado exatamente igual ao predicado Imagem de Terceiros, conforme denota a Figura 3.3.

No terceiro nível, o predicado Avaliação Compartilhada é gerado a partir da agregação do predicado Comunicação Avaliada com a imagem que o avaliador possui do agente informante, conforme o processo descrito na seção 3.3. O agente ag-0 não possui nenhuma informação a respeito da imagem do agente ag-1 como informante. O agente ag-0, então, adota novamente a imagem padrão, ou seja, a de "avaliação identidade". Como resultado, obtemos o predicado Comunicação Avaliada com um valor que apresenta uma pequena prevalência para os valores 


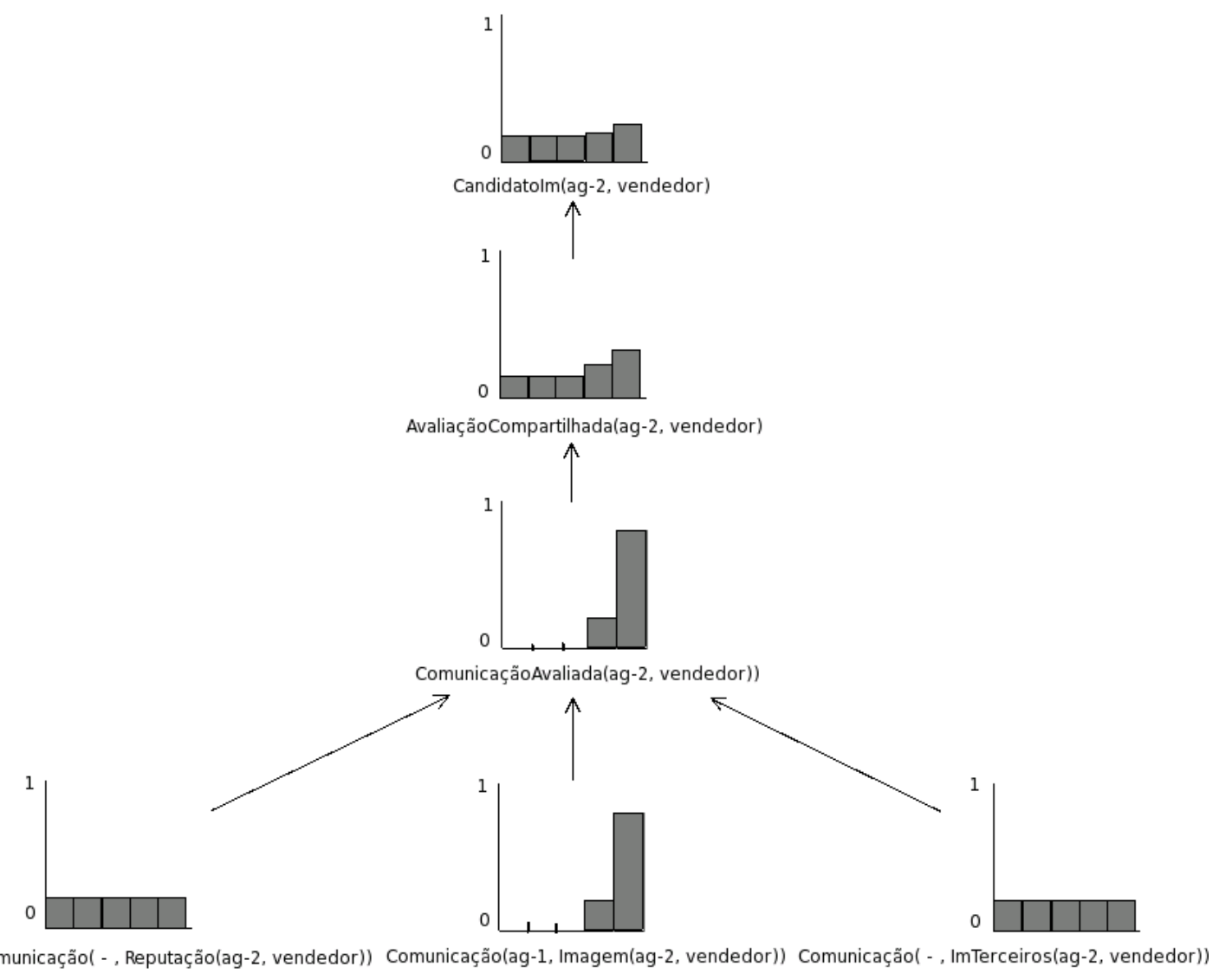

Figura 3.3: Cálculo do predicado Candidato a Imagem do agente ag-2 como vendedor

bom e muito bom. Este predicado servirá de base para o cálculo do predicado Candidato a Imagem do nível subseqüente, que será exatamente igual ao mesmo. Todo o processo pode ser visualizado na Figura 3.3.

Neste momento, o agente ag-0 decide realizar uma transação com o agente ag-2. O resultado desta interação é muito satisfatório, o que gera dois efeitos importantes na memória Repage: (1) atualização da imagem de ag-2 como vendedor e (2) atualização da imagem de ag-1 como informante.

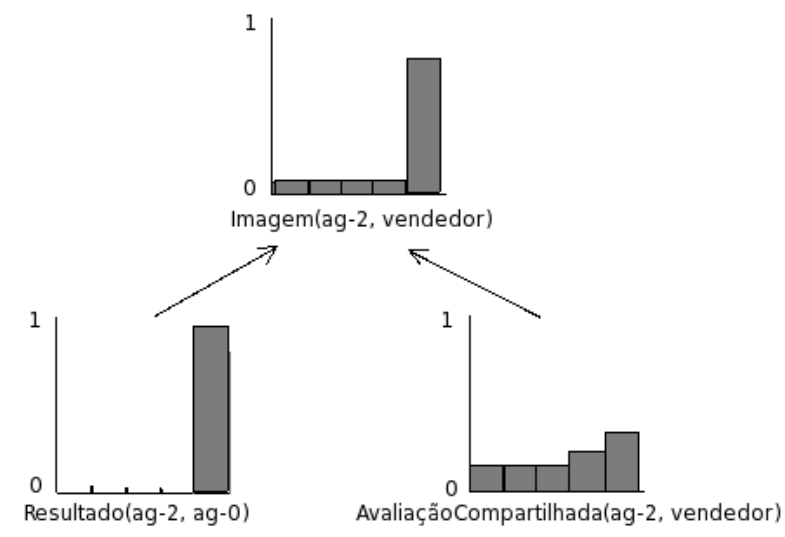

Figura 3.4: Cálculo do predicado Imagem do agente ag-2 como vendedor 
O predicado Candidato a Imagem do agente ag-2 torna-se então uma Imagem. Para tanto, o predicado Resultado (nível 2), obtido a partir da comparação entre os predicados Contrato e Cumprimento do primeiro nível, é combinado ao predicado Avaliação Compartilhada, já previamente calculado. Como resultado, a Imagem do agente ag-2 como vendedor apresenta um alto grau de aderência ao conjunto fuzzy muito bom, conforme indica a Figura 3.4.

Além disso, esta imagem positiva do agente ag-2 como vendedor é comparada por meio da métrica fuzzy (equações 3.2 e 3.3) com a informação fornecida pelo agente ag-1. Como as avaliações são bastante similares, uma imagem positiva do agente ag-1 como informante é gerada (vide Figura 3.5).

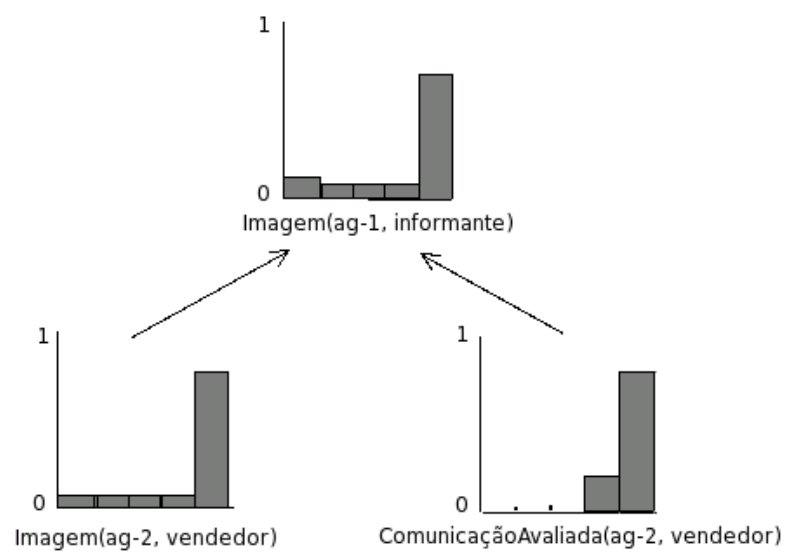

Figura 3.5: Cálculo do predicado Imagem do agente ag-1 como informante

O segundo exemplo, que tem por finalidade denotar a diferenciação dos conceitos de imagem e reputação no modelo Repage, consiste na seguinte situação: após algumas interações bem-sucedidas entre o agente ag-0 e o agente ag-1, quatro agentes distintos fornecem uma informação a respeito da reputação do agente ag-1 como vendedor, que difere da imagem que o agente ag-0 possui do alvo.

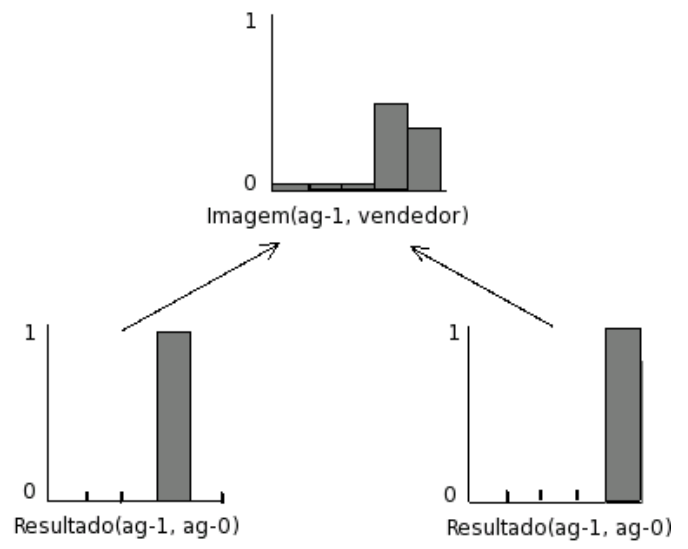

Figura 3.6: Cálculo do predicado Imagem do agente ag-1 como vendedor 
A Figura 3.6 demonstra os resultados das interações entre os agentes ag-0 e ag-1, que, por serem bastante satisfatórias, geram uma imagem extremamente positiva do agente ag-1 por parte de ag-0.

A Figura 3.7 apresenta as informações sobre a reputação recebidas. Tais reputações são na sua totalidade negativas, o que gera o predicado Voz Compartilhada com uma grande acentuação nos conjuntos ruim e muito ruim. A reputação final do agente ag-1 calculada, por sua vez, também é negativa.
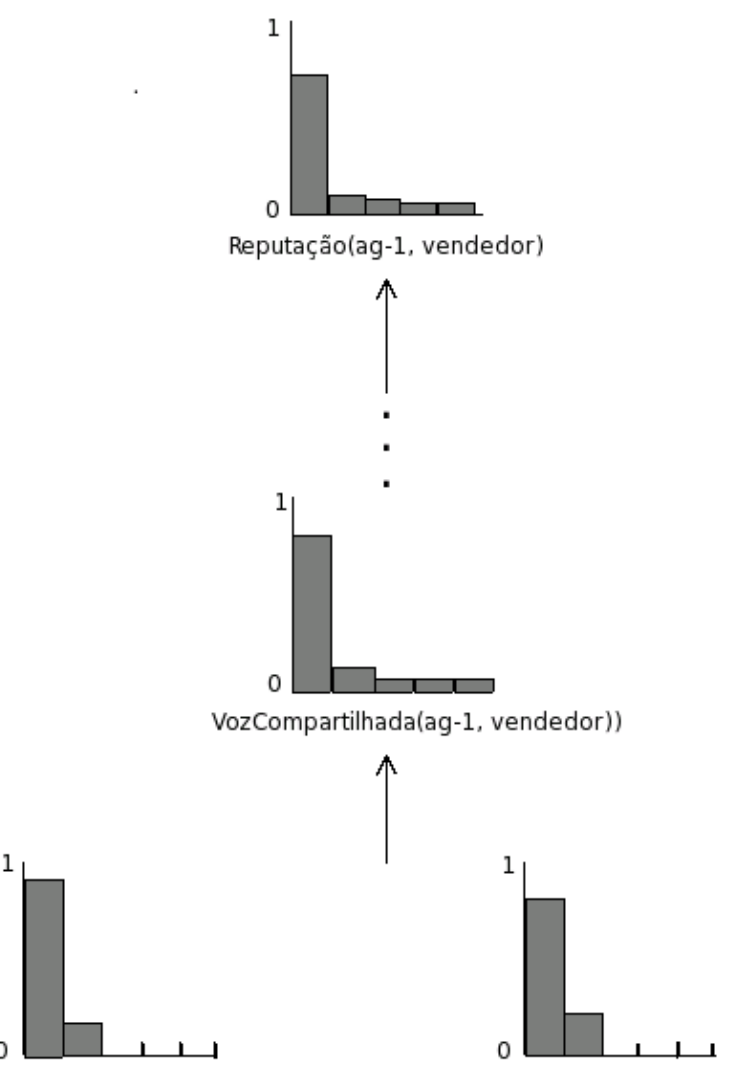

Comunicação(ag-3, Reputação(ag-1, vendedor)) Comunicação(ag-2, Reputação(ag-1, vendedor))

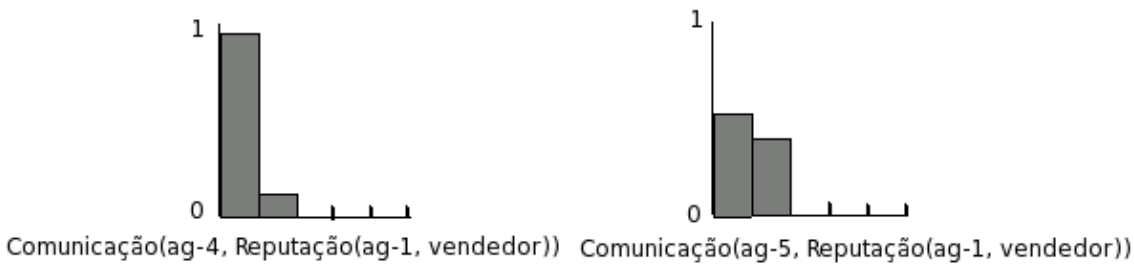

Figura 3.7: Cálculo do predicado Reputação do agente ag-1 como vendedor

Esta discrepância entre imagem e reputação não é um problema para o modelo Repage, visto que esta diferenciação é intrínseca ao modelo. É importante ressaltar que, neste caso, a transmissão da reputação do agente ag-1 não interfere nas imagens dos agentes como informantes, visto que a reputação é apenas um boato e que o agente transmissor não se comprometeu com o conteúdo da informação repassada, que é anônima. Sendo assim, as imagens dos agentes ag-2, 
ag-3, ag-4 e ag-5 como informantes não serão depreciadas. Tal fato não ocorre quando um agente informante comunica a imagem que este possui de um alvo, já que, desta forma, o agente informante está se comprometendo com o conteúdo da informação.

\subsection{Síntese}

O modelo Repage é utilizado no cálculo de reputação por parte dos agentes que integram o sistema RePart, apresentado detalhadamente no próximo capítulo. A imagem/reputação calculada pelo módulo Repage será adotada como um dos fatores decisivos na escolha de um parceiro no processo de simulação. 


\section{RePart}

O objetivo deste capítulo é descrever a ferramenta de simulação RePart: Reputation-based Partnership, que tem como finalidade possibilitar uma análise mais detalhada do uso da reputação como fator integrante na escolha de um parceiro e na atuação de um agente na sociedade.

Este capítulo é composto por 4 seções. Na primeira delas, é apresentada a justificativa para o desenvolvimento da ferramenta de simulação RePart. A seguir, na seção 4.2, é descrito o funcionamento do sistema RePart. Na seção 4.3, a arquitetura do sistema é detalhada: os agentes, o núcleo de simulação e a interface são apresentados. Por fim, uma síntese da ferramenta de simulação é apresentada.

\subsection{Introdução}

Os diversos modelos desenvolvidos para o cálculo da reputação em SMA trouxeram a necessidade de comparar seus desempenhos. Para tanto, inicialmente foram utilizados os experimentos propostos em (ZACHARIA, 1999) para o teste do modelo SPORAS e, posteriormente, o Dilema do Prisioneiro (AXELROD, 1997) como cenários para a realização de tais testes. Tais comparações de desempenho são apresentadas em (CARBO; MOLINA; DAVILA, 2002; SCHILLO, 2000; MUI; MOHTASHEMI; HALBERSTADT, 2002b)

Entretanto, ambos os cenários de testes sugeridos falham na avaliação de aspectos importantes. No caso dos experimento SPORAS, não ocorre o isolamento de agentes nocivos, já que não se permite que os agentes escolham com quem interagir. Por outro lado, a modelagem multi-dimensional de reputação não é avaliada na versão iterada do Dilema do Prisioneiro, visto que, neste cenário, cada agente possui uma reputação que se refere a todos os papéis que possam ser dempenhados pelo alvo. Estas abordagens não obtiveram uma aceitação unânime por parte da comunidade de pesquisa de reputação em SMA (FULLAM; SABATER; BARBER, 2005). 
Posteriormente, foi anunciada a plataforma de testes denominada ART (Agent Reputation Testbed) (FULLAM et al., 2005), que tem como cenário o mercado de avaliações de obras de arte e é considerada uma ferramenta mais completa na análise do cálculo de reputação por parte dos agentes. Em 2006, esta plataforma foi utilizada em uma competição internacional ${ }^{1}$, que contou com a participação de 17 times de pesquisadores que fizeram com que seus modelos duelassem, o que denota a grande aceitação desta plataforma de testes por parte da comunidade.

Todos os experimentos e plataformas de testes mencionados acima analisam a reputação como o único fator relevante na escolha de um parceiro. As métricas envolvem, basicamente, a questão de qual o algoritmo que calcula um valor mais próximo da realidade, com o menor custo computacional e com o menor tempo.

Neste trabalho, a ferramenta de simulação RePart tem como objetivo avaliar o impacto do uso da reputação nos processos decisórios internos dos agentes. Em um sistema aberto, no qual existe uma dependência mútua de agentes cooperativos, a reputação do parceiro em potencial é apenas um dos fatores a ser considerado. Outros fatores importantes, como o custo da parceria, também influenciam o processo de decisão. Agentes cognitivos podem optar por diferentes parceiros quando deparados com tais possibilidades. Esta foi a questão propulsora para o desenvolvimento de uma ferramenta de simulação, ou mesmo para a alteração de alguma já existente.

Inicialmente, a plataforma ART foi tida como candidata para uma possível modificação que suprisse as necessidades dos experimentos a serem realizados. Entretanto, a propagação de avaliações anônimas (a reputação do modelo Repage) não é prevista neste sistema. Além disso, o domínio proposto para a realização de simulações não torna possível a análise da relação custo-benefício do uso do conceito de reputação em parcerias. Dados estes motivos que demandariam uma mudança estrutural custosa na plataforma ART, optou-se pelo desenvolvimento da ferramenta de simulação denominada RePart, descrita em detalhes a seguir.

\subsection{Descrição do sistema}

O sistema RePart é uma ferramenta de simulação baseada em um cenário simplificado de um mercado composto por consumidores e empresas.

\footnotetext{
${ }^{1}$ Maiores detalhes em http://www.lips.utexas.edu/art-testbed/competition.htm.
} 


\subsubsection{Cenário da aplicação}

No cenário proposto para o sistema RePart existem dois tipos de agentes: consumidores e empresas. Em cada passo discreto de tempo (ciclo), os consumidores devem adquirir uma mercadoria, produzida por uma empresa, que pode representar um bem material ou um serviço. Esta escolha, feita segundo o perfil de cada consumidor ${ }^{2}$, leva em conta a imagem/reputação da empresa e o custo da mercadoria.

Para fins de simplificação, considera-se que existe apenas um tipo de mercadoria transacionada entre consumidores e empresas. A quantia de recursos disponíveis para cada consumidor é considerada ilimitada.

As empresas possuem duas características que as diferem no sistema: a qualidade e o custo da mercadoria produzida. Inicialmente, estes valores são determinados no momento de criação da empresa, por meio de uma função pseudoaleatória. Estes valores são variáveis independentes e são normalizadas no intervalo de 0 a 1 . Durante os ciclos de simulação, e dependendo da estratégia da empresa, estes valores podem ser ajustados, para mais ou para menos, de acordo com seu perfil.

O estoque das empresas também é considerado ilimitado, ou seja, as empresas podem realizar infinitas transações de venda de mercadoria em um único ciclo de simulação. O risco da formação de parcerias neste contexto não está ligado, então, à entrega da mercadoria, mas sim à qualidade desta, que pode variar e que se considera desconhecida por parte dos consumidores.

A qualidade da mercadoria entregue pela empresa determinará sua imagem frente aos consumidores. Estes avaliarão o bem recebido e irão gerar uma imagem proporcional a esta qualidade. Também para efeitos de simplificação, considera-se que a avaliação dada pelos consumidores com relação à qualidade da mercadoria recebida seja igual a avaliação da qualidade da mercadoria entregue pela empresa.

Assim como sua imagem ou reputação, o preço cobrado por uma empresa também pode determinar o número de consumidores que uma empresa pode angariar, pois preços mais baixos podem ser mais atrativos.

\footnotetext{
${ }^{2}$ Maiores detalhes sobre estes perfis são apresentados na seção 4.2.2.
} 


\subsubsection{Perfis dos agentes}

O sistema RePart apresenta diversos perfis de agentes que foram estabelecidos a fim de representar as diferentes estratégias que podem ser adotadas por um consumidor ao selecionar um parceiro ou por uma empresa ao agir em uma sociedade orientada à reputação.

\subsubsection{Perfis de agentes consumidores}

Foram implementados 3 perfis distintos de consumidores na ferramenta de simulação RePart.

Conservadores Priorizam a confiança depositada na empresa em detrimento do custo cobrado pela mesma. Este tipo de consumidor sempre irá selecionar a empresa na qual ele deposite uma maior confiança;

Ousados Apresentam também uma preocupação com o custo demandado pela parceria. É possível dizer que uma ação que demande um custo maior represente uma perda maior, caso o "contrato" não seja cumprido. Por conseguinte, agentes ousados selecionarão a empresa que apresentar a melhor relação entre a confiança dividida pelo custo cobrado pela mesma. Desta forma, tendem a se sentir seduzidos por um custo menor, mesmo que a reputação do parceiro não seja a melhor possível;

Avaros Buscam sempre custos inferiores. Agentes avaros optarão pela empresa que apresentar o custo mais baixo, independentemente da confiança depositada na mesma.

\subsubsection{Perfis de agentes empresas}

Por outro lado, sete perfis distintos de empresa, representando cada qual uma estratégia de negócio, foram implementados na ferramenta de simulação RePart. Tais perfis envolvem a ação de atualização de custos e qualidades das mercadorias por parte das empresas.

Reativo O perfil mais simples, não altera o custo e qualidade da mercadoria ao longo da simulação. Este perfil foi adicionado por ser uma referência importante para a análise do desempenho dos demais perfis; 
Investidor Aumenta a qualidade da mercadoria na medida em que o número de parcerias estabelecidas aumenta. Este agente acredita que, se seu desempenho for melhor, angariará um maior número de parceiros, acumulando, por conseguinte, um maior benefício;

Decadente Diminui a qualidade da mercadoria conforme o número de parcerias diminui. Este tipo de perfil reflete a crença de que se o número de parcerias está diminuindo, não é compensador despender grandes esforços nas parcerias;

Trapaceiro Diminui a qualidade da mercadoria na medida em que o número de parcerias aumenta. Agentes com este perfil tentam se beneficiar do fato de terem construído uma boa imagem/reputação. Na medida em que recebem um maior benefício, acarretado pelo maior número de parcerias, decrescem a qualidade de seus produtos;

Ganancioso Aumenta o custo cobrado pela mercadoria conforme o número de parcerias aumenta. Este agente possui a crença de que se seu desempenho for satisfatório, poderá aumentar o custo de seus produtos, acumulando um maior benefício.

Estrategista Diminui o custo na medida em que o número de parcerias diminui. Com este perfil, o agente acredita que com custos inferiores, conseguirá angariar um maior número de parcerias e, por conseguinte, atingirá um maior benefício acumulado no longo prazo.

Atacadista Diminui o custo conforme o número de parcerias aumenta. Assim como o perfil estrategista, também acredita que mercadorias com custos menores são um atrativo para possíveis parceiros.

\subsubsection{Estabelecimento de parcerias}

A ferramenta de simulação RePart apresenta como foco a simulação do estabelecimento de parcerias entre agentes heterogêneos, baseada no conceito de reputação. Conforme apresentado na seção 2.2.1 deste documento, uma parceria é firmada entre dois agentes quando ambos têm benefícios a oferecer mútua e reciprocamente. Neste caso, as ações desempenhadas por parte de ambos os agentes devem estar de acordo com o objetivo de cada qual. No caso do sistema RePart, para fins de simplificação, foi definido que existe apenas um tipo de mercadoria desejada pelos consumidores e que é produzida por todas as empresas. Os passos de escolha do objetivo a ser perseguido, seleção do plano para atingi-lo e verificação 
da possibilidade de execução de todas as ações foram simplificadas. O fato de os consumidores almejarem um único tipo de bem material faz com que o passo 4 , de seleção do parceiro, apresentado na seção 2.2.2, seja o foco da simulação.

Por sua vez, uma empresa selecionada por um consumidor sempre aceita o pedido, firmando, por conseguinte, a parceria. A etapa de negociação entre os agentes, que determina quais ações serão executadas por ambos os agentes na parceria, também foi eliminada baseado no fato de as empresas sempre desejarem o dinheiro dos consumidores ${ }^{3}$.

No sistema RePart, algumas ações devem ser executadas pelos agentes a fim de que o estabelecimento de parcerias seja efetivado. Os consumidores devem:

1. Consultar outros consumidores em busca de informações sobre as empresas disponíveis no mercado;

2. Avaliar as imagens coletadas e as já armazenadas a fim de selecionar a empresa;

3. Contratar a empresa escolhida, ou seja, efetivar o pagamento;

4. Formar uma avaliação acerca do desempenho da empresa, baseando-se na qualidade da mercadoria recebida;

5. Repassar informações sobre as empresas aos demais agentes consumidores, sejam estas informações oriundas de experiências próprias ou de terceiros (imagens) ou sobre o que se diz anonimamente na sociedade sobre determinada empresa (reputação) .

Já as empresas devem:

1. Receber os pedidos de compra por parte dos consumidores e entregar as mercadorias;

2. Analisar seu desempenho (por meio do número de parcerias firmadas em cada ciclo) e atualizar seu custo ou qualidade de mercadorias, de acordo com sua estratégia de negócio.

Agentes consumidores demandam que exista uma troca de mensagens para um intercâmbio de informações sobre o desempenho das empresas. Os mecanismos que regem esta comunicação entre agentes consumidores são apresentados a seguir.

\footnotetext{
${ }^{3}$ Pode-se imaginar o dinheiro como sendo a contrapartida de ação ou recurso de um possível parceiro.
} 


\subsubsection{Comunicação entre agentes}

Além de permitir que os agentes formem parcerias, o sistema RePart deve também possibilitar a propagação na sociedade da informação acerca da reputação de seus integrantes. Para que a comunicação da reputação ou a consulta a informantes ocorra, o sistema deve determinar com quem cada agente pode se comunicar, ou seja, deve estabelecer a vizinhança de cada agente.

Os vizinhos são obrigatoriamente do mesmo tipo que o agente. Consumidores apenas trocam informações a respeito de empresas com outros vizinhos também consumidores.

A vizinhança é baseada em uma distribuição topológica dos agentes consumidores ao longo de um reticulado de células. Cada célula representa um agente, que terá uma vizinhança linear de raio fixo, conforme denota a Figura 4.1 abaixo.

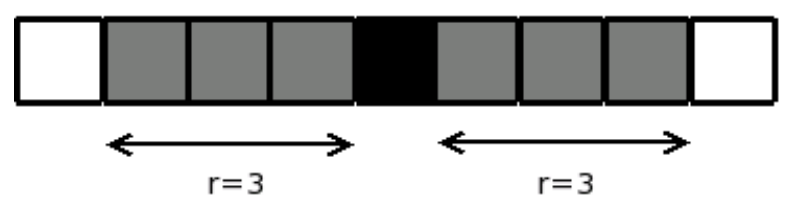

Figura 4.1: Vizinhança linear com $r=3$

O estabelecimento da vizinhança é feito no momento de inicialização da ferramenta de simulação, que aloca os agentes ao longo do reticulado de células.

No sistema RePart, para fins de simplificação, estipulou-se que os agentes consumidores devem consultar a todos os seus vizinhos em busca de informações sobre o desempenho das empresas. Quando atuarem como informantes, os consumidores nunca transmitirão falsas avaliações, ou seja, avaliações que sejam divergentes de suas crenças internas. Assim, também para fins de simplificação, não foi adotado um mecanismo de avaliação de um dado agente como informante, visto que todos são confiáveis.

Já a propagação da reputação na sociedade está calcada em 3 regras que definem como e quando a reputação será transmitida:

1. Somente a reputação de candidatos a parceiro serão retransmitidas, isto é, consumidores transmitirão exclusivamente a reputação de empresas. Isto implica que a intersecção entre alvos e informantes é nula, e, por conseguinte, não existirá a possibilidade de retaliação. Com isso, a transmissão da informação sobre a reputação é favorecida, ao mesmo tempo que a acurácia 
dos valores é intensificada, já que as avaliações do tipo Poliana ${ }^{4}$ não terão razão para existir (CONTE; PAOLUCCI, 2002);

2. Ao receber a informação sobre a reputação de um alvo, o agente deverá armazená-la e transmiti-la no próximo ciclo de simulação segundo duas condições: caso a reputação seja negativa, transmiti-la sempre; caso a reputação seja positiva, transmiti-la somente se for condizente com a imagem que o agente possui do alvo. Segundo (CONTE; PAOLUCCI, 2002), uma certa percentagem de calúnias (má reputação não merecida) é melhor do que o silêncio, ou seja, a não transmissão de nenhum tipo de reputação;

3. Os agentes integrantes receberão as informações sobre a reputação de agentes candidatos a parceiro sem precisar solicitá-las aos vizinhos, aumentando drasticamente a eficiência do mecanismo de reputação (CONTE; PAOLUCCI, 2002). Um agente, ao ser informado sobre uma reputação de um alvo que estiver de acordo com a regra número 2, acima, deverá transmiti-la a todos os seus vizinhos, sem que estes a tenham solicitado.

Estas restrições diminuem a complexidade do sistema RePart, ao mesmo tempo que fazem com que a reputação transmitida apresente uma maior eficiência, ou seja, desempenhe de forma mais satisfatória seu papel como mecanismo de controle social.

\subsection{Arquitetura do sistema}

O sistema RePart é formado por três componentes básicos: um núcleo de simulação, uma interface com o usuário e os agentes (consumidores e empresas).

\subsubsection{Visão geral}

A arquitetura do sistema RePart é representada na Figura 4.2. Seus componentes apresentam as seguintes funções:

1. Agentes: são os protagonistas das parcerias, sendo cada qual autônomo para a escolha de seus parceiros. Agentes consumidores apresentam perfis distintos para a seleção de parceiros, definidos pelo usuário, e capacidade de armazenar imagens e reputações de agentes alvo, obtidos por meio do

\footnotetext{
${ }^{4}$ Avaliações otimistas, exageradamente positivas.
} 


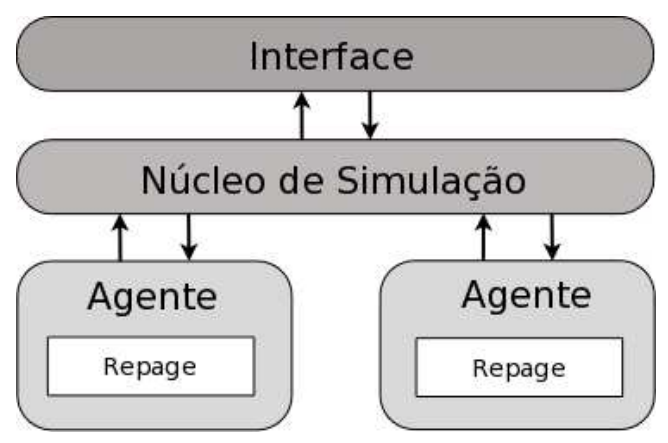

Figura 4.2: Arquitetura da ferramenta de simulação RePart

módulo Repage. Já agentes empresas têm sua atuação na sociedade regida pelo seu perfil, também determinado pelo usuário;

2. Núcleo de Simulação: inicia a simulação, criando os agentes de acordo com os parâmetros especificados pelo usuário, atribuindo-lhes também sua vizinhança. Ao longo do processo de simulação, permite a troca de mensagens entre os agentes vizinhos, inserção de boatos e é responsável pelo incremento nos passos discretos de tempo do sistema (ciclos);

3. Interface: permite que o usuário entre com os parâmetros da simulação, como percentagem de agentes com perfis distintos na sociedade, número total de agentes na simulação, número de ciclos a serem simulados.

Um ciclo no processo de simulação é apresentado no Pseudo-algoritmo 4.1.

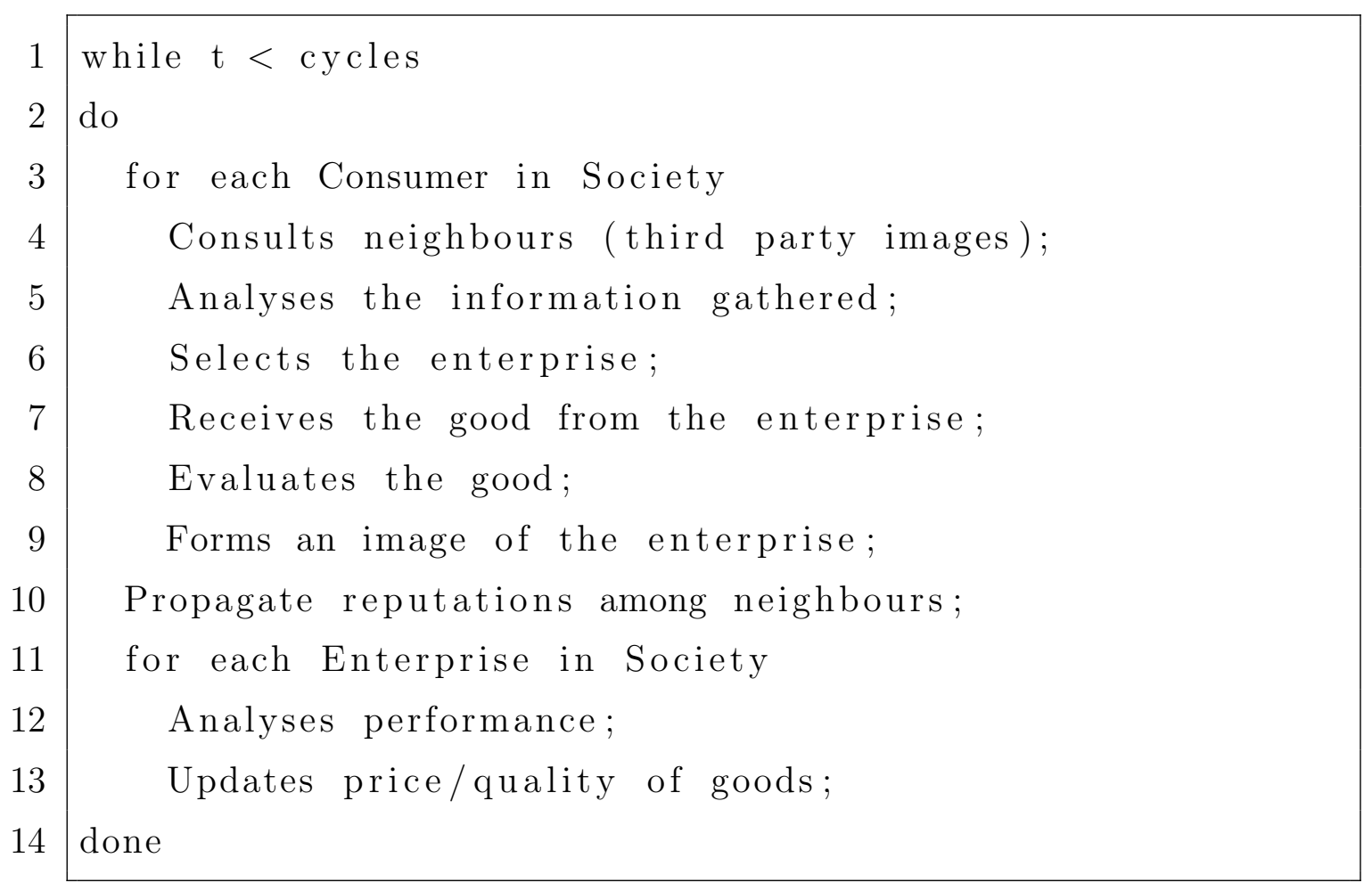


Os passos 6 e 13 relativos à seleção de empresas por parte dos consumidores e à atualização de custo e qualidade da mercadoria por parte das empresas são feitos segundo o perfil de cada agente e encontram-se descritos em maiores detalhes nas seções 4.3 .2 e 4.3.3.

\subsubsection{Agentes consumidores}

Protagonistas das parcerias, os agentes consumidores devem ser autônomos nas suas escolhas de parceiros. Esta opção deve ser coerente com seu perfil, suas crenças e seu estado mental. Sendo assim, no sistema RePart, cada agente consumidor deve possuir mecanismos internos para suas tomadas de decisão. A seguir, serão descritos estes mecanismos e a arquitetura interna dos agentes consumidores que permitem que tal fato ocorra.

\subsubsection{Arquitetura interna}

A arquitetura interna dos agentes consumidores, ilustrada na Figura 4.3, divide-se em três módulos, listados a seguir.

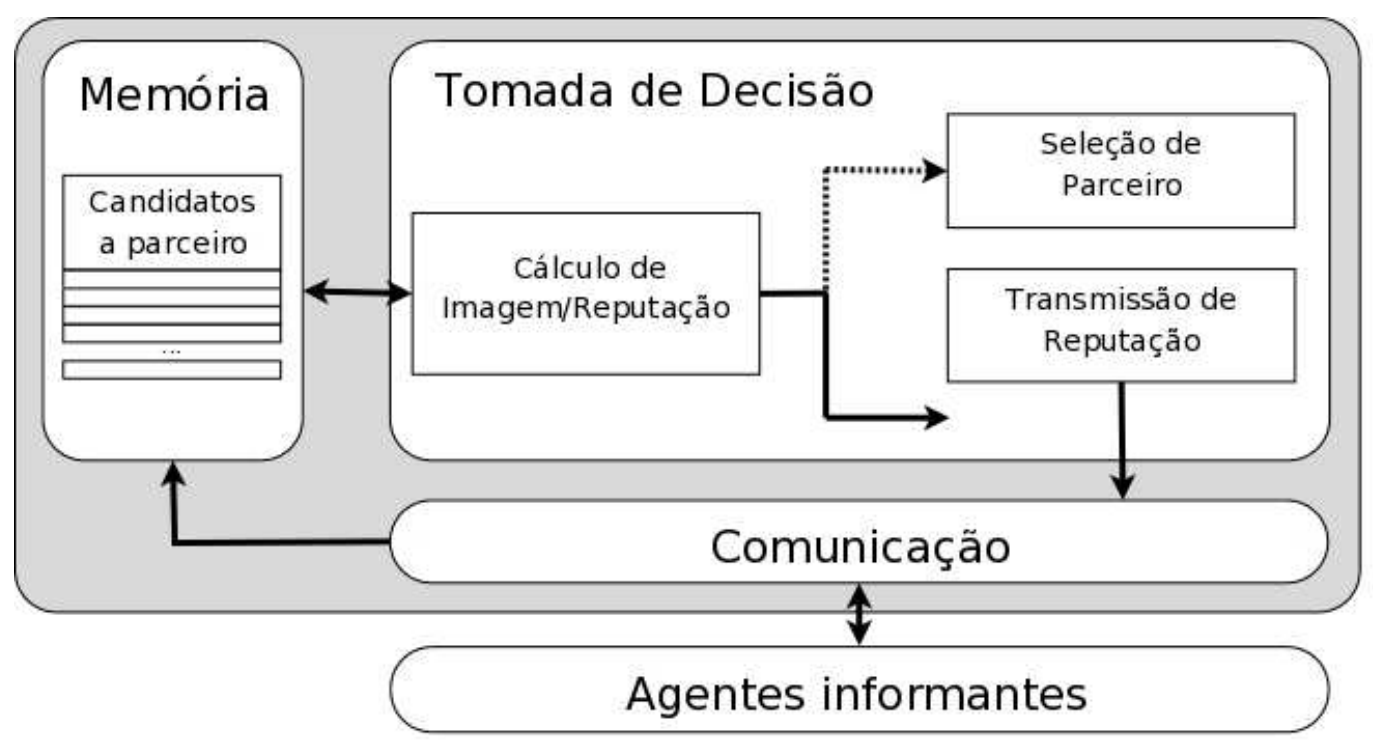

Figura 4.3: Arquitetura interna dos agentes consumidores integrantes do sistema RePart

Memória Consiste em uma lista que contém a identificação dos candidatos a parceiro, bem como sua imagem, sua reputação, a confiança depositada e o custo cobrado pela empresa, conforme indica a Figura 4.4.

Segundo (CASTELFRANCHI; FALCONE, 2000), a confiança que um agente deposita em um alvo é forte e claramente baseada na imagem/reputação 


\begin{tabular}{|c|c|c|c|c|}
\hline Id & Imagem & Reputação & Confiança & Custo \\
\hline 1 & 1 & 0,75 & 1 & 0,89 \\
\hline 2 & 0,75 & 0,75 & 0,75 & 0,23 \\
\hline 3 & 0,25 & 0,5 & 0,25 & 0,08 \\
\hline
\end{tabular}

Figura 4.4: Memória dos agentes consumidores

deste frente ao avaliador. Portanto, para fins de simplificação, na plataforma RePart adotaremos que a confiança depositada em um agente será calculada segundo o Pseudo-algoritmo 4.2.

1

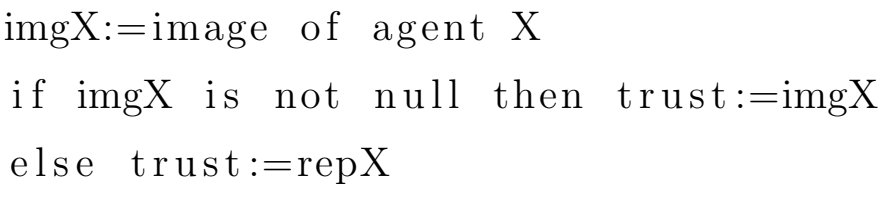

Pseudo-Algoritmo 4.2: Cálculo de confiança

A imagem do agente alvo sempre possui prioridade frente a reputação do mesmo, visto que uma imagem é uma avaliação proveniente de experiências diretas ou de terceiros, enquanto que a reputação é apenas uma informação sobre o que se diz na sociedade sobre determinado alvo (PINYOL et al., 2007).

O modelo Repage não retorna um valor exato da imagem ou reputação, e sim uma tupla de números que indica a aderência do conceito a cada conjunto fuzzy. Sendo assim, a confiança no agente alvo será calculada por meio de uma defuzzicação dos valores da tupla que indica sua imagem ou reputação.

A memória do sub-módulo Cálculo de Imagem/Reputação (modelo Repage) acessa esta memória principal do agente para fornecer subsídio a seus processos de inferência. Esta integração é feita de forma direta e clara (PINYOL et al., 2007).

A memória do agente é atualizada (1) a cada nova interação com uma empresa; (2) após a coleta de imagens de terceiros e (3) após o recebimento de informações sobre a reputação de uma empresa alvo. Ao final de cada ciclo, o valor dos custos cobrados pelas empresas também é atualizado.

Módulo de Tomada de Decisão Este módulo é responsável pelas escolhas feitas pelos consumidores ao longo do processo de simulação. No sistema RePart, elas são duas: (1) com quem formar parceria? e (2) quando retransmitir uma reputação recebida aos vizinhos? Este é o módulo central 
dos consumidores, sendo formado por três sub-módulos.

O primeiro deles, Cálculo de Imagem/Reputação é responsável pelo cálculo da imagem e reputação dos demais agentes. A imagem é calculada a partir de experiências diretas do avaliador com o alvo e de informações sobre a imagem de terceiros. Já a reputação é obtida por meio da coleta de informações anônimas que circulam na sociedade a respeito do agente alvo. Este módulo é baseado no modelo Repage (SABATER; PAOLUCCI; CONTE, 2005; PAOLUCCI et al., 2005).

O sub-módulo Seleção de Parceiros fornece a resposta à questão número (1), com quem formar parceria. Neste processo, cabe ao agente ponderar se o mesmo deseja realizar uma parceria com um agente já conhecido ou tentar explorar a sociedade na tentativa de descobrir um parceiro que lhe seja mais atrativo.

A questão exploração versus explotação é um dos pontos cruciais na área de pesquisa de Aprendizado por Reforço (SUTTON; BARTO, 1998). Geralmente, adotam-se políticas denominadas "gulosas", que selecionam ações que o agente já conhece e que mais lhes sejam atrativas. Estas ações são selecionadas com a probabilidade $(1-\alpha)$. Ações desconhecidas são selecionadas, por conseguinte, com a probabilidade $\alpha$. No caso do sistema RePart, as ações representam os possíveis parceiros.

Para os agentes consumidores, adotaremos $\alpha=\frac{1}{\text { numparceiros }}$. A variável numparceiros armazena o número de empresas já conhecidas pelo consumidor, ou seja, com quantas empresas este já realizou parcerias. Neste caso, $\alpha$ terá um decaimento exponencial, sendo que o fator com que o agente explora o ambiente é maior no ínicio das simulações e decai na medida em que o agente adquire um maior conhecimento a respeito dos demais agentes. Quando numparceiros for igual a zero, ou seja, na primeira interação do agente, adotaremos $\alpha=1$.

Caso seja determinado que um parceiro já conhecido deva ser selecionado, a empresa que ocupar a primeira posição na memória do agente será escolhida. Os perfis dos consumidores atuam de forma diferente no processo de ordenação da memória, utilizando cada qual uma métrica para determinar qual a empresa, possível parceira, lhe é mais atrativa.

1. Conservadores: Priorizam a confiança depositada na empresa em detrimento do custo cobrado pela mesma. A ordenação de empresas na memória de agentes conservadores é feita baseando-se estritamente no 
campo confiança. Quanto maior a confiança, mais no topo da lista estará a empresa alvo.

A lista apresentada na Figura 4.4 é ordenada segundo este perfil, originando a lista indicada na Figura 4.5.

\begin{tabular}{|c|c|c|c|c|}
\hline Id & Imagem & Reputaçã̃o & Confiança & Custo \\
\hline 1 & 1 & 0,75 & 1 & 0,89 \\
\hline 2 & 0,75 & 0,75 & 0,75 & 0,23 \\
\hline 3 & 0,25 & 0,5 & 0,25 & 0,08 \\
\hline
\end{tabular}

Figura 4.5: Memória ordenada segundo o perfil conservador

2. Ousados: Apresentam também uma preocupação com o custo demandado pela parceria. A ordenação da memória é feita, por conseguinte, baseando-se na relação existente entre o campo confiança e custo. Quanto maior o resultado da divisão destes dois campos, mais no topo da lista estará a empresa alvo.

A lista apresentada na Figura 4.4 é ordenada segundo este perfil, originando a lista indicada na Figura 4.6. Neste exemplo, temos que a relação obtida entre os campos confiança e custo para os agentes 1, 2 e 3 é, respectivamente, 1,12, 3,26 e 3,13. Sendo assim, o agente 2 ocupa o topo da lista, seguido pelos agentes 3 e 1.

\begin{tabular}{|c|c|c|c|c|}
\hline Id & Imagem & Reputaçã̃o & Confiança & Custo \\
\hline 2 & 0,75 & 0,75 & 0,75 & 0,23 \\
\hline 3 & 0,25 & 0,5 & 0,25 & 0,08 \\
\hline 1 & 1 & 0,75 & 1 & 0,89 \\
\hline
\end{tabular}

Figura 4.6: Memória ordenada segundo o perfil ousado

3. Avaros: Buscam custos inferiores, portanto baseiam a ordenação de sua memória exclusivamente no campo custo. Quanto menor o mesmo, mais no topo da lista estará a empresa alvo.

A lista apresentada na Figura 4.4 é ordenada segundo este perfil, originando a lista indicada na Figura 4.7.

\begin{tabular}{|c|c|c|c|c|}
\hline Id & Imagem & Reputação & Confiança & Custo \\
\hline 3 & 0,25 & 0,5 & 0,25 & 0,08 \\
\hline 2 & 0,75 & 0,75 & 0,75 & 0,23 \\
\hline 1 & 1 & 0,75 & 1 & 0,89 \\
\hline
\end{tabular}

Figura 4.7: Memória ordenada segundo o perfil avaro 
A informação sobre a imagem fornecida pelo sub-módulo Cálculo de Imagem/Reputação também é utilizado pelo sub-módulo Transmissão de Reputação, que determina se uma reputação deve ser propagada aos vizinhos segundo as regras apresentadas na seção 4.2.4, respondendo à questão número (2).

Comunicação Armazena as mensagens recebidas dos agentes informantes (imagens de terceiros e reputações) até que estas precisem ser analisadas pelo módulo de Tomada de Decisão. Também é responsável por armazenar as reputações a serem retransmitidas, aprovadas pelo sub-módulo Transmissão de Reputação.

\subsubsection{Agentes empresas}

As empresas, também protagonistas das parcerias, expressam sua autonomia no momento em que selecionam sua forma de atuação em uma sociedade norteada pelo conceito de reputação. As variáveis custo e qualidade da mercadoria podem ser alteradas pelas empresas de acordo com sua estratégia de negócio.

\subsubsection{Arquitetura interna}

Os agentes que representam as empresas no sistema RePart são agentes reativos simples (RUSSELL; NORVIG, 2004), baseando suas ações somente na sua percepção atual. No caso, o número de parcerias (input) determina a ação do agente que, de acordo com seu perfil, atualiza seu preço ou qualidade da mercadoria.

Como descrito na seção 4.2.2.2, existem 7 perfis distintos de empresas no sistema RePart, que representam as estratégias de negócio com relação ao custo e à qualidade das mercadorias. Estas estratégias representam possíveis decisões de agentes que, inseridos em uma sociedade orientada à reputação, tentam extrair o maior benefício possível de tal fato.

As variáveis quality e cost representam respectivamente a qualidade da mercadoria e seu custo. Estas variáveis são alteradas de acordo com o perfil da empresa, expresso na variável personality, com o número de parcerias do ciclo anterior, lastNumPartnerships e com o número de parcerias realizadas no ciclo atual, numPartnerships.

Reativo (Reactive) Não altera as variáveis quality e cost ao longo do processo de simulação; 
Investidor (Investor) Incrementa a variável quality caso numPartnerships seja maior que lastNumPartnerships;

Decadente (Decadent) Decrementa a variável quality caso numPartnerships seja menor que lastNumPartnerships;

Trapaceiro (Cheater) Decrementa a variável quality caso numPartnerships seja maior que lastNumPartnerships;

Ganancioso (Greedy) Incrementa a variável cost caso numPartner ships seja maior que lastNumPartnerships;

Estrategista (Strategist) Decrementa a variável cost caso numPartnerships seja menor que lastNumPartnerships;

Atacadista (Wholesaler) Decrementa a variável cost caso numPartnerships seja maior que lastNumPartnerships.

Este processo é descrito no Pseudo-algoritmo 4.3.

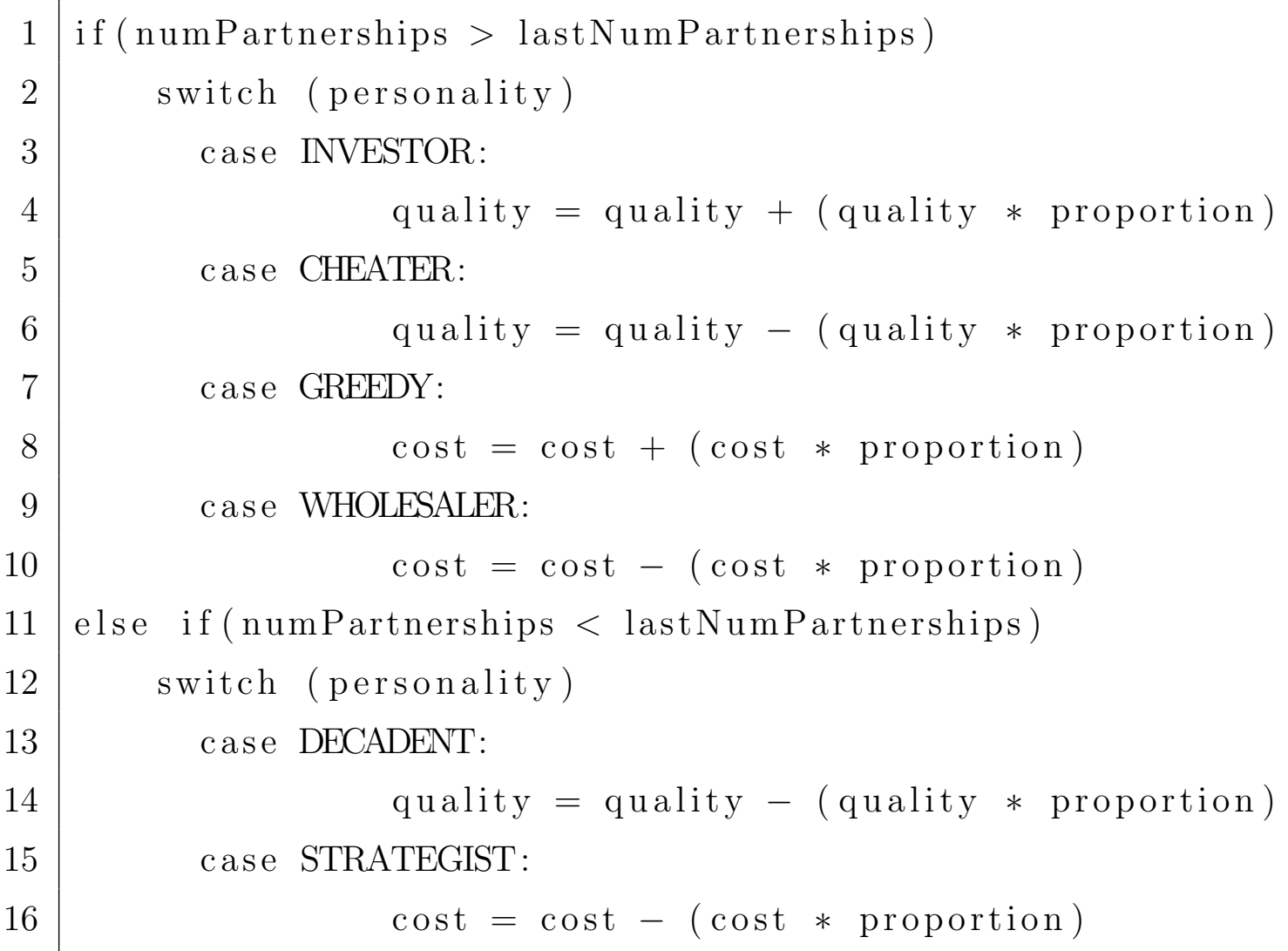

Pseudo-Algoritmo 4.3: Atualização de qualidade e custo da mercadoria por parte dos agentes empresas 
A variável proportion, que representa a proporção com a qual as variáveis quality e cost serão alteradas, está configurada no sistema RePart com o valor de 0,2 , podendo ser alterada para suprir as necessidades de outras simulações.

\subsubsection{Núcleo de simulação}

Este componente do sistema, conforme denotado pelo seu próprio nome, é responsável pelas funções centrais no processo de simulação, sendo elas:

1. inicialização dos parâmetros da simulação e criação de agentes segundo especificação do usuário e variáveis aleatórias;

2. estabelecimento de comunicação entre os agentes;

3. incremento nos passos de tempo;

4. inserção de boato;

5. armazenamento dos resultados em um arquivo de log.

A política de escalonamento de ações numa plataforma de simulação, que está fortemente vinculada ao incremento nos passos de tempo, desempenha papel crucial nos resultados obtidos com o processo de simulação (MICHEL; FERBER; GUTKNECHT, 2001). Na ferramenta de simulação RePart, optou-se por um escalonador de tempo discreto, que consiste na execução seqüencial de ações por parte dos agentes. Após o término desta seqüência de ações pré-estabelecida, o passo de tempo da ferramenta de simulação é incrementado. Esta abordagem evita conflitos no acesso a variáveis globais e faz com que os agentes estejam sincronizados por definição, dado o modelo de escalonamento.

Por outro lado, a ordem escolhida para a execução das ações pode alterar os resultados obtidos. Na tentativa de minimizar estes efeitos, uma solução bastante recorrente é a ordenação aleatória dos agentes que executarão as ações (EPSTEIN; AXTELL, 1996). No caso do sistema RePart, esta aleatoriedade é gerada no processo de alocação dos agentes consumidores no reticulado de células. A lista na memória de cada agente também apresenta um grau de aleatoriedade quanto a ordem das empresas, evitando assim que no início da simulação a empresa que ocupasse a primeira posição de memória se beneficiasse de tal fato ${ }^{5}$.

Dado o caráter seqüêncial inerente à formação das parcerias, o método de escalonamento de tempo discreto mostra-se adequado, tendo inclusive o benefício

\footnotetext{
${ }^{5}$ Vide seção 4.3.2.1.
} 
de ser a abordagem mais simples, que demanda o menor poder computacional para a execução dos ciclos de simulação.

A funcionalidade 4 apresentada, de inserção de boato, é ativada pelo usuário por meio da interface. No sistema RePart, um boato é o equivalente ao conceito de reputação do modelo Repage, ou seja, é uma avaliação anônima sobre determinado alvo propagada na sociedade. Sua inserção é feita pelo Núcleo de Simulação, que fornece a uma percentagem de consumidores uma informação anônima sobre uma empresa alvo. Esta informação é então incorporada pelos agentes, por meio do predicado Reputação (Figura 3.1).

Todo o processo de simulação pode ser posteriormente analisado por meio do log gerado, armazenado pelo sistema RePart no arquivo simulation.txt.

\subsubsection{Interface}

No sistema RePart o usuário pode definir alguns parâmetros de simulação a fim de que estes se adaptem às necessidades de seus experimentos. A Figura 4.8 denota as opções apresentadas ao usuário. O idioma inglês foi adotado a fim de que a interface fosse o mais universal possível.

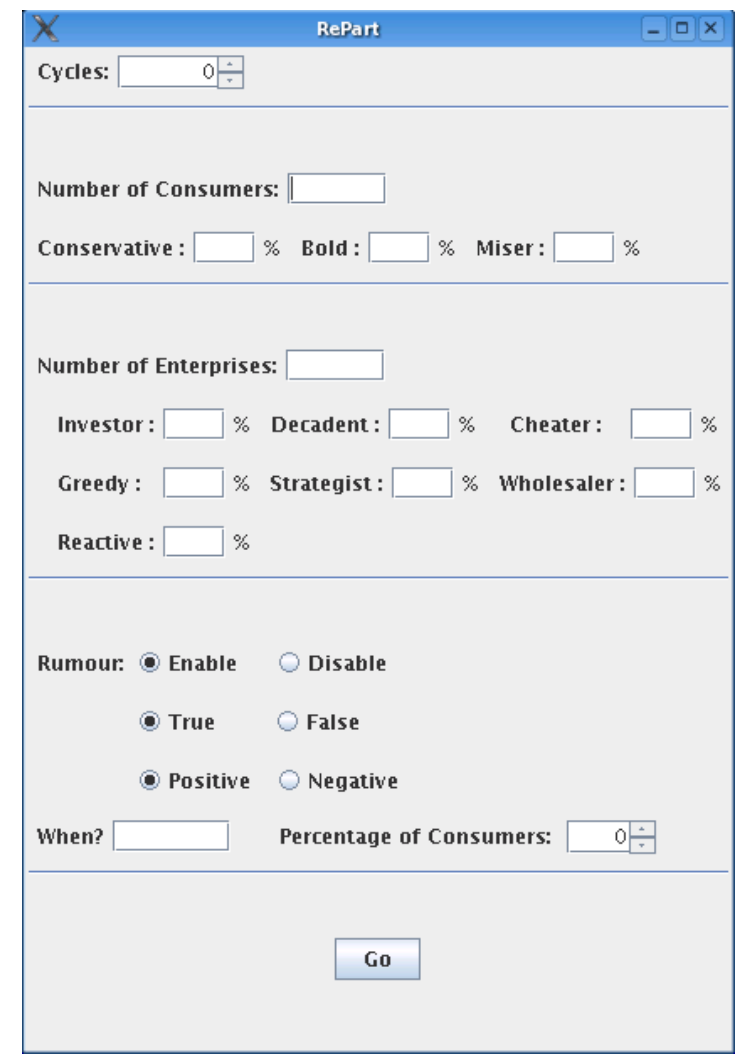

Figura 4.8: Interface do sistema RePart

No primeiro campo, o usuário deve fornecer o número de ciclos de simulação 
desejados. No segundo agrupamento, a percentagem de perfis de consumidores é requerida, bem como o número total de consumidores que deverão compor a sociedade na simulação. O terceiro agrupamento coleta as mesmas informações que o precedente, só que com relação às empresas. O quarto e último agrupamento é responsável pela ativação da inserção de boato na sociedade, além de suas propriedades. As opções "enabled" e "disabled" ativam e desativam, respectivamente, a propagação de avaliações anônimas na sociedade. Quando ativado, um boato pode ser verdadeiro ou falso (campos "true" e "false"). Da mesma forma, a reputação propagada pode ser positiva (uma avaliação muito boa), ou negativa (uma avaliação muito ruim). Além disso, o usuário também deve determinar em que ciclo a inserção do boato deve ocorrer e quantos consumidores devem ser inicialmente expostos a tal informação, o que é denotado pelos campos "When?" e "Percentage of Consumers", respectivamente.

A seleção das opções que ativam a propagação de uma falso boato negativo, por exemplo, faz com que no ciclo determinado pelo usuário seja inserida uma informação sobre uma avaliação muito ruim referindo-se à empresa com o melhor desempenho no momento, ou seja, que tenha formado o maior número de parcerias no ciclo imediatamente anterior. Já um falso boato positivo representa uma informação sobre uma avaliação muito boa referindo-se à empresa com a pior qualidade de mercadorias (menor valor associado à variável quality).

\subsection{Síntese}

A ferramenta de simulação RePart foi desenvolvida na linguagem Java. O módulo Repage, disponibilizado pela sua equipe de desenvolvimento ${ }^{6}$, foi utilizado como uma biblioteca, integrando os agentes consumidores.

O processo de simulação gera o arquivo de saída simulation.txt, que fornece as informações das variáveis atribuídas aos agentes no seu processo de criação, bem como os resultados da simulação. Estes estão distribuídos em 15 colunas que indicam: (1) ciclo, (2) qualidade média das mercadorias recebidas pelos consumidores conservadores, (3) qualidade média das mercadorias recebidas pelos consumidores ousados, (4) qualidade média das mercadorias recebidas pelos consumidores avaros, (5) gasto médio dos consumidores conservadores, (6) gasto médio dos consumidores ousados, (7) gasto médio dos consumidores avaros, (8) ganho médio das empresas investidoras, (9) ganho médio das empresas decadentes, (10) ganho médio das empresas trapaceiras, (11) ganho médio das empresas

\footnotetext{
${ }^{6}$ Disponível para download em http://sourceforge.net/projects/repage/ .
} 
gananciosas, (12) ganho médio das empresas estrategistas, (13) ganho médio das empresas atacadistas, (14) ganho médio das empresas reativas e (15) número de parcerias firmadas com a empresa alvo do boato inserido na sociedade. Caso a opção de inserção de boato esteja desabilitada, está coluna apresentará o símbolo - .

Os testes realizados com a ferramenta RePart, que visam investigar o uso do conceito de reputação na formação de parcerias, serão apresentados a seguir. 


\section{Experimentos}

A plataforma RePart tem por objetivo proporcionar a simulação de diversos cenários envolvendo o conceito de reputação como parâmetro no processo de tomada de decisão de agentes autônomos. Os experimentos aqui descritos possuem a finalidade de responder às questões propostas inicialmente na seção 1.1:

Questão 1 Como escolher um parceiro, levando em conta a reputação do candidato e o custo associado à parceria?

Questão 2 O quão vantajoso é manipular informações visando benefício próprio?

Questão 3 Como agir em uma sociedade norteada pelo conceito de reputação a fim de que melhores resultados sejam obtidos?

Este capítulo apresenta, primeiramente, a técnica adotada para a análise dos resultados dos experimentos. A seguir, os experimentos realizados, bem como seus resultados são detalhados. Os experimentos, divididos em 3 tipos, são apresentados respectivamente nas seções 5.2, 5.3 e 5.4. Cada tipo de experimento responde a uma das 3 questões supramencionadas. Ao final, na seção 5.5, é apresentada uma síntese da análise dos resultados.

\subsection{Metodologia de testes}

Resultados obtidos a partir de simulações distintas em um mesmo cenário podem apresentar grandes diferenças e discrepâncias. Muitas vezes, à primeira vista, torna-se impossível realizar uma afirmação com propriedade e segurança. Por isso, neste trabalho são utilizados recursos estatísticos que fornecem subsídio à inferência de conclusões sobre uma população a partir de amostras da mesma.

Neste processo são adotadas as chamadas hipóteses estatísticas, que representam suposições sobre a população em análise. Primeiramente deve ser formulada a hipótese nula $(\mathrm{HO})$. Esta é uma hipótese que, geralmente, tem o propósito de 
ser rejeitada ou anulada. Se quisermos comprovar, por exemplo, que o uso do conceito de reputação acarreta uma melhor qualidade das parcerias estabelecidas, devemos formular a hipótese $H 0$ que afirma que agentes que usam o conceito de reputação apresentam a mesma satisfação que aqueles que escolhem seus parceiros aleatoriamente. Rejeitando $H O$ estaríamos, então, inferindo que existe uma diferença estatística significativa na qualidade das parcerias, que não é meramente fruto de flutuações de amostragem.

Os processos que são empregados para determinar a aceitação ou a rejeição de uma hipótese são chamados de testes de hipótese (SPIEGEL, 2004). Neste trabalho adotaremos para esta finalidade o Teste T de Student, que pode ser definido pela expressão:

$$
T=\frac{X_{1}-X_{2}}{\sigma \sqrt{\frac{1}{n_{1}}+\frac{1}{n_{2}}}}
$$

onde:

$$
\sigma=\sqrt{\frac{n_{1} S_{1}^{2}+n_{2} S_{2}^{2}}{n_{1}+n_{2}-2}}
$$

e $X_{1}$ e $X_{2}$ representam as médias dos grupos de teste 1 e 2 , respectivamente, $S_{1}$ e $S_{2}$ seus desvios padrão e $n_{1}$ e $n_{2}$ o número de pontos nas amostras de cada grupo.

Após determinar o valor de T, uma tabela deve ser consultada. De acordo com o intervalo de certeza desejado e os graus de liberdade, que dependendem do número de pontos das amostras, o valor de $\mathrm{T}$ deve ser comparado ao da tabela. Se o valor calculado for inferior ao da tabela, então não é possível rejeitar $H 0$.

Além disso, como não existem atualmente na área padrões bem estabelecidos que determinem a quantidade de ciclos a serem simulados, adotou-se um número de ciclos que se mostrou suficiente para a estabilização dos valores das qualidades recebidas e gastos dispendidos por parte dos agentes.

\subsection{Experimento 1: análise dos perfis de consu- midores}

Este experimento visa responder à questão: Como escolher um parceiro, levando em conta a reputação do candidato e o custo associado à parceria?

O cenário proposto para a simulação foi o de uma sociedade de agentes com- 
posta por 100 consumidores e 100 empresas. Estes valores foram adotados para que o número de possíveis parceiros não fosse muito reduzido, o que poderia comprometer os resultados (HERMOSO et al., 2006).

As empresas apresentavam somente o perfil reativo, enquanto que os consumidores foram divididos em $1 / 3$ conservadores, $1 / 3$ ousados e $1 / 3$ avaros.

Neste experimento, a inserção de boato estava desabilitada. Por conseguinte, os consumidores basearam suas escolhas exclusivamente na imagem das empresas.

Foram executadas 20 simulações distintas, com 200 ciclos cada. Os consumidores foram analisados por perfil segundo a qualidade das mercadorias recebidas acumulada ao longo da simulação, custo associado acumulado, além do benefício líquido.

O objetivo deste experimento é, em suma, analisar a relação custo-benefício do uso do conceito de reputação por parte de agentes selecionadores de parceiros.

\subsubsection{Análise da qualidade}

Os valores médios das 20 simulações da qualidade das mercadorias recebidas, bem como seus desvios-padrão, são apresentados na Tabela 5.1.

Tabela 5.1: Valores médios da qualidade da mercadoria recebida acumulada ao longo dos ciclos de simulação

\begin{tabular}{|c|c|}
\hline & qualidade \\
\hline \hline conservadores & $171.16 \pm 7.75$ \\
\hline ousados & $139.63 \pm 34.34$ \\
\hline avaros & $100.93 \pm 48.76$ \\
\hline
\end{tabular}

Para a análise dos resultados com relação à qualidade das mercadorias recebidas, foi formulada a seguinte hipótese, sendo $Q_{p e r f i l}$ a qualidade média acumulada por perfil:

Hipótese A A qualidade das mercadorias recebidas pelos agentes conservadores deve ser superior à dos ousados, que por sua vez deve ser maior que a qualidade das mercadorias recebidas pelos avaros. Matematicamente, podemos expressar a hipótese da seguinte maneira:

$Q_{\text {conservadores }}>Q_{\text {ousados }}>Q_{\text {avaros }}$ 
A fim de validar a hipótese acima, devemos desmembrá-la e formular as hipóteses nulas. A Hipótese A demandará dois testes. São eles:

Teste 1 Neste caso, adotaremos:

H0. $Q_{\text {conservadores }}=Q_{\text {ousados }}$

H1. $Q_{\text {conservadores }}>Q_{\text {ousados }}$

Teste 2 Neste caso, adotaremos:

H0. $Q_{\text {ousados }}=Q_{\text {avaros }}$

H1. $Q_{\text {ousados }}>Q_{\text {avaros }}$

Aplicando-se a fórmula 5.1, obtivemos os valores de T iguais a 3,905 e 2,828 para os Testes 1 e 2, respectivamente. Com base num teste unilateral ao nível de 0,01, para 38 graus de liberdade $\left(n_{1}+n_{2}-2\right)$, devemos rejeitar $H 0$ se o valor de $\mathrm{T}$ for maior que 2,429. Portanto, podemos descartar as hipóteses H0, o que nos leva a confirmar a Hipótese A:

$$
\begin{aligned}
& Q_{\text {conservadores }}>Q_{\text {ousados }} \\
& Q_{\text {ousados }}>Q_{\text {avaros }}
\end{aligned}
$$

A análise obtida por meio do uso do Teste T de Student pode ser claramente visualizado no gráfico apresentado na Figura 5.1, que denota a qualidade média de todas as simulações realizadas, a cada ciclo.

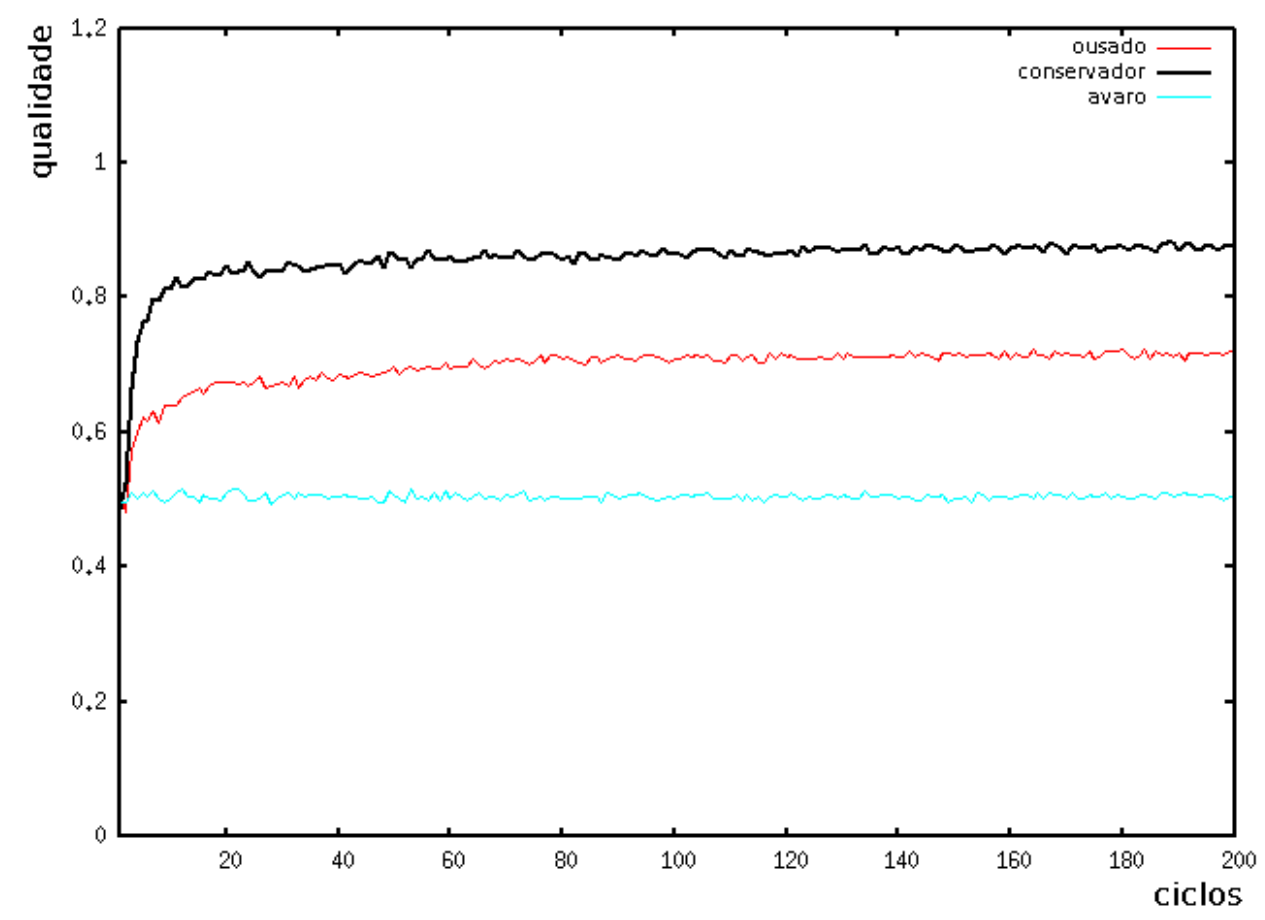

Figura 5.1: Média de qualidade dos agentes consumidores 
Uma análise mais detalhada do desempenho de cada perfil pode ser feito por meio da comparação dos valores obtidos em cada simulação isoladamente. As tabelas 5.2, 5.3, e 5.4 apresentam os valores da qualidade de mercadoria acumulada ao longo da simulação, a qualidade média ao longo da mesma e seu desvio padrão para os perfis conservador, ousado e avaro, respectivamente.

Tabela 5.2: Resultados detalhados da qualidade da mercadoria recebida pelos agentes conservadores

\begin{tabular}{|c|c|c|}
\hline & qualidade acumulada & qualidade média \\
\hline \hline s1 & 163.35 & $0.82 \pm 0.04$ \\
\hline s2 & 157.54 & $0.79 \pm 0.03$ \\
\hline s3 & 162.91 & $0.81 \pm 0.04$ \\
\hline s4 & 179.33 & $0.90 \pm 0.06$ \\
\hline s5 & 168.62 & $0.84 \pm 0.05$ \\
\hline s6 & 182.35 & $0.91 \pm 0.06$ \\
\hline s7 & 171.17 & $0.86 \pm 0.04$ \\
\hline s8 & 168.35 & $0.84 \pm 0.06$ \\
\hline s9 & 175.78 & $0.88 \pm 0.05$ \\
\hline s10 & 177.99 & $0.89 \pm 0.06$ \\
\hline s11 & 158.37 & $0.79 \pm 0.04$ \\
\hline s12 & 162.75 & $0.81 \pm 0.05$ \\
\hline s13 & 175.12 & $0.88 \pm 0.06$ \\
\hline s14 & 163.40 & $0.81 \pm 0.04$ \\
\hline s15 & 178.92 & $0.89 \pm 0.06$ \\
\hline s16 & 178.68 & $0.89 \pm 0.06$ \\
\hline s17 & 182.33 & $0.91 \pm 0.06$ \\
\hline s18 & 172.11 & $0.86 \pm 0.05$ \\
\hline s19 & 166.68 & $0.83 \pm 0.04$ \\
\hline s20 & 177.44 & $0.89 \pm 0.05$ \\
\hline média & 171.16 & $0.86 \pm 0.04$ \\
\hline
\end{tabular}

O desempenho dos agentes conservadores é bastante uniforme ao longo das simulações com relação à qualidade da mercadoria média e acumulada. Os agentes ousados apresentaram grande variação no seu comportamento, apresentando por vezes o mesmo desempenho de agentes conservadores e por vezes de agentes avaros. De maneira geral, agentes ousados possuem um resultado intermediário entre os valores de agentes conservadores e avaros.

A qualidade das mercadorias recebidas pelos agentes avaros é dependente da distribuição das variáveis aleatórias do sistema que determinam a qualidade das mercadorias entregues pelas empresas. Esta variação, entretanto, já era prevista, sendo evidenciada pela Figura 5.1, que retrata que a média de todos os ciclos de simulação, com relação à qualidade das mercadorias recebidas pelos agentes avaros, é 0,5. Este valor corresponde exatamente à média entre os valores 0 e 1 . 
Tabela 5.3: Resultados detalhados da qualidade da mercadoria recebida pelos agentes ousados

\begin{tabular}{|c|c|c|}
\hline & qualidade acumulada & qualidade média \\
\hline \hline $\mathrm{s} 1$ & 127.45 & $0.64 \pm 0.04$ \\
\hline s2 & 115.18 & $0.58 \pm 0.02$ \\
\hline s3 & 58.86 & $0.29 \pm 0.03$ \\
\hline s4 & 131.50 & $0.66 \pm 0.08$ \\
\hline s5 & 168.16 & $0.84 \pm 0.05$ \\
\hline s6 & 182.62 & $0.91 \pm 0.06$ \\
\hline s7 & 167.50 & $0.84 \pm 0.06$ \\
\hline s8 & 82.47 & $0.41 \pm 0.08$ \\
\hline s9 & 176.15 & $0.88 \pm 0.05$ \\
\hline s10 & 142.10 & $0.71 \pm 0.04$ \\
\hline s11 & 104.01 & $0.52 \pm 0.02$ \\
\hline s12 & 149.32 & $0.75 \pm 0.09$ \\
\hline s13 & 172.81 & $0.86 \pm 0.08$ \\
\hline s14 & 163.71 & $0.82 \pm 0.04$ \\
\hline s15 & 171.93 & $0.86 \pm 0.08$ \\
\hline s16 & 117.49 & $0.59 \pm 0.02$ \\
\hline s17 & 95.19 & $0.48 \pm 0.02$ \\
\hline s18 & 133.26 & $0.67 \pm 0.03$ \\
\hline s19 & 157.02 & $0.76 \pm 0.01$ \\
\hline s20 & 175.80 & $0.87 \pm 0.06$ \\
\hline média & 139.63 & $0.70 \pm 0.03$ \\
\hline
\end{tabular}

Tabela 5.4: Resultados detalhados da qualidade da mercadoria recebida pelos agentes avaros

\begin{tabular}{|c|c|c|}
\hline & qualidade acumulada & qualidade média \\
\hline \hline s1 & 71.02 & $0.36 \pm 0.03$ \\
\hline s2 & 115.39 & $0.58 \pm 0.01$ \\
\hline s3 & 58.66 & $0.29 \pm 0.03$ \\
\hline s4 & 60.60 & $0.30 \pm 0.03$ \\
\hline s5 & 168.37 & $0.84 \pm 0.05$ \\
\hline s6 & 182.71 & $0.91 \pm 0.05$ \\
\hline s7 & 116.77 & $0.58 \pm 0.02$ \\
\hline s8 & 42.74 & $0.21 \pm 0.04$ \\
\hline s9 & 175.96 & $0.88 \pm 0.06$ \\
\hline s10 & 142.28 & $0.71 \pm 0.04$ \\
\hline s11 & 103.30 & $0.52 \pm 0.02$ \\
\hline s12 & 19.97 & $0.10 \pm 0.05$ \\
\hline s13 & 47.40 & $0.24 \pm 0.03$ \\
\hline s14 & 162.96 & $0.81 \pm 0.05$ \\
\hline s15 & 86.67 & $0.43 \pm 0.02$ \\
\hline s16 & 118.06 & $0.59 \pm 0.02$ \\
\hline s17 & 95.85 & $0.48 \pm 0.02$ \\
\hline s18 & 133.45 & $0.67 \pm 0.02$ \\
\hline s19 & 92.40 & $0.46 \pm 0.02$ \\
\hline s20 & 24.00 & $0.12 \pm 0.06$ \\
\hline média & 100.93 & $0.50 \pm 0.01$ \\
\hline
\end{tabular}




\subsubsection{Análise do custo}

Os valores médios das 20 simulações obtidos com relação ao custo acumulado das mercadorias, bem como seus desvios-padrão, são apresentados na Tabela 5.5.

Tabela 5.5: Valores médios do custo acumulado ao longo dos ciclos de simulação

\begin{tabular}{|c|c|}
\hline & custo \\
\hline \hline conservadores & $19.08 \pm 9.98$ \\
\hline ousados & $12.49 \pm 2.67$ \\
\hline avaros & $11.71 \pm 1.99$ \\
\hline
\end{tabular}

Para a análise dos resultados com relação aos custos, foi formulada a seguinte hipótese, sendo $C_{p e r f i l}$ o custo médio acumulado por perfil:

Hipótese B O custo associado às parcerias dos agentes conservadores deve ser superior ao dos ousados, que por sua vez deve ser maior que os custos associados às parcerias estabelecidas por agentes avaros. Matematicamente, esta afirmação pode ser expressa da seguinte forma:

$C_{\text {conservadores }}>C_{\text {ousados }}>C_{\text {avaros }}$

De forma análoga à Hipótese A, podemos dividir a Hipótese B em dois testes:

Teste 1 Neste caso, adotaremos:

H0. $C_{\text {conservadores }}=C_{\text {ousados }}$

H1. $C_{\text {conservadores }}>C_{\text {ousados }}$

Teste 2 Neste caso, adotaremos:

H0. $C_{\text {ousados }}=C_{\text {avaros }}$

H1. $C_{\text {ousados }}>C_{\text {avaros }}$

Com base no teste unilateral ao nível de 0,01, para 38 graus de liberdade, HO deve ser rejeitado caso o valor de $\mathrm{T}$ seja maior que 2,429. Com o Teste 1 , obtivemos o valor de 2,783, o que nos leva a concluir que as parcerias realizadas pelos agentes conservadores realmente acarretaram um custo superior, se comparadas ao desempenho dos agentes ousados. Já o resultado do Teste 2 foi de 1,013, fazendo com que $H 0$ não possa ser rejeitado. Conseqüentemente, podemos inferir que os custos associados às parcerias de agentes avaros e ousados não apresentam diferença estatística significativa. Assim, foi obtido um primeiro resultado bastante interessante: 


$$
\begin{aligned}
& C_{\text {conservadores }}>C_{\text {ousados }} \\
& C_{\text {ousados }}=C_{\text {avaros }}
\end{aligned}
$$

A análise obtida por meio do uso do Teste T de Student pode ser claramente visualizado no gráfico apresentado na Figura 5.2, que denota o custo médio de todas as simulações realizadas, a cada ciclo.

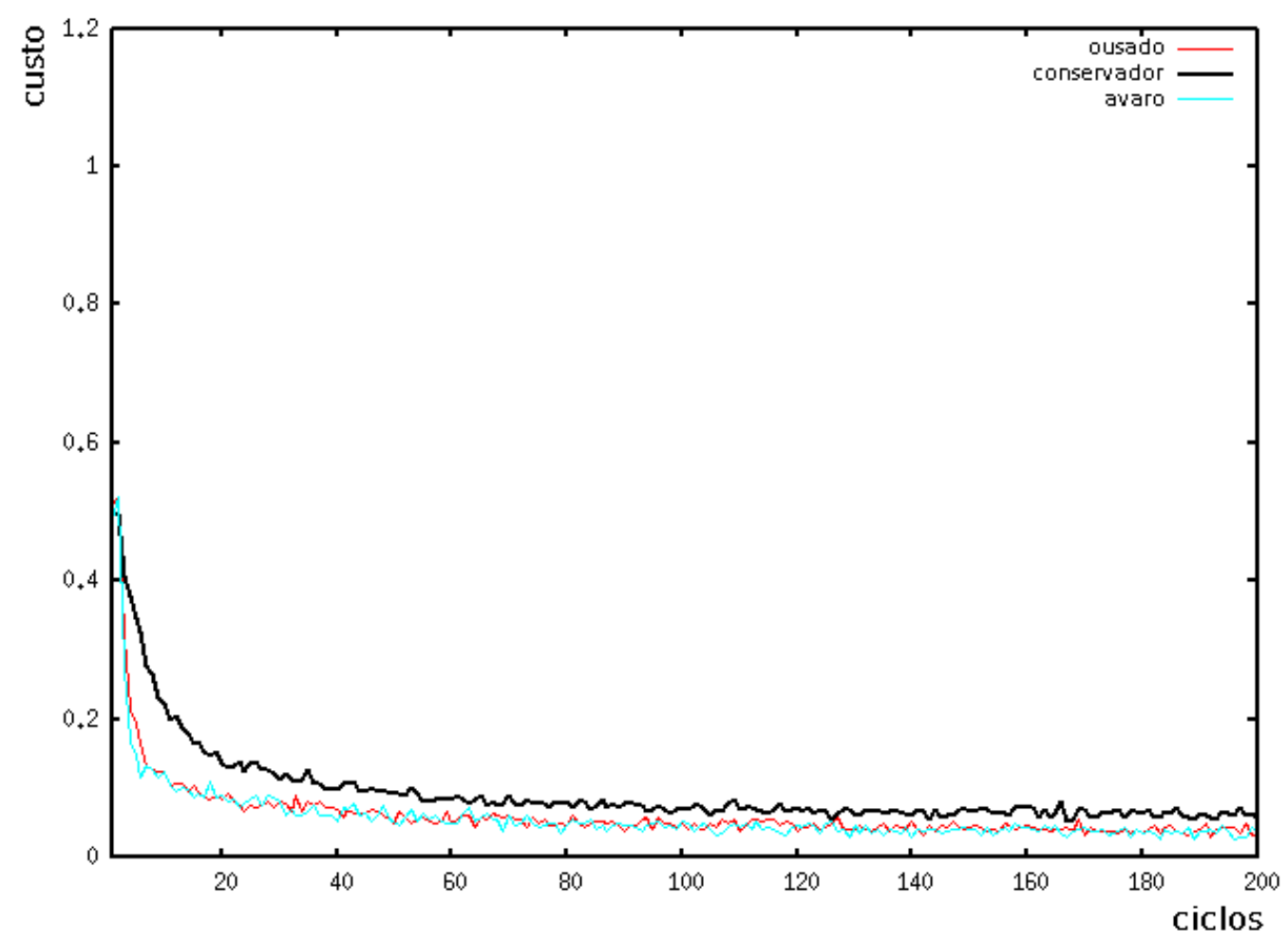

Figura 5.2: Média de custos dos agentes consumidores

Uma análise mais detalhada do desempenho de cada perfil pode ser feito por meio da comparação dos valores obtidos em cada simulação isoladamente. As tabelas 5.6, 5.7, e 5.8 apresentam os valores dos custos acumulados ao longo da simulação, o custo médio ao longo da mesma e o desvio padrão para os perfis de consumidores.

Um resultado que seria esperado em relação ao custo médio dos agentes conservadores não foi confirmado: este valor ficou muito abaixo do valor de referência 0,5 , que indica a total aleatoriedade. Isto ocorreu porque as imagens das empresas calculadas enquadram-se nas avaliações fuzzy do modelo Repage. Com isso, empresas com qualidade 0,81 e 0,89, por exemplo, apresentam a mesma imagem frente a um avaliador, igual a 1,00. Como o preço cobrado pela empresa é o fator de desempate, a empresa com o menor preço foi então selecionada. 
Tabela 5.6: Resultados detalhados dos custos associados às parcerias de agentes conservadores

\begin{tabular}{|c|c|c|}
\hline & custo acumulado & custo médio \\
\hline \hline $\mathrm{s} 1$ & 14.58 & $0.07 \pm 0.05$ \\
\hline $\mathrm{s} 2$ & 12.76 & $0.06 \pm 0.08$ \\
\hline $\mathrm{s} 3$ & 29.07 & $0.15 \pm 0.10$ \\
\hline $\mathrm{s} 4$ & 16.81 & $0.08 \pm 0.07$ \\
\hline $\mathrm{s} 5$ & 10.37 & $0.05 \pm 0.06$ \\
\hline $\mathrm{s} 6$ & 13.80 & $0.07 \pm 0.07$ \\
\hline $\mathrm{s} 7$ & 16.40 & $0.08 \pm 0.07$ \\
\hline $\mathrm{s} 8$ & 23.86 & $0.12 \pm 0.11$ \\
\hline s9 & 10.05 & $0.05 \pm 0.06$ \\
\hline s10 & 56.27 & $0.28 \pm 0.05$ \\
\hline s11 & 12.16 & $0.06 \pm 0.06$ \\
\hline s12 & 15.01 & $0.07 \pm 0.08$ \\
\hline s13 & 24.10 & $0.12 \pm 0.10$ \\
\hline s14 & 11.71 & $0.06 \pm 0.06$ \\
\hline s15 & 11.64 & $0.06 \pm 0.07$ \\
\hline s16 & 22.04 & $0.11 \pm 0.10$ \\
\hline s17 & 19.04 & $0.10 \pm 0.07$ \\
\hline s18 & 22.54 & $0.11 \pm 0.06$ \\
\hline s19 & 21.50 & $0.11 \pm 0.06$ \\
\hline s20 & 17.93 & $0.09 \pm 0.08$ \\
\hline média & 19.08 & $0.10 \pm 0.07$ \\
\hline
\end{tabular}

Tabela 5.7: Resultados detalhados dos custos associados às parcerias de agentes ousados

\begin{tabular}{|c|c|c|}
\hline & custo acumulado & custo médio \\
\hline \hline $\mathrm{s} 1$ & 12.07 & $0.06 \pm 0.06$ \\
\hline $\mathrm{s} 2$ & 10.19 & $0.05 \pm 0.07$ \\
\hline $\mathrm{s} 3$ & 10.54 & $0.05 \pm 0.06$ \\
\hline $\mathrm{s} 4$ & 12.71 & $0.06 \pm 0.06$ \\
\hline $\mathrm{s} 5$ & 10.44 & $0.05 \pm 0.06$ \\
\hline $\mathrm{s} 6$ & 13.33 & $0.07 \pm 0.06$ \\
\hline $\mathrm{s} 7$ & 15.67 & $0.08 \pm 0.07$ \\
\hline $\mathrm{s} 8$ & 12.24 & $0.06 \pm 0.07$ \\
\hline $\mathrm{s} 9$ & 10.05 & $0.05 \pm 0.06$ \\
\hline $\mathrm{s} 10$ & 11.17 & $0.05 \pm 0.06$ \\
\hline $\mathrm{s} 11$ & 9.86 & $0.05 \pm 0.06$ \\
\hline $\mathrm{s} 12$ & 13.41 & $0.07 \pm 0.07$ \\
\hline $\mathrm{s} 13$ & 17.99 & $0.09 \pm 0.06$ \\
\hline $\mathrm{s} 14$ & 11.55 & $0.05 \pm 0.07$ \\
\hline $\mathrm{s} 15$ & 10.91 & $0.05 \pm 0.06$ \\
\hline $\mathrm{s} 16$ & 13.45 & $0.07 \pm 0.07$ \\
\hline $\mathrm{s} 17$ & 9.57 & $0.05 \pm 0.06$ \\
\hline $\mathrm{s} 18$ & 11.05 & $0.05 \pm 0.06$ \\
\hline $\mathrm{s} 19$ & 19.98 & $0.10 \pm 0.06$ \\
\hline $\mathrm{s} 20$ & 13.58 & $0.07 \pm 0.06$ \\
\hline média & 12.49 & $0.06 \pm 0.06$ \\
\hline
\end{tabular}


Tabela 5.8: Resultados detalhados dos custos associados às parcerias de agentes avaros

\begin{tabular}{|c|c|c|}
\hline & custo acumulado & custo médio \\
\hline \hline $\mathrm{s} 1$ & 11.09 & $0.06 \pm 0.05$ \\
\hline $\mathrm{s} 2$ & 10.47 & $0.05 \pm 0.06$ \\
\hline $\mathrm{s} 3$ & 10.74 & $0.05 \pm 0.06$ \\
\hline $\mathrm{s} 4$ & 10.62 & $0.05 \pm 0.05$ \\
\hline $\mathrm{s} 5$ & 9.86 & $0.05 \pm 0.06$ \\
\hline $\mathrm{s} 6$ & 13.37 & $0.07 \pm 0.05$ \\
\hline $\mathrm{s} 7$ & 14.95 & $0.07 \pm 0.06$ \\
\hline $\mathrm{s} 8$ & 11.27 & $0.06 \pm 0.06$ \\
\hline $\mathrm{s} 9$ & 9.28 & $0.05 \pm 0.05$ \\
\hline $\mathrm{s} 10$ & 11.04 & $0.06 \pm 0.07$ \\
\hline $\mathrm{s} 11$ & 9.83 & $0.05 \pm 0.06$ \\
\hline $\mathrm{s} 12$ & 10.35 & $0.05 \pm 0.06$ \\
\hline $\mathrm{s} 13$ & 16.15 & $0.08 \pm 0.06$ \\
\hline $\mathrm{s} 14$ & 12.31 & $0.06 \pm 0.06$ \\
\hline $\mathrm{s} 15$ & 11.59 & $0.06 \pm 0.07$ \\
\hline $\mathrm{s} 16$ & 12.95 & $0.06 \pm 0.06$ \\
\hline $\mathrm{s} 17$ & 9.75 & $0.05 \pm 0.06$ \\
\hline $\mathrm{s} 18$ & 10.74 & $0.05 \pm 0.06$ \\
\hline $\mathrm{s} 19$ & 16.18 & $0.08 \pm 0.06$ \\
\hline $\mathrm{s} 20$ & 11.78 & $0.06 \pm 0.06$ \\
\hline média & 11.71 & $0.06 \pm 0.05$ \\
\hline
\end{tabular}

\subsubsection{Análise do benefício líquido}

Uma outra análise dos resultados obtidos pode ser feita, por meio dos resultados dos benefícios acumulados por perfil, ou seja, a qualidade da mercadoria recebida (benefício) menos o custo. Sendo $B L_{\text {perfil }}$ o benefício líquido acumulado por determinado perfil, podemos formular, então:

Hipótese C O benefício líquido acumulado pelos agentes conservadores é maior que o benefício líquido acumulado pelos agentes ousados, que pos sua vez é maior que o dos agentes avaros.

$$
B L_{\text {conservadores }}>B L_{\text {ousados }}>B L_{\text {avaros }}
$$

Novamente, devemos efetuar dois testes para confirmar a Hipótese C.

Teste 1 Neste caso, adotaremos:

H0. $B L_{\text {conservadores }}=B L_{\text {ousados }}$

H1. $B L_{\text {conservadores }}>B L_{\text {ousados }}$ 
Teste 2 Neste caso, adotaremos:

H0. $B L_{\text {ousados }}=B L_{\text {avaros }}$

H1. $B L_{\text {ousados }}>B L_{\text {avaros }}$

Os valores obtidos com as simulações são apresentados na Tabela 5.9.

Tabela 5.9: Valores médios do benefício líquido acumulado ao longo dos ciclos de simulação

\begin{tabular}{|c|c|}
\hline & benefício líquido \\
\hline \hline conservadores & $151.65 \pm 9.27$ \\
\hline ousados & $123.26 \pm 31.54$ \\
\hline avaros & $86.59 \pm 54.28$ \\
\hline
\end{tabular}

Os valores para os Testes 1 e 2 obtidos são respectivamente 3,764 e 2,547, que denotam que, com um teste unilateral com 38 graus de liberdade e com um nível de significância 0,01, podemos rejeitar H0. É possível afirmar, portanto, que a Hipótese C está correta, ou seja:

$$
\begin{aligned}
& B L_{\text {conservadores }}>B L_{\text {ousados }} \\
& B L_{\text {ousados }}>B L_{\text {avaros }}
\end{aligned}
$$

\subsection{Experimento 2: análise do impacto da ma- nipulação de informações}

Este experimento tem a finalidade de responder à questão: O quão vantajoso é manipular informações visando benefício próprio?

Na simulação, foi testada a eficiência do conceito de reputação como uma avaliação anônima, segundo a perspectiva defendida em (CONTE; PAOLUCCI, 2002). Uma sociedade composta exclusivamente por consumidores conservadores e que permite a propagação de avaliações anônimas se apresenta como um cenário ideal para a manipulação de informação.

Tendo isto em vista, foram propostos 3 tipos de simulações relacionados à inserção de um boato na sociedade e que compõem este experimento. Eles representam, repectivamente, todos os tipos de manipulações das quais uma empresa pode se beneficiar:

1. Propaganda enganosa: tentar se promover falsamente; 
2. Difamação: deteriorar falsamente a reputação de um bom competidor;

3. Publicidade verdadeira: realizar uma propaganda verdadeira acerca de seu desempenho, a fim de aumentar o número de parcerias realizadas.

As situações acima representam respectivamente a inserção de um falso boato positivo, de um falso boato negativo e de um boato positivo verdadeiro. Tais opções podem ser definidas pelo usuário na interface do sistema RePart, conforme demonstra a Figura 4.8.

As simulações que refletem tais situações são descritas a seguir. O cenário das simulações apresentava uma sociedade composta por 100 empresas com o perfil reativo e 100 consumidores com o perfil conservador, sendo que $50 \%$ destes tiveram contato com o boato no momento de sua inserção na sociedade.

\subsubsection{Análise do efeito de propaganda enganosa}

Neste caso, no décimo-terceiro ciclo de simulação, foi difundida entre os consumidores uma boa reputação ${ }^{1}$ sobre a empresa com a pior qualidade de mercadoria.

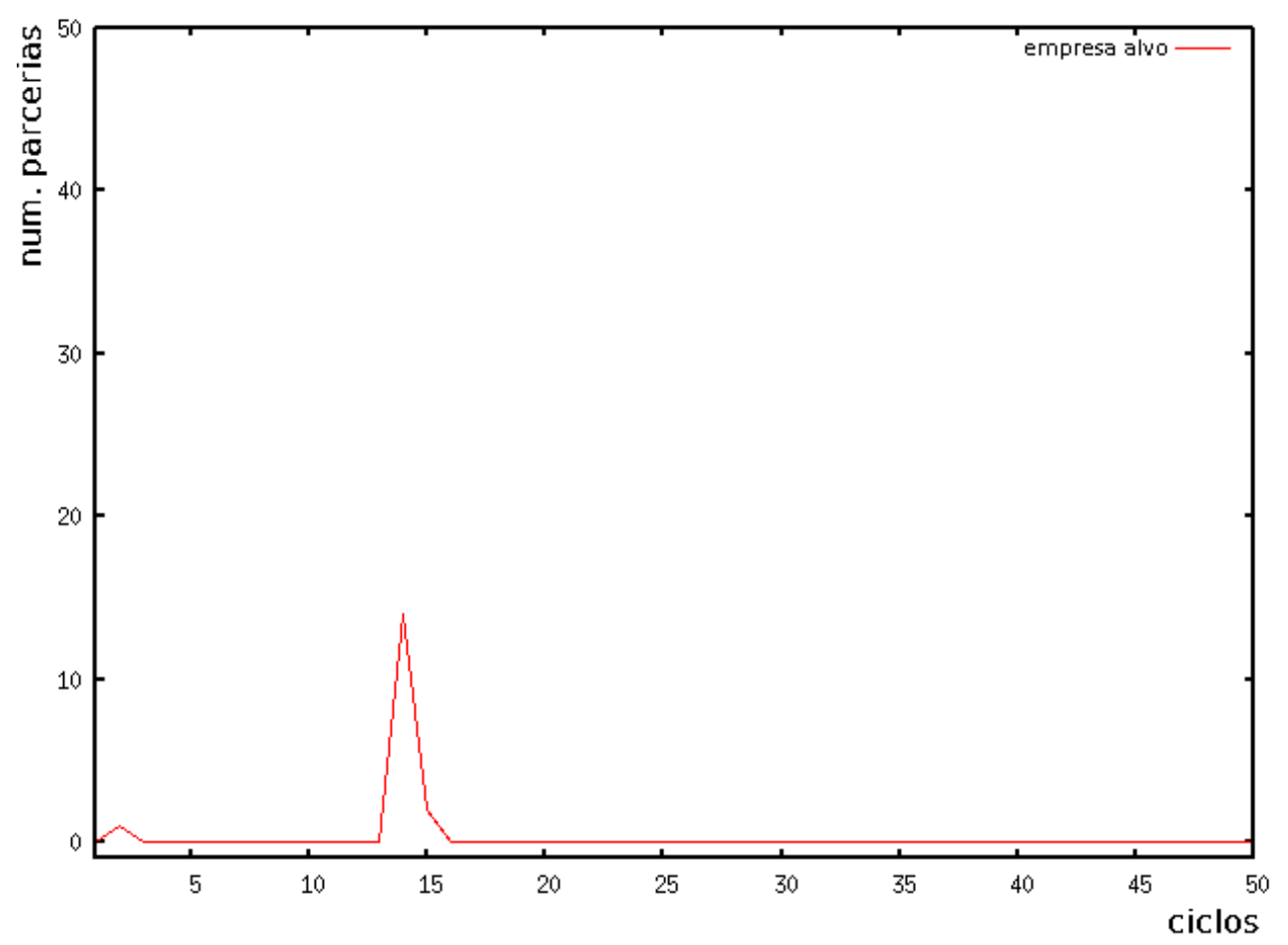

Figura 5.3: Impacto de uma propaganda enganosa (falso boato positivo) no número de parcerias da empresa alvo

Foram executadas 20 simulações, sendo que a alteração no número de parcerias estabelecidas com a empresa alvo do boato é apresentada na Figura 5.3. Os

\footnotetext{
${ }^{1}$ Avaliação com grau de aderência de $100 \%$ ao conjunto "muito bom".
} 
valores expressos no gráfico denotam os valores médios destas 20 simulações.

No segundo ciclo de simulação foi realizada, em média, 1 parceria ocasionada pelo fato de ser grande neste período a probabilidade de exploração do ambiente por parte dos consumidores.

No ciclo imediatamente posterior à inserção do falso boato positivo (ciclo 14), nota-se que o número de parcerias com a empresa alvo do boato sofreu um grande aumento, passando de 0 parcerias a 14 . No ciclo de número 15, este efeito já é reduzido para 2 parcerias, que retornam, então, para o valor estável de 0 parcerias no ciclo de número 16, assim permanecendo até o final da simulação.

Este efeito ocorre exclusivamente quando o falso boato positivo é propagado no início da simulação. Com o passar dos ciclos, a grande maioria dos consumidores começa a formar uma imagem sobre a empresa alvo (uma imagem ruim, visto que a qualidade da sua mercadoria é baixa) proveniente de experiências próprias ou de terceiros. O pico de parcerias apresentado na Figura 5.3 foi ocasionado, basicamente, por consumidores sem uma prévia imagem do alvo, visto que, segundo o a implementação dos agentes, a imagem sempre possui prioridade frente à reputação de um mesmo alvo. Após realizarem uma parceria com a empresa alvo e formarem uma imagem ruim sobre a mesma, os consumidores não voltam a realizar parcerias com esta mesma empresa.

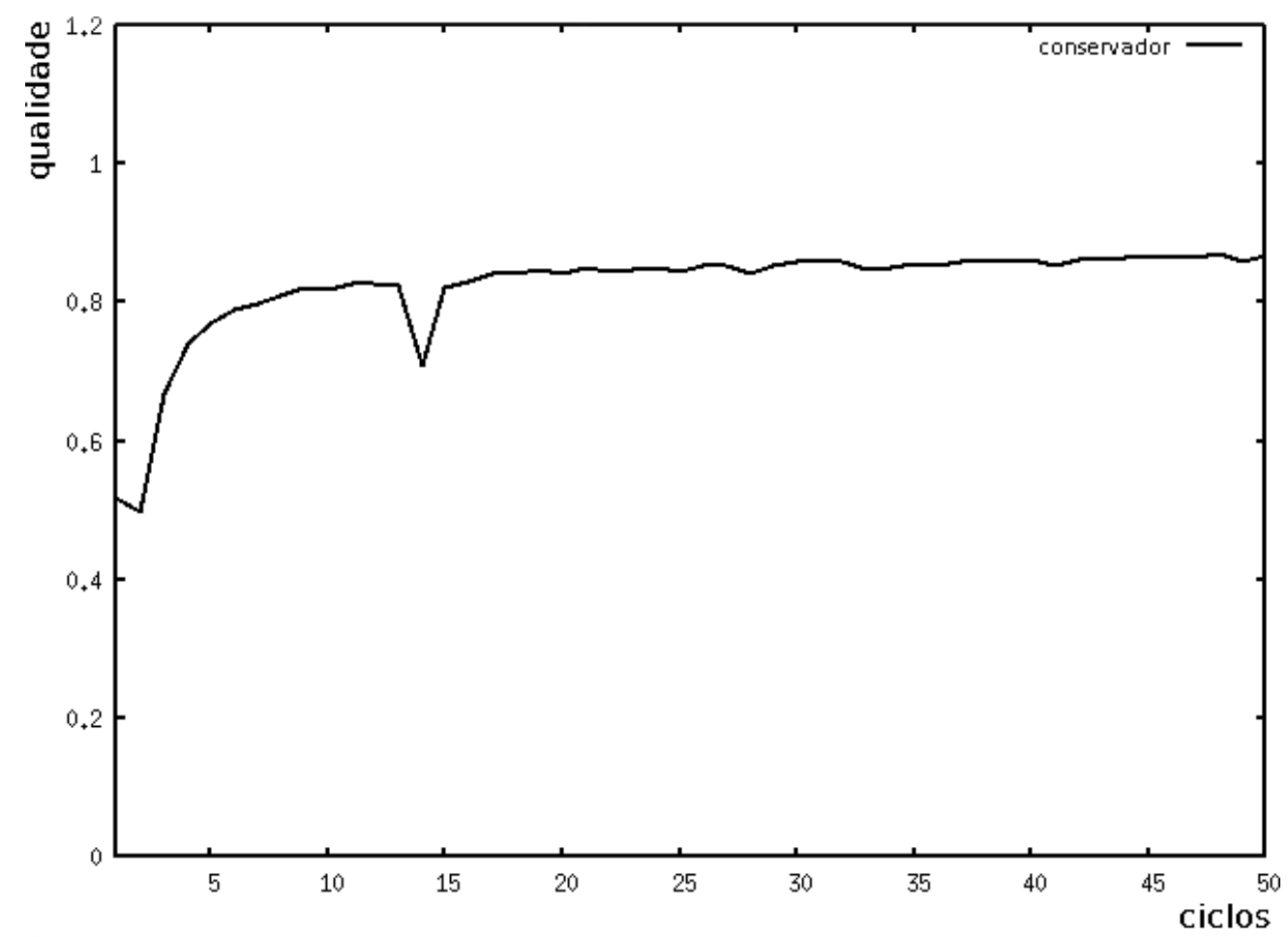

Figura 5.4: Impacto de uma propaganda enganosa (falso boato positivo) na qualidade de mercadorias recebidas pelos consumidores 
O efeito da propagação do boato também impacta a qualidade média da mercadoria recebida por parte dos consumidores, conforme denota a Figura 5.4.

Com este experimento mostrou-se que os efeitos de uma propaganda enganosa são efêmeros, apesar da propagação de informações anônimas aparentemente propiciar um ambiente favorável à mesma.

\subsubsection{Análise do efeito de difamação}

Estas simulações foram realizadas no mesmo cenário apresentado na simulação anterior, com 100 consumidores conservadores e 100 empresas reativas. O boato inserido na sociedade foi do tipo difamação, na tentativa de denegrir a imagem da empresa com o melhor desempenho na sociedade. Este tipo de manipulação não surtiu efeito na sociedade, visto que grande parte dos consumidores já havia formado uma boa imagem sobre a empresa alvo da difamação, que não sofreu alteração com o recebimento de uma avaliação anônima negativa.

O gráfico com o número de parcerias médio (proveniente de 20 simulações) com a inserção do falso boato negativo, no ciclo 10, é apresentado na Figura 5.5. Já o desempenho médio da empresa sem a inserção do falso boato é apresentado na Figura 5.6.

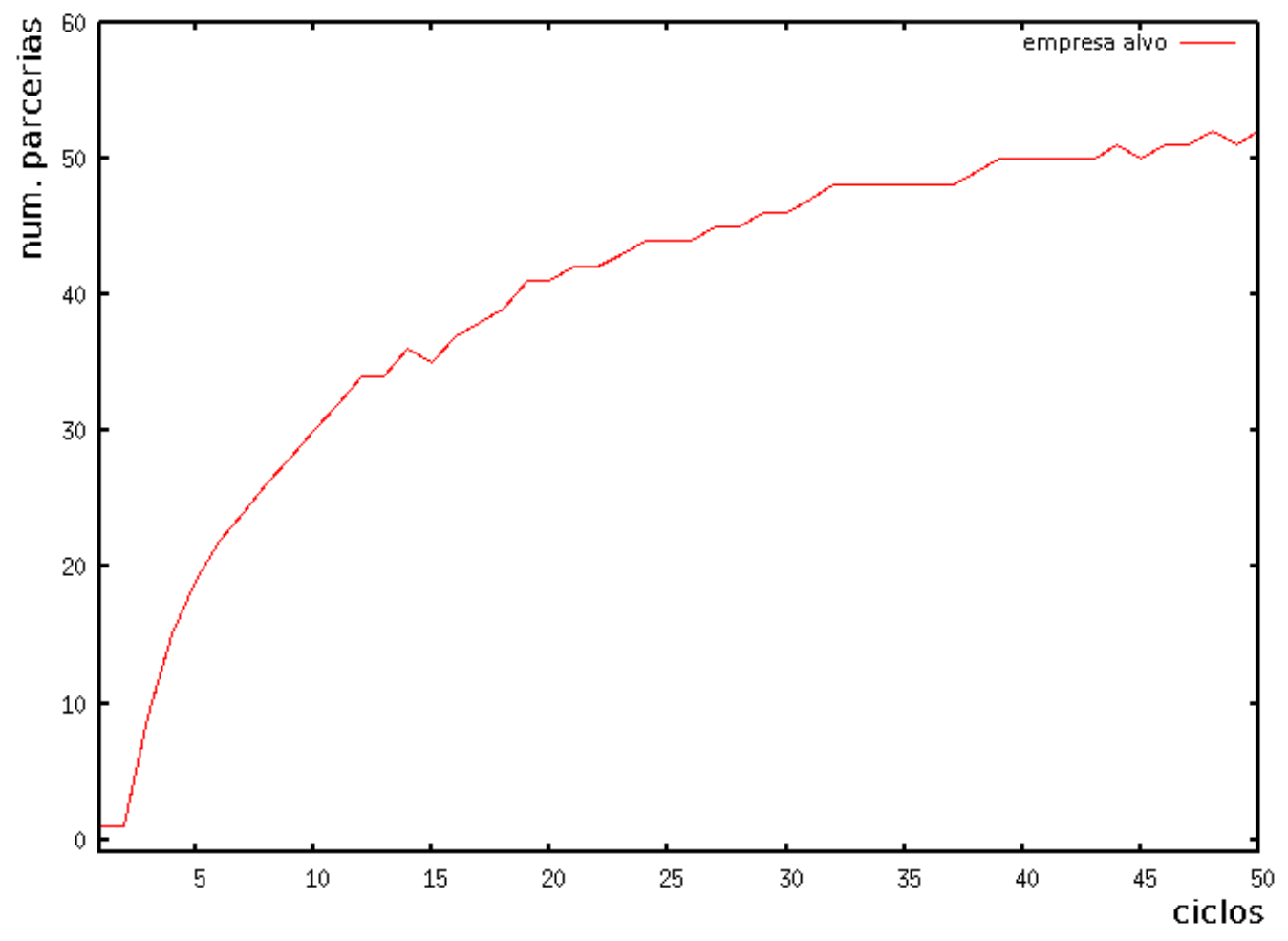

Figura 5.5: Impacto de difamação (falso boato negativo) no número de parcerias da empresa alvo 


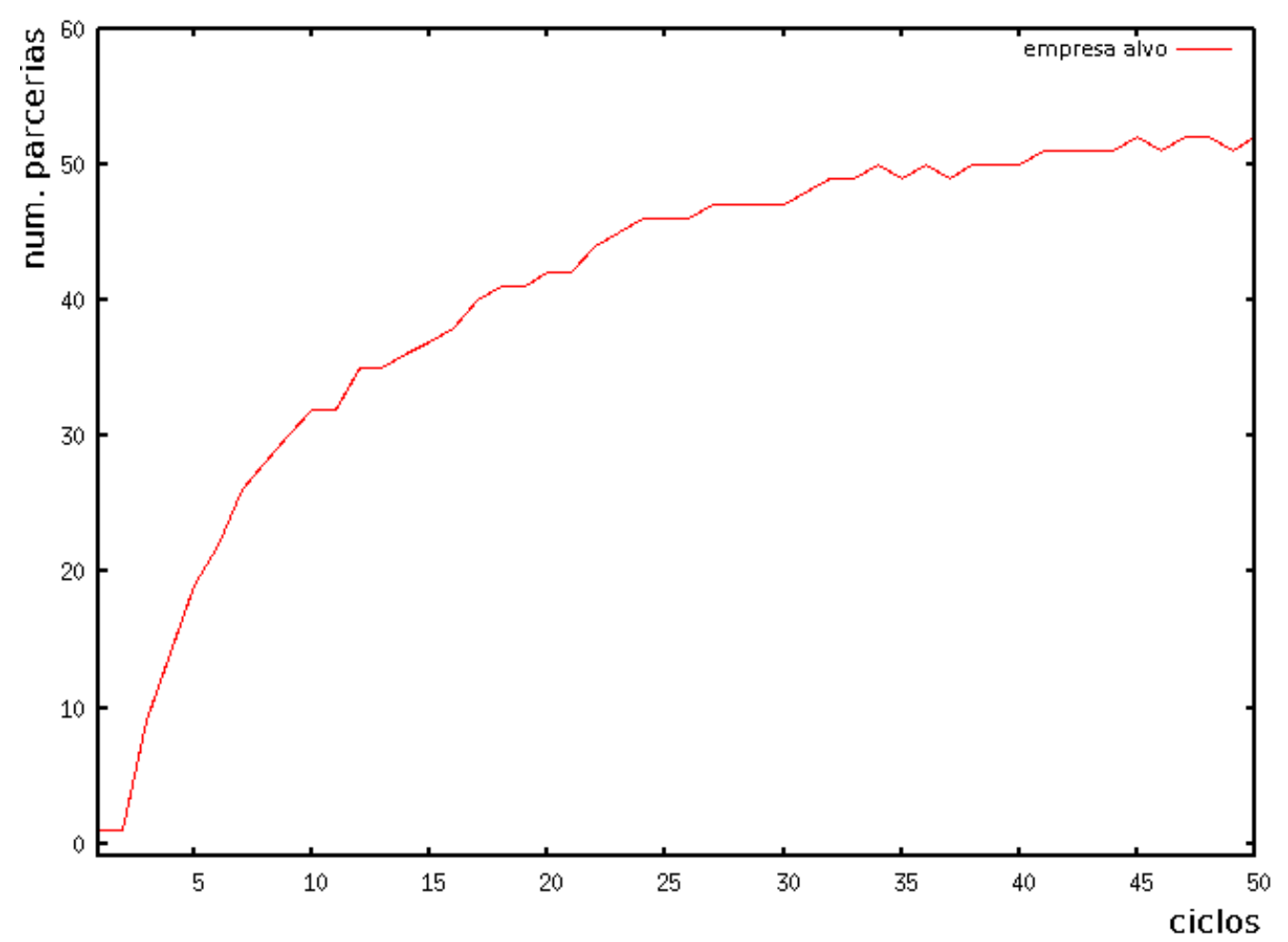

Figura 5.6: Número médio de parcerias da empresa com melhor desempenho sem inserção de boato

As pequenas flutuações que ocorrem ao longo da simulação são provenientes da probabilidade de exploração do ambiente presente nos agentes consumidores que, apesar de apresentar um decaimento exponencial, permanece ativo ao longo do processo de simulação.

Este experimento mostra que, devido à diferenciação entre as noções de imagem e reputação por parte dos agentes, uma tentativa de difamação não surte efeito.

\subsubsection{Análise do efeito de publicidade verdadeira}

O mesmo cenário com 100 consumidores conservadores e 100 empresas reativas foi utilizado para a inserção de um boato positivo verdadeiro, ou seja, uma boa publicidade sobre as características positivas de uma empresa, propagada em meio aos consumidores.

O boato foi inserido no ciclo de número 10 e gerou um grande aumento no número de parcerias da empresa com melhor desempenho no ciclo subseqüente, conforme indica a Figura 5.7. Este aumento foi de aproximadamente $80 \%$ no número de parcerias, que subiram de 26 para 47.

A tendência de crescimento no número de parcerias ainda se manteve por 


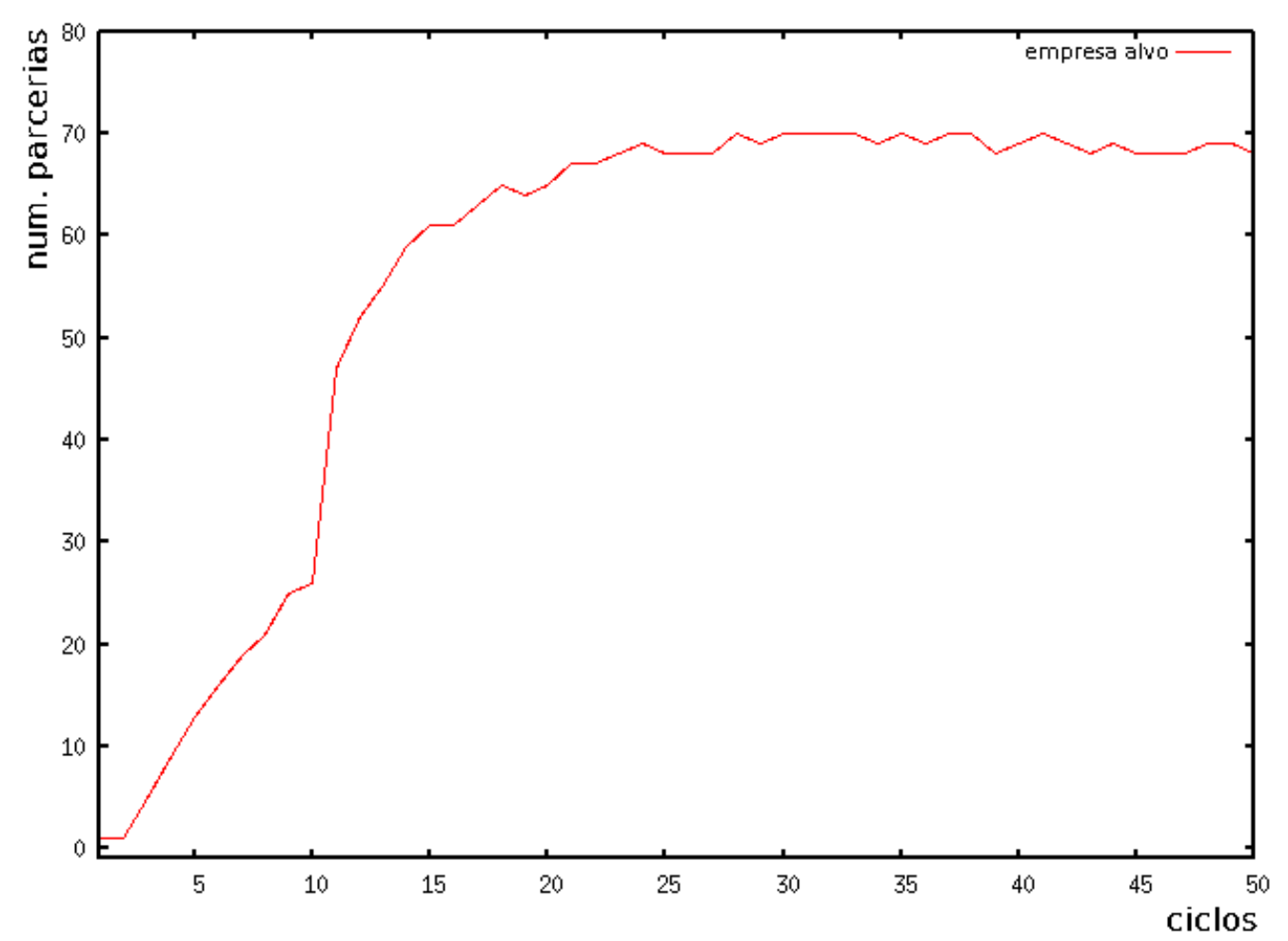

Figura 5.7: Impacto de publicidade verdadeira (boato positivo verdadeiro) no número de parcerias da empresa alvo

alguns ciclos posteriores, o que acarretou a estabilização em um patamar de equilíbrio superior ao apresentado na Figura 5.6. Enquanto que sem a inserção da publicidade verdadeira, o valor de equilíbrio do número de parcerias é por volta de 50 parcerias, com a presença deste nota-se que o valor de equilíbrio aumenta para próximo de 70. Portanto, além de ter um efeito positivo e duradouro, a inserção de um boato positivo verdadeiro mostrou ser uma estratégia bastante eficaz para angariar um maior número de parceiros.

\subsection{Experimento 3: análise dos perfis de empre- sas}

Este experimento visa responder à questão: Como agir em uma sociedade norteada pelo conceito de reputação a fim de que melhores resultados sejam obtidos?

Para tanto, os perfis de empresas foram adicionados aos cenários de simulação. A fim de facilitar a análise dos resultados obtidos, tais perfis foram classificados em dois grupos de acordo com a variável que é alterada ao longo do processo de simulação. São eles:

1. Perfis orientados à qualidade das mercadorias: os perfis investidor, deca- 
dente e trapaceiro fazem parte deste grupo;

2. Perfis orientados ao custo das mercadorias: os perfis ganacioso, estrategista e atacadista pertencem a este grupo.

Foram propostos, então, dois tipos distintos de simulação neste experimento, um para cada grupo de perfis de empresas. Os agente reativos também foram incluídos em ambas as simulações para atuarem como uma referência de desempenho.

\subsubsection{Análise de desempenho de perfis orientados à qua- lidade das mercadorias}

O cenário de simulação apresentava 100 agentes consumidores, sendo 1/3 deles conservadores, $1 / 3$ ousados e $1 / 3$ avaros. Havia também 100 empresas, que apresentavam equilibradamente os 3 perfis do grupo de perfis orientados à qualidade, além do perfil reativo, na percentagem de $25 \%$ cada. Foram executadas 20 seções de simulação para cada um dos grupos, com 400 ciclos cada.

Os resultados estão expressos na Tabela 5.10. O desempenho de cada perfil representa os valores de ganho acumulado ao longo do processo de simulação.

Tabela 5.10: Desempenho de perfis orientados à qualidade

\begin{tabular}{|c|c|}
\hline & Desempenho \\
\hline \hline investidor & $53.69 \pm 35.49$ \\
\hline decadente & $15.01 \pm 2.28$ \\
\hline trapaceiro & $15.71 \pm 1.75$ \\
\hline reativo & $22.20 \pm 7.15$ \\
\hline
\end{tabular}

A partir dos dados apresentados, podemos formular uma hipótese a ser validada com o Teste $\mathrm{T}$ de Student. Sendo $D_{\text {perfil }}$ o desempenho de determinado perfil de empresa:

Hipótese D O desempenho de agentes investidores é superior ao de agentes reativos, que por sua vez é melhor que o desempenho dos agentes trapaceiros, que é superior ao desempenho de agentes decadentes. Matematicamente, podemos expressar a hipótese da seguinte maneira:

$D_{\text {investidor }}>D_{\text {reativo }}>D_{\text {trapaceiro }}>D_{\text {decadente }}$

A comprovação da Hipótese D demandará 3 testes distintos. 
Teste 1 Neste caso, adotaremos:

H0. $D_{\text {investidor }}=D_{\text {reativo }}$

H1. $D_{\text {investidor }}>D_{\text {reativo }}$

Teste 2 Neste caso, adotaremos:

H0. $D_{\text {reativo }}=D_{\text {trapaceiro }}$

H1. $D_{\text {reativo }}>D_{\text {trapaceiro }}$

Teste 3 Neste caso, adotaremos:

H0. $D_{\text {trapaceiro }}=D_{\text {decadente }}$

H1. $D_{\text {trapaceiro }}>D_{\text {decadente }}$

Com base no teste unilateral ao nível de 0,01, para 38 graus de liberdade, $H 0$ deve ser rejeitado caso o valor de $\mathrm{T}$ seja maior que 2,429. Os valores correspondentes aos Testes 1, 2 e 3 são respectivamente: 3,791, 3,843 e 1,059. Portanto, podemos rejeitar as hipóteses H0 dos Testes 1 e 2. Já com relação ao Teste 3, não podemos afirmar que há diferença estatística significativa no desempenho de agentes trapaceiros e decadentes.

O desempenho dos perfis de empresas ao longo do processo de simulação pode ser visualizado na Figura 5.8, que se refere aos perfis orientados à qualidade das mercadorias.

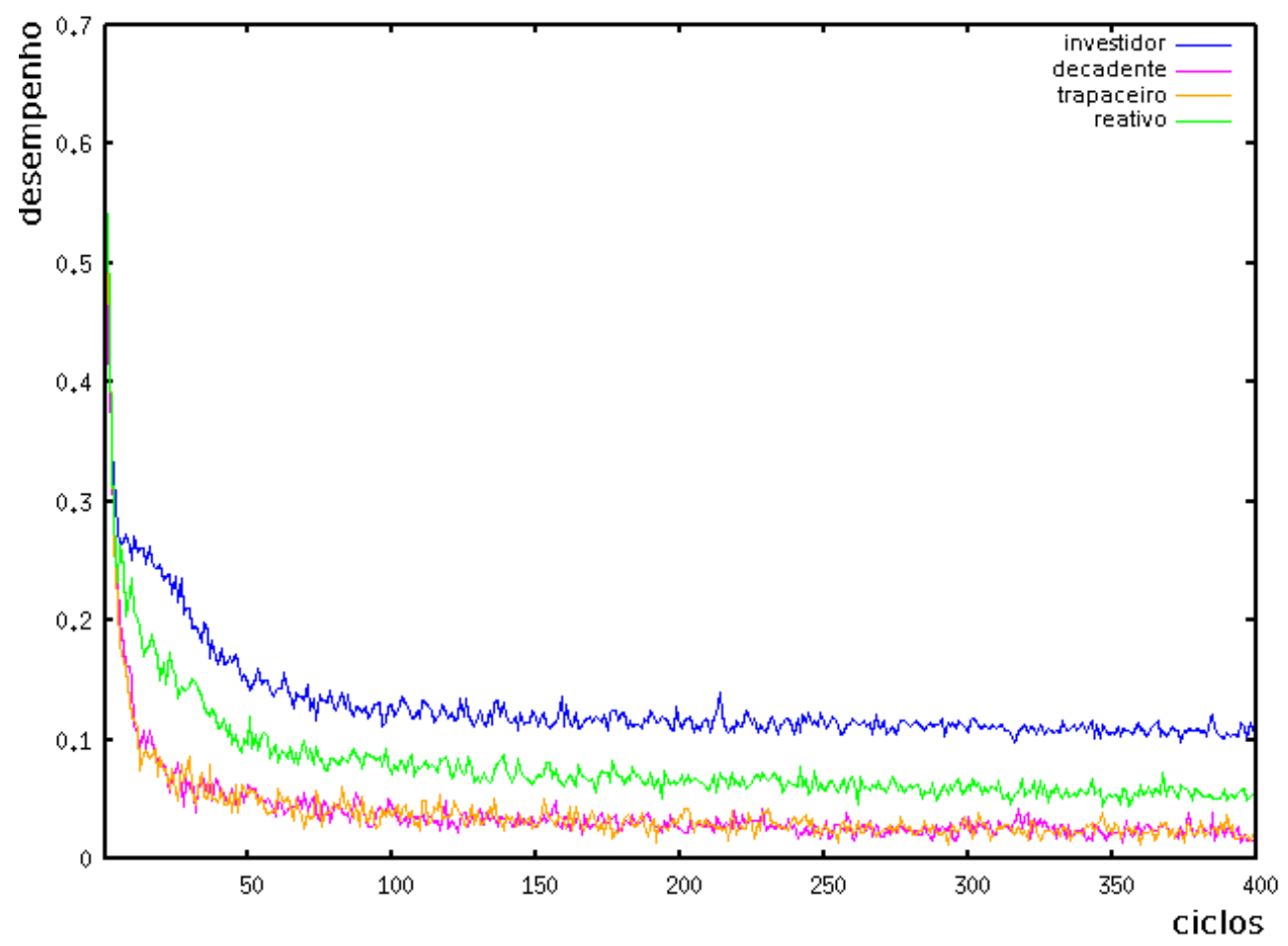

Figura 5.8: Desempenho de perfis de agentes empresa orientados à qualidade 
Conclui-se portanto que:

$$
\begin{aligned}
& D_{\text {investidor }}>D_{\text {reativo }} \\
& D_{\text {reativo }}>D_{\text {trapaceiro }} \\
& D_{\text {trapaceiro }}=D_{\text {decadente }}
\end{aligned}
$$

\subsubsection{Análise de desempenho de perfis orientados ao custo das mercadorias}

Os resultados das simulações, que apresentavam o mesmo cenário das simulações executadas para a análise dos perfis de empresas orientadas ao custo das mercadorias, são expressos na Tabela 5.11.

Tabela 5.11: Desempenho de perfis orientados ao custo

\begin{tabular}{|c|c|}
\hline & Desempenho \\
\hline \hline ganancioso & $24.72 \pm 1.10$ \\
\hline estrategista & $4.78 \pm 0.87$ \\
\hline atacadista & $4.24 \pm 0.85$ \\
\hline reativo & $14.23 \pm 1.72$ \\
\hline
\end{tabular}

A partir dos dados apresentados, podemos formular uma hipótese a ser validada com o Teste $\mathrm{T}$ de Student. Sendo $D_{\text {perfil }}$ o desempenho de determinado perfil de empresa:

Hipótese E O desempenho de agentes gananciosos é superior ao de agentes reativos, que por sua vez é melhor que o desempenho dos agentes estrategistas, que é supeior ao desempenho de agentes atacadistas. Matematicamente, podemos expressar a hipótese da seguinte maneira:

$D_{\text {ganacioso }}>D_{\text {reativo }}>D_{\text {estrategista }}>D_{\text {atacadista }}$

De forma análoga à comprovação da Hipótese $\mathrm{D}$, realizaremos 3 testes para a comprovação da Hipótese E.

Teste 1 Neste caso, adotaremos:

H0. $D_{\text {ganancioso }}=D_{\text {reativo }}$

H1. $D_{\text {ganancioso }}>D_{\text {reativo }}$ 
Teste 2 Neste caso, adotaremos:

H0. $D_{\text {reativo }}=D_{\text {estrategista }}$

H1. $D_{\text {reativo }}>D_{\text {estrategista }}$

Teste 3 Neste caso, adotaremos:

H0. $D_{\text {estrategista }}=D_{\text {atacadista }}$

H1. $D_{\text {estrategista }}>D_{\text {atacadista }}$

Os valores obtidos para os Testes 1, 2 e 3, respectivamente são 22,415, 21,393 e 1,951, o que nos leva a rejeitar as hipóteses H0 dos Testes 1 e 2 e a afirmar que não existe diferença estatística significativa entre o desempenho de estrategistas e atacadistas, visto que, o teste unilateral com 38 graus de liberdade e nível de significância 0,01 fornece o valor 2,429.

Portanto:

$$
\begin{aligned}
& D_{\text {ganancioso }}>D_{\text {reativo }} \\
& D_{\text {reativo }}>D_{\text {estrategista }} \\
& D_{\text {estrategista }}=D_{\text {atacadista }}
\end{aligned}
$$

O desempenho dos perfis de empresas com perfis orientados ao custo das mercadorias pode ser visualizado na Figura 5.9.

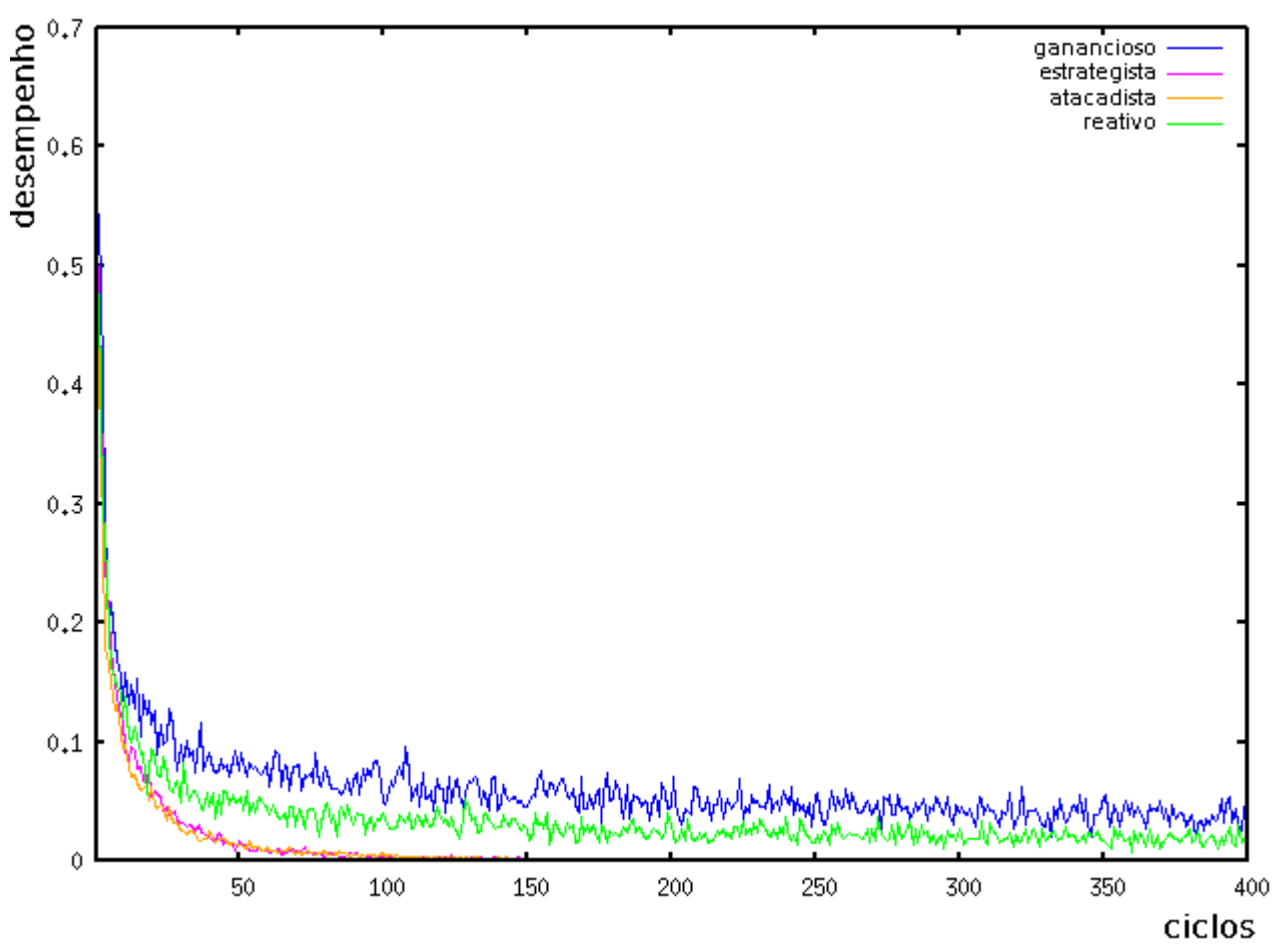

Figura 5.9: Desempenho de perfis de agentes empresa orientados ao custo 


\subsubsection{Análise de desempenho de perfis mistos}

A partir dos dados obtidos com os dois conjuntos de simulação com os grupos de perfis de empresa, um outro tipo de simulação foi proposto a fim de comparar os dois perfis que apresentaram o melhor desempenho, cada qual no seu grupo. O cenário para a simulação consistia em 100 consumidores, sendo 1/3 conservador, $1 / 3$ ousado e $1 / 3$ avaro, além de 100 empresas que apresentavam equilibradamente os perfis investidor e ganacioso (ou seja, 50\% cada). Os valores acumulados obtidos ao longo dos 400 ciclos do processo de simulação são apresentados na Tabela 5.12, a seguir.

Tabela 5.12: Desempenho de perfis mistos

\begin{tabular}{|c|c|}
\hline & ganho acumulado \\
\hline \hline investidor & $29.15 \pm 10.95$ \\
\hline ganancioso & $24.71 \pm 0.96$ \\
\hline
\end{tabular}

A Hipótese $\mathrm{F}$ pode ser então formulada.

Hipótese F O desempenho de agentes investidores é superior a de agentes gananciosos. Matematicamente, podemos expressar tal hipótese da seguinte maneira:

$D_{\text {investidor }}>D_{\text {ganancioso }}$

O Teste T de Student deverá ser aplicado para validar as seguintes hipóteses:

H0. $D_{\text {investidor }}=D_{\text {ganancioso }}$

H1. $D_{\text {investidor }}>D_{\text {ganancioso }}$

Ao nível de 0,01, para 38 graus de liberdade, obtém-se o valor de $\mathrm{T}$ igual a 2,429. Aplicando-se a fórmula 5.2 aos valores apresentados na Tabela 5.12, obteve-se o valor de 1,762, o que nos leva a concluir que não se pode rejeitar H0. Portanto, o desempenho dos dois perfis não apresenta diferença significativa. $\mathrm{Ou}$ seja:

$D_{\text {investidor }}=D_{\text {ganancioso }}$

O desempenho dos dois perfis ao longo dos ciclos de simulação pode ser visualizado na Figura 5.10. 


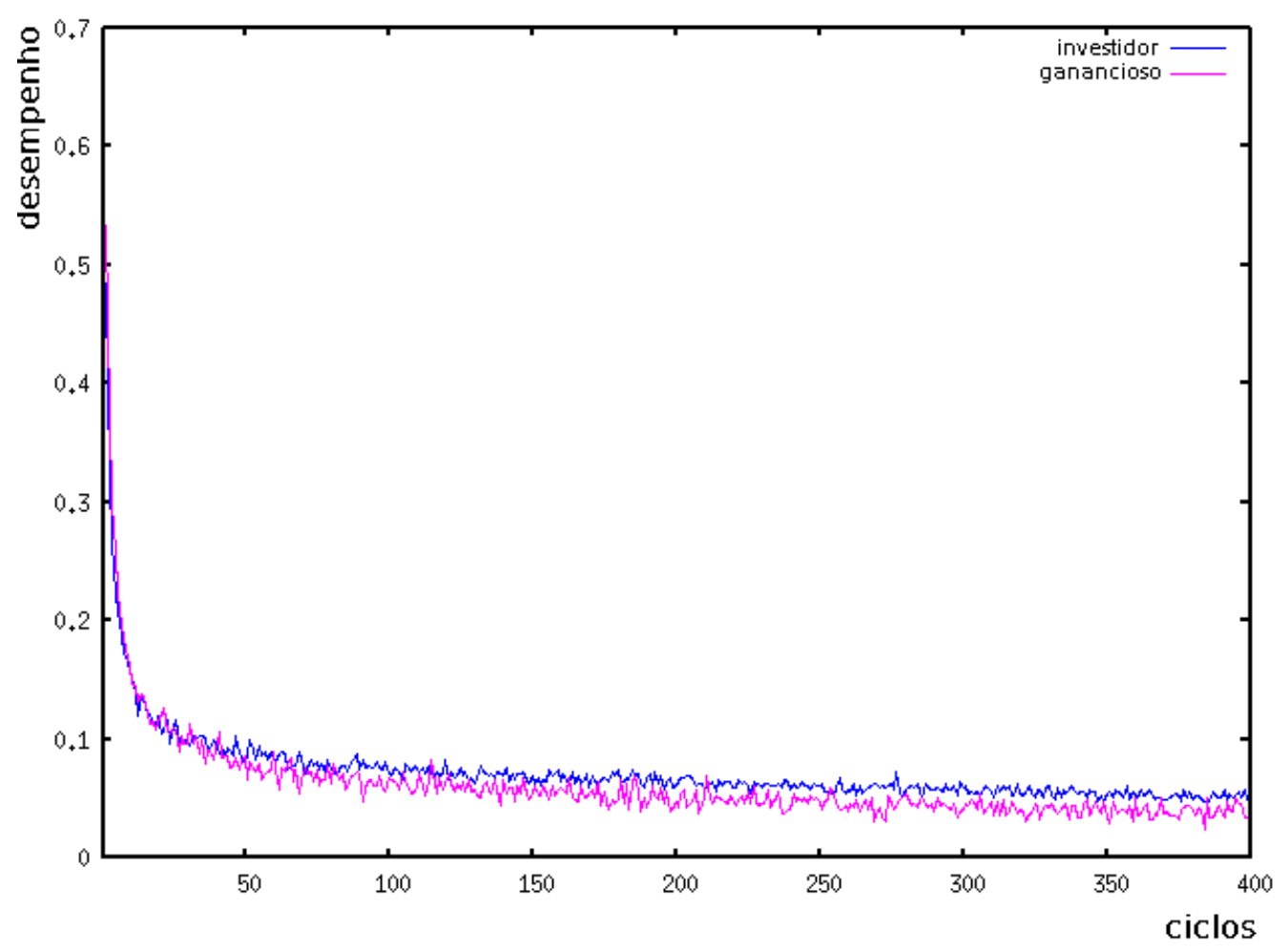

Figura 5.10: Desempenho de perfis de agentes empresa investidor e ganancioso

\subsection{Síntese dos resultados}

Sendo $Q_{\text {perfil }}$ a qualidade média acumulada por determinado perfil, $C_{\text {perfil }}$, o custo médio associado às parcerias realizadas e $B L_{\text {perfil }}$ o benefício líquido acumulado, as simulações realizadas no Experimento 1 indicaram que:

$$
\begin{aligned}
& Q_{\text {conservadores }}>Q_{\text {ousados }}>Q_{\text {avaros }} \\
& C_{\text {conservadores }}>C_{\text {ousados }}=C_{\text {avaros }} \\
& B L_{\text {conservadores }}>B L_{\text {ousados }}>B L_{\text {avaros }}
\end{aligned}
$$

O conceito de reputação ${ }^{2}$ mostrou-se ser, por conseguinte, um mecanismo bastante eficiente para a seleção de parceiros, garantindo uma satisfação superior às parcerias estabelecidas, sendo possível, ainda, balanceá-la com o fator custo. O desempenho dos agentes ousados foi bastante significativo, demonstrando que é possível se obter certo grau de satisfação sem acarretar custos superiores aos dos agentes avaros. Além disso, o uso do conceito de reputação na seleção de parceiros promoveu um comportamento e nível de satisfação mais estáveis.

Já o Experimento 2 provou a eficiência do conceito de reputação como um mecanismo de controle social. A manipulação fraudulenta de informações apresentou um impacto cujos resultados foram bastante efêmeros ou, em alguns casos,

\footnotetext{
${ }^{2}$ No caso do modelo Repage, utilizou-se a noção de imagem.
} 
não obtendo impacto algum, como demonstrados respectivamente nas simulações com inserção de uma propaganda enganosa (falso boato negativo) e de uma difamação (falso boato positivo). A propagação de informações anônimas, porém verdadeiras, surtiu grande efeito nos possíveis parceiros, originando um aumento significativo e sustentável no número de parcerias estabelecidas com o alvo do boato. Conclui-se que a difamação e propaganda enganosa em uma sociedade orientada à reputação não surtem o efeito desejado por parte dos manipuladores de informação, embora a propagação de uma publicidade verdadeira tenha um resultado duradouro e positivo.

Finalmente, no Experimento 3 o conceito de reputação foi analisado como parte integrante nos processos decisórios de um agente referentes à sua atuação na sociedade. De certa forma, os diversos perfis implementados tentavam extrair benefícios de sua reputação frente aos demais integrantes da sociedade. Sendo $D_{\text {perfil }}$ o desempenho de determinado perfil, os resultados indicam que:

$$
\begin{aligned}
& D_{\text {investidor }}>D_{\text {reativo }}>D_{\text {trapaceiro }}=D_{\text {decadente }} \\
& D_{\text {ganancioso }}>D_{\text {reativo }}>D_{\text {estrategista }}=D_{\text {atacadista }} \\
& D_{\text {investidor }}=D_{\text {ganacioso }}
\end{aligned}
$$

Do ponto de vista do agente, pode-se supor que aqueles que fizeram um uso positivo de sua imagem obtiveram melhores resultados, como agentes que apresentavam o perfil investidor e ganancioso. Agentes que tentaram extrair benefício próprio em detrimento dos demais agentes, diminuindo a qualidade das mercadorias, como os decadentes e trapaceiros, receberam sua "punição" por parte dos possíveis parceiros, apresentando um desempenho inferior aos demais. Além disso, estratégias que não englobam o caráter individualista inerente aos agentes computacionais autônomos, como atacadista e estrategista, não apresentaram um desempenho satisfatório, sendo seus resultados inferiores aos demais perfis.

A igualdade no desempenho de agentes investidores e ganaciosos é devida à similaridade das estratégias: agentes investidores aumentam a qualidade das mercadorias, esperando obter um aumento futuro no número de parcerias, que acarretará uma arrecadação maior de recursos para cobrir seu "investimento" em qualidade. Já agentes ganaciosos aumentam o preço, a fim de acumular maiores recursos, que podem ser empregados para financiar um futuro aumento de qualidade. Caso não realizem este movimento de então investir na melhora da qualidade da mercadoria, os agentes ganaciosos provavelmente tenderão a ser "punidos" em um cenário no qual os consumidores não apresentem recursos ilimitados. 
Sob a perspectiva da sociedade, novamente se reafirma a função do conceito de reputação como mecanismo de controle social, que desfavorece agentes fraudadores e privilegia estratégias que proporcionam um ganho superior para a sociedade, tal como o perfil investidor. 


\section{Conclusões}

Segundo (CONTE; PAOLUCCI, 2002), reputação é provavelmente um dos instrumentos mais poderosos, espontâneos e difundidos para a solução de problemas de ordem social. Compartilham este conceito áreas como a Psicologia, Filosofia, Economia, Sociologia e, ultimamente, SMA. Após a análise dos resultados obtidos nas simulações realizadas neste trabalho, o conhecimento acerca da relevância da reputação nos processos decisórios internos dos agentes para formação de parcerias em sociedades (virtuais ou não) foi aprofundado.

A ferramenta de simulação RePart possibilitou a análise da reputação em diferentes níveis: micro, meso e macro. O primeiro nível permite responder à questão de qual o uso mais vantajoso do conceito de reputação, sob o ponto de vista do agente; o segundo possibilita a observação da difusão da reputação; já o terceiro permite que seja feita uma análise do impacto do uso da reputação para a sociedade como um todo.

Foram realizados diversos experimentos a fim de se obter respostas para as questões apresentadas na seção 1.1. Após a análise dos resultados, podemos concluir, em resposta a tais questões:

Questão 1 Como escolher um parceiro, levando em conta a reputação do candidato e o custo associado à parceria?

Não existe uma única resposta correta para tal questão. O uso do conceito de reputação garante uma satisfação superior nas parcerias estabelecidas. Porém, seu uso como único fator decisivo na seleção de um parceiro acarreta custos superiores. Balancear a reputação do parceiro em potencial com o custo associado à parceria gerou uma satisfação superior à obtida por agentes norteados exclusivamante pelo fator custo, sem ocasionar, entretanto, um aumento significativo dos custos.

Caso a qualidade das parcerias seja o foco principal de ação, o ideal é selecionar o parceiro baseado exclusivamente em sua reputação. Já no caso de haver restrições com relação a custos, a reputação do parceiro e o custo 
da parceria devem ser ponderados, já que a utilização exclusiva do custo na seleção leva a resultados de pior qualidade e custos semelhantes.

O que se pode afirmar com propriedade é que o uso da reputação na formação de parcerias provou ser obrigatório para se atingir uma qualidade satisfatória.

Questão 2 O quão vantajoso é manipular informações visando benefício próprio? A teoria que fundamenta o modelo Repage introduz a propagação de informações anônimas na sociedade, o que pode, à primeira vista, aparentar ser um atrativo para a manipulação de informações. Entretanto, os experimentos indicam que a inserção de boatos anônimos fraudulentos não é vantajosa. A propaganda enganosa ocasionou um efeito bastante efêmero e transitório no número de parcerias efetuadas com o alvo de tal boato. A formação de uma imagem ruim por parte dos agentes parceiros fez com que fosse retomado rapidamente o nível de equilíbrio. Já no caso da inserção de uma difamação, na tentativa de denegrir a reputação do concorrente com melhor desempenho, não houve impacto perceptível na sociedade e no número de parcerias realizadas com o alvo da difamação, uma vez que os consumidores já possuíam uma boa imagem da empresa alvo.

Por outro lado, a propagação de uma avaliação anônima positiva e verdadeira surtiu bons resultados, que se mostraram duradouros. Portanto, manipular informações de modo fraudulento não é vantajoso para agentes em uma sociedade na qual está presente o conceito de reputação como ferramenta de controle social.

Questão 3 Como agir em uma sociedade norteada pelo conceito de reputação a fim de que melhores resultados sejam obtidos?

Diversas estratégias relacionadas ao modo de agir na tentativa de extrair benefício de uma reputação já formada ou em processo de formação foram testadas no Experimento 3. Agentes que atuavam de forma prejudicial a seus parceiros e à sociedade como um todo, como os decadentes e trapaceiros, foram punidos por meio do uso do conceito de reputação, apresentando um desempenho inferior aos demais perfis na simulação. Agentes que não apresentavam a característica de individualismo, como atacadistas e estrategistas, também não apresentaram desempenho satisfatório, estando abaixo da média, considerada como o desempenho obtido pelos agentes reativos. 
Aqueles agentes cuja estratégia era altruísta (investidora) ou individualista (gananciosa), mas sem gerar prejuízos para sociedade, apresentaram desempenho superior às demais e estatisticamente semelhante entre ambos, quando comparados em um mesmo cenário de simulação. Do ponto de vista da sociedade, agentes investidores são mais vantajosos, embora agentes gananciosos não representem um prejuízo para a mesma, sendo, por isso, também privilegiados na obtenção de parcerias.

Pode-se concluir então que, sob a perspectiva dos agentes, construir uma boa reputação e se esforçar para mantê-la é um investimento rentável.

Em suma, o conceito de reputação como ferramenta para a seleção de um parceiro teve sua importância reafirmada e sua eficácia comprovada neste trabalho, além ter sido apontado como um investimento com retorno garantido para agentes "honestos".

Além das análises realizadas e apresentadas neste documento, a construção da ferramenta de simulação RePart é uma contribuição deste trabalho para outros experimentos futuros que se concentrem na mesma linha de pesquisa. $\mathrm{O}$ desenvolvimento da ferramenta de simulação RePart, assim como alguns resultados preliminares obtidos, foram publicados em (AVEGLIANO; SICHMAN, 2007a) e (AVEGLIANO; SICHMAN, 2007b).

Possíveis trabalhos futuros incluem o desenvolvimento de uma interface de saída que exiba graficamente o resultado das simulações, além da implementação de perfis de consumidores e empresas mais sofisticados que apresentem, por exemplo, algum tipo de aprendizado. Uma outra possibilidade seria o desenvolvimento de mecanismos que permitam aos usuários definir perfis de agentes, tanto consumidores quanto empresas, a fim de tornar a ferramenta de simulação RePart mais flexível, suprindo, assim, as necessidades de outros estudos que envolvam o uso da reputação em SMA. 


\section{Referências Bibliográficas}

ADAMATTI, D. Inserção de jogadores virtuais em jogos de papéis para uso em sistemas de apoio à decisão em grupo: um experimento no domínio da gestão de recursos naturais. Tese (Doutorado) - Escola Politécnica da Universidade de São Paulo, São Paulo, 2007.

ADAMATTI, D.; SICHMAN, J.; COELHO, H. Using virtual players in GMABS methodology: a case study in natural resources management. In: European Social Simulation Association Conference (ESSA 2007), 4, Toulousse, France, 2007. Proceedings. [S.l.: s.n.], 2007. p. 241-252.

AVEGLIANO, P.; SICHMAN, J. Experimentos preliminares sobre o uso da reputação na formação de parcerias entre agentes. In: XVI Seminário de Computação (SEMINCO), 2007, Blumenau, Brasil. Anais. [S.l.: s.n.], 2007. p. $100-111$.

AVEGLIANO, P.; SICHMAN, J. RePart: a reputation-based simulation tool for partnership formation. In: ACM Symposium on Applied Computing (SIGAPP), 23, 2008, Fortaleza, Brazil. Proceedings. New York, USA: ACM Press, 2007. To appear.

AXELROD, R. The evolution of cooperation. Ontario, Canada: HarperCollins, 1997.

BARBER, K.; FULLAM, K.; KIM, J. Challenges for trust, fraud, and deception research in multi-agent systems. In: Trust, reputation, and security: theories and practice. Berlin, Germany: Springer, 2003. (Lecture Notes in Computer Science, v. 2631), p. 8-14.

BROMLEY, D. Reputation, image, and impression management. New York, USA: Wiley, 1993.

BUCHANAN, B.; SHORTLIFFE, E. The mycin experiments of the stanford heuristic programming project. In: BUCHANAN, B.; SHORTLIFE, E. (Ed.). Rule-based expert systems. Reading, USA: Addison-Wesley, 1984. (Addison-Wesley Series in Artificial Intelligence, v.1).

BUSKENS, V. The social structure of trust. Social Networks, Elsevier, Lausanne, Switzerland, v. 20, n. 3, p. 265-289, 1998.

CARBO, J.; MOLINA, J.; DAVILA, J. Comparing predictions of sporas vs. a fuzzy reputation agent system. In: WSEAS International Conference on Fuzzy Sets and Fuzzy Systems, 3, 2002, Interlaken, Switzerland. Proceedings. [S.l.: s.n.], 2002. p. 147-153.

CASTELFRANCHI, C. Social power: a point missed in multi-agent dai and hci. In: DEMAZEAU, Y.; MULLER, J.-P. (Ed.). Decentralized AI. USA: Elsevier Science Publishers B. V., 1990. p. 49-62. 
CASTELFRANCHI, C.; FALCONE, R. Trust and control: a dialectic link. Applied Artificial Intelligence, Taylor \& Francis, v. 14, n. 8, p. 799-823, 2000.

CASTELFRANCHI, C.; MICELLI, M.; CESTA, A. Dependende relations among autonomous agents. In: WENER, E.; DEMAZEAU, Y. (Ed.). Decentralized AI. Amsterdam, The Netherlands: Elsevier Science Publishers B. V., 1992. v. 3, p. $215-227$.

CELETANI, M. et al. Maintaining a reputation against a long-lived opponent. Econometrica, The Econometric Society (JSTOR), New York, USA, v. 64, n. 3, p. 691-704, 1996.

CONTE, R.; GILBERT, N.; SICHMAN, J. MAS and social simulation: A suitable commitment. In: Multi-Agent Systems and Agent-Based Simulation. Berlin, Germany: Springer-Verlag, 1998. (Lecture Notes in Artificial Intelligence, v. 1534), p. 1-9.

CONTE, R.; PAOLUCCI, M. Reputation in Artificial Societies: Social Beliefs for Social Order. New York, USA: Springer, 2002.

CONTE, R.; PEDONE, R. Finding the best partner: The PART-NET system. In: International Workshop on Multi-Agent Systems and Agent-Based Simulation, 1, 1998, Paris, França. Proceedings. London, UK: Springer-Verlag, 1998. (Lecture Notes in Artificial Intelligence, v. 1534), p. 156-168.

DAVIDSSON, P. Multi agent based simulation: Beyond social simulation. In: International Workshop on Multi-Agent Based Simulation (MABS 2000), 2, 2000, Boston, USA. Proceedings. Berlin, Germany: Springer-Verlag, 2000. (Lecture Notes in Artificial Intelligence, v. 1979), p. 97-107.

DAVIDSSON, P. Agent based social simulation: A computer science view. Journal of Artificial Societies and Social Simulation (JASSS), v. 5, n. 1, 2002.

DEMPSTER, A. P. Upper and lower probabilities induced by a multivalued mapping. Annals Mathematics Statistics, Institute of Mathematical Statistics (JSTOR), Baltimore, USA, v. 38, p. 325-339, 1967.

DROGOUL, A.; FERBER, J. Multi-agent simulation as a tool for modeling societies: Application to social differentiation in ant colonies. In: CASTELFRANCHI, C.; WERNER, E. (Ed.). European Workshop on Modelling Autonomous Agents in a Multi-Agent World (MAAMAW'94), 4, 1992, S. Martino al Cimino, Italy. Selected Papers. Berlin, Germany: Springer, 1994. (Lecture Notes in Computer Science, v. 830), p. 2-23.

DUNBAR, R. Grooming, gossip, and the evolution of language. Cambridge, Massachusetts, USA: Harvard University Press, 1996.

EDMONDS, B. The use of models-making mabs more informative. In: International Workshop on Multi-Agent Based Simulation (MABS 2000), 2, 2000, Boston, USA. Proceedings. Berlin, Germany: Springer-Verlag, 2001. (Lecture Notes in Artificial Intelligence, v. 1979), p. 15-32.

ENGELMORE, R. S.; MORGAN, A. (Ed.). Blackboard Systems. [S.l.]: Addison-Wesley, 1998. 
EPSTEIN, J.; AXTELL, R. Growing artificial societies: social science from the bottom up. Washington, USA: Brookings Institution Press, 1996.

ESFANDIARI, B.; CHANDRASEKHARAN, S. On how agents make friends: mechanisms for trust acquisition. In: Workshop on Deception, Fraud and Trust in Agent Societies, 4, 2001, Montreal, Canada. Proceedings. [S.l.: s.n.], 2001. p. $27-34$.

FERBER, J.; GUTKNECHT, O.; MICHEL, F. From agents to organizations: an organizational view of multi-agent systems. In: GIORGINI, P.; MULLER, J. P.; ODELL, J. (Ed.). Agent-Oriented Software Engineering IV: 4th International Workshop, AOSE 2003, Melbourne, Australia, July, 2003, Revised Papers. Berlin, Germany: Springer, 2004. (Lecture Notes in Computer Science, v. 2935), p. 214-230.

FULLAM, K.; SABATER, J.; BARBER, K. A design foundation for a trust-modeling experimental testbed. In: Trusting Agents for Trusting Electronic Societies: Theory and Applications in HCI and E-Commerce. Berlin, Germany: Springer-Verlag, 2005. (Lecture Notes in Artificial Intelligence, v. 3577), p. 95-109.

FULLAM, K. K. et al. A specification of the agent reputation and trust (art) testbed: experimentation and competition for trust in agent societies. In: International Joint Conference on Autonomous Agents and Multiagent Systems (AAMAS'05), 4, 2005, Utrecht, Netherlands. Proceedings. New York, USA: ACM Press, 2005. p. 512-518.

GAMBETTA, D. Can we trust trust. In: GAMBETTA, D. (Ed.). Trust: Making and breaking cooperative relations. [S.l.]: Basil Blackwell, 1988. p. 213-237.

GARCIA, A.; SICHMAN, J. Agentes e sistemas multiagentes. In: REZENDE, S. (Ed.). Sistemas inteligentes: fundamentos e aplicações. São Paulo, Brasil: Manole, 2003. cap 11. p. 269-306.

GUTNECHT, O.; FERBER, J. Madkit: a generic multi-agent platform. In: Agents Workshop on Infrastructure for Multi-Agent Systems (Agents'00), 4, 2000, Barcelona, Spain. Proceedings. New York, USA: ACM Press, 2000. p. $78-79$.

HANNOUN, M. et al. Dependence relations between roles in a multi-agent system: Towards the detection of inconsistencies in organization. In: International Workshop on Multi-Agent Based Simulation (MABS'98), 1, 1998, Paris, France. Proceedings. [S.l.: s.n.], 1998. p. 169-182.

HARDING, A. Microsimulation and public policy (contrinutions to economic analysis). Amsterdam, The Netherlands: North Holland, 1996.

HERMOSO, R. et al. Effective use of organisational abstractions for confidence models. In: International Workshop on Engineering Societies in the Agents World (ESAW06), 7, 2006, Dublin, Ireland. Proceedings. Berlin, Germany: Springer, 2006. (Lecture Notes in Computer Science, v. 4457), p. 246-261.

JENSEN, F. Bayesian networks and decision graphs. New York, USA: Springer, 2001. 
KARLINS, M.; ABELSON, H. Persuasion: how opinions and attitudes are changed. New York, USA: Springer Pub. Co, 1970.

KREPS, D.; WILSON, R. Reputation and imperfect information. Journal of Economic Theory, Academic Press, v. 27, n. 2, p. 253-279, 1982.

MACKENZIE, D.; ARKIN, R.; CAMERON, J. Multiagent mission specification and execution. Autonomous Robots, Springer, Amsterdam, The Netherlands, v. 4 , n. 1 , p. 29-52, 1997.

MARIMON, R.; NICOLINI, J.; TELES, P. Competition and reputation. In: Econometric Society World Cogress (ESWC 2000), 8, 2000, Seattle, USA. Proceedings. [S.1.: s.n.], 2000. p. 1-37.

MICHEL, F.; FERBER, J.; GUTKNECHT, O. Generic simulation tools based on mas organization. In: WERNER, E.; DEMAZEAU, Y. (Ed.). Modelling Autonomous Agents in a Multi-Agent World (MAAMAW01), 10, 2001, Annecy, France. Proceedings. Amsterdam, The Netherlands: Elsevier Science Publishers B.V., 2001.

MINAR, N. et al. The swarm simulation system: a toolkit for building multi-agent simulations. Santa Fe, USA: Santa Fe Institute, 1996. (Santa Fe Institute Working Papers, v. 96-06-042).

MISRA, J. Distributed discrete-event simulation. ACM Computing Surveys (CSUR), ACM Press, New York, USA, v. 18, n. 1, p. 39-65, 1986.

MONTEIRO, J. de Lima do R.; SICHMAN, J. S. A simulator for multi-agent partnership formation based on dependence graphs. In: International Joint Conference on Autonomous Agents and Multiagent Systems (AAMAS'05), 4, 2005, Utrecht, Netherlands. Proceedings. New York, NY, USA: ACM Press, 2005. p. $1223-1224$.

MUI, L.; MOHTASHEMI, M.; HALBERSTADT, A. A computational model of trust and reputation. In: Annual Hawaii International Conference on System Sciences (HICSS), 35, 2002, Hawaii, USA. Proceedings. [S.l.: s.n.], 2002. p. 2431-2439.

MUI, L.; MOHTASHEMI, M.; HALBERSTADT, A. Notions of reputation in multi-agents systems: a review. In: International Joint Conference on Autonomous Agents and Multiagent Systems (AAMAS'02), 1, 2002, Bologna, Italy. New York, USA: ACM Press, 2002. p. 280-287.

NIETZSCHE. Além do bem e do mal. São Paulo, Brasil: Companhia de Bolso, 2005 .

PAGE, C. L. et al. CORMAS: A multiagent simulation toolkit to model natural and social dynamics at multiple scales. In: Workshop "The ecology of scales", 2000, Wageningen, The Netherlands. Proceedings. [S.l.: s.n.], 2000. p. 1-20.

PAOLUCCI, M. et al. "What if?" dealing with uncertainity in repage's mental landscape. In: The 2005 IEEE/WIC/ACM International Conference on Intelligent Agent Technology (IAT'05), 2005, Compiègne, France. Proceedings. Washington, USA: IEEE Computer Society, 2005. p. 372-378. 
PARUNAK, H.; SAVIT, R.; RIOLO, R. Agent-based modeling vs. equationbased modeling: A case study and users' guide. In: SICHMAN, J.; CONTE, R.; GILBERT, N. (Ed.). Multi-Agent Systems and Agent-Based Simulation. Berlin, Germany: Springer, 1998. (Lecture Notes in Computer Science, v. 1534), p. $10-25$.

PINYOL, I. et al. Beyond accuracy. Reputation for partner selection with lies and retaliation. In: Workshop on Multi-Agent Based Simulation (MABS07), 8, 2007, Hawaii, USA. Proceedings. New York, USA: ACM Press, 2007. p. 134-146.

PLATÃO. A República (3r7aa.C.). São Paulo, Brasil: Rideel, 2005.

RAO, A. S.; GEORGEFF, M. P. Modeling rational agents within a BDIarchitecture. In: ALLEN, J.; FIKES, R.; SANDEWALL, E. (Ed.). International Conference on Principles of Knowledge Representation and Reasoning (KR'91), 2, 1991, Cambridge, USA. San Mateo, USA: Morgan Kaufmann, 1991. p. $473-484$.

RESNICK, M. StarLogo: an environment for decentralized modeling and decentralized thinking. In: Conference Companion on Human Factors in Computing Systems (CHI'96), 1996, Vancouver, Canada. Proceedings. New York, USA: ACM Press, 1996. p. 11-12.

RUBIERA, J. C.; LOPEZ, J. M. M.; MURO, J. D. A fuzzy model of reputation in multi-agent systems. In: International Conference on Autonomous Agents (AGENTS'01), 5, 2001, Montreal, Canada. Proceedings. New York, USA: ACM Press, 2001. p. 25-26.

RUSSELL, S.; NORVIG, P. Inteligência Artificial. Rio de Janeiro, Brasil: Elsevier, 2004.

SABATER, J.; PAOLUCCI, M.; CONTE, R. Repage: Reputation and image among limited autonomous partners. Journal of Artificial Societies and Social Simulation (JASSS), v. 9, n. 2, 2005.

SABATER, J.; SIERRA, C. Regret: reputation in gregarious societies. In: International Conference on Autonomous Agents (AGENTS'01), 5, 2001, Montreal, Canada. Proceedings. New York, USA: ACM Press, 2001. p. 194-195.

SABATER, J.; SIERRA, C. Review on computational trust and reputation models. Artificial Intelligence Review, Springer, Amsterdam, The Netherlands, v. 24, n. 1, p. 33-60, 2005.

SCHILLO, M. Using trust for detecting deceitful agents in artificial societies. Applied Artificial Intelligence, Taylor \& Francis, v. 14, n. 8, p. 825-848, 2000.

SICHMAN, J. DEPINT: Dependence-based coalition formation in an open multi-agent scenario. Journal of Artificial Societies and Social Simulation (JASSS), v. 1, n. 2, 1998.

SICHMAN, J.; CONTE, R. Multi-agent dependence by dependence graphs. In: International Joint Conference on Autonomous Agents and Multiagent Systems (AAMAS'02), 1, 2002, Bologna, Italy. Proceedings. New York, USA: ACM Press, 2002. p. $483-490$. 
SICHMAN, J. et al. A social reasoning mechanism based on dependence networks. European Conference on Artificial Intelligence (ECAI94), 11, 1994, Amsterdam, The Netherlands. Proceedings. [S.l.]:John Wiley and Sons, 1994. p. 188-192.

SHAFER, G. A mathematical theory of evidence. Princeton, USA: Princeton University Press, 1996.

SPIEGEL, M. Probabilidade e estística. São Paulo, Brasil: Pearson Education, 2004.

SUTTON, R.; BARTO, A. Reinforcement learning: an introduction. Cambridge, USA: MIT Press, 1998.

TESFATSION, L. Agent-based computational economics: modeling economies as complex adaptive systems. Information Sciences, Elsevier, v. 149, n. 4, p. 262-268, 2003.

TISUE, S.; WILENSKY, U. NetLogo: A simple environment for modeling complexity. In: International Conference on Complex Systems (ICCS2004), 2004, Boston, USA. Proceedings. [S.1.: s.n.], 2004. p. 1-10.

YU, B.; SINGH, M. P. An evidential model of distributed reputation management. In: International Joint Conference on Autonomous agents and multiagent systems(AAMAS'02), 1, 2002, Bologna, Italy. Proceedings. New York, USA: ACM Press, 2002. p. 294-301.

ZACHARIA, G. Collaborative reputation mechanisms for online communities. Thesis (Master of Sciences) - Massachusetts Institute of Technology, Cambridge, USA, 1999.

ZACHARIA, G.; MOUKAS, A.; MAES, P. Collaborative reputation mechanism in eletronic marketplaces. In: Hawaii International Conference on System Sciences (HICSS'99), 32, 1999, Hawaii, USA. [S.l.]: IEEE, 1999. p. 1-7.

ZEIGLER, B. Object-oriented simulation with hierarchical, modular models: intelligent agents and endomorphic systems. San Diego, USA: Academic Press Professional, 1990. 